\title{
Prototyping A GIS-based Spatial Decision Support System in A Manufacturing Environment
}

\author{
A Thesis \\ submitted to the School of Graduate Studies of Ryerson University \\ in partial fulfillment of the requirements for the degree of \\ Master of Applied Science in the Program of Civil Engineering
}

By

XIANG QIAN GAO, B.Eng.

Tianjin University, China, 1988 
UMI Number: EC53445

\section{INFORMATION TO USERS}

The quality of this reproduction is dependent upon the quality of the copy submitted. Broken or indistinct print, colored or poor quality illustrations and photographs, print bleed-through, substandard margins, and improper alignment can adversely affect reproduction.

In the unlikely event that the author did not send a complete manuscript and there are missing pages, these will be noted. Also, if unauthorized copyright material had to be removed, a note will indicate the deletion.

\section{UMI}

UMI Microform EC53445

Copyright 2009 by ProQuest LLC

All rights reserved. This microform edition is protected against unauthorized copying under Title 17, United States Code.

ProQuest LLC

789 East Eisenhower Parkway

P.O. Box 1346

Ann Arbor, MI 48106-1346 



\section{Borrower's Page}

Ryerson University requires the signatures of all persons using or photocopying this thesis. Please sign below, and give address and date.

\begin{tabular}{|c|c|c|}
\hline Signature & Address & Date \\
\hline & & \\
\hline & & \\
\hline & & \\
\hline & & \\
\hline & & \\
\hline & & \\
\hline & & \\
\hline & & \\
\hline & & \\
\hline & & \\
\hline & & \\
\hline & & \\
\hline & & \\
\hline & & \\
\hline & & \\
\hline & & \\
\hline & & \\
\hline & & \\
\hline & & \\
\hline & & \\
\hline & & \\
\hline & & \\
\hline & & \\
\hline
\end{tabular}




\section{ABSTRACT}

Current spatial decision support systems (SDSS) in manufacturing environments, which are mostly CAD-based, have many drawbacks and thus may make less effective and efficient spatial decisions. GIS-based SDSS can overcome those drawbacks and support decision-making in a much effective manner. Unfortunately, there is little research on GIS-based SDSS in a manufacturing environment.

This thesis study focuses on a systematic approach to the development of GIS-based SDSS in a manufacturing environment. By using Trane China as an example, the prototype of Trane China SDSS (TCSDSS) is developed by adopting the unified software development process. The TCSDSS prototype contains eight object modules, which incorporate ArcGIS imbedded models, ArcGIS feature data, and MS Access attribute data, to support decision-making in Trane China. The benefits from the use of the TCSDSS prototype that have been found include its spatial analysis, network analysis, and 3D analysis functions besides the improvement on communication and efficiency. It is also found that the newly developed GIS software packages such as ArcGIS 8.3, with the enhanced drawing functions, can provide enough adequate precision level required by facility layout.

Key words: Spatial Decision Support System, CAD, GIS, Unified Software Development Process 


\section{ACKNOWLEDGMENTS}

First of all, I would like to thank my supervisor Dr. Jonathan Li for his kind supervision and many good ideas. Special thanks for all fruitful discussions, invaluable suggestions and critical remarks. I would also like to thank him for bringing me to the active research fields of geographic information system (GIS) and spatial decision support system (SDSS). His serious and significant research had a great influence on my work. His efforts to ensure my financial support during my study are also appreciated.

I am indebted to my thesis examiners, Dr. Liping Fang and Dr. Songnian Li, for spending their time on evaluating my thesis. Their comments and suggestions are gratefully acknowledged.

I also attribute my accomplishment to Dr. Michael A. Chapman, Dr. Songnian Li, and other faculty and staff members in the Department of Civil Engineering, for their encouragements, in particular, Desmond Rogan for kindly helping me many times to solve computer and networking related problems. Many thanks also due to the department secretaries, especially Kim Kritzer and Dianne Mendonca, for their kindness and assistance.

I would like to acknowledge all my graduate student fellows at Ryerson University, who have helped me in countless ways and made the period in an enjoyable time, in particular, Hongmei Zhao, Jun Nie, Wenglong He, Yinfeng Li, and $\mathrm{Yu} \mathrm{Li}$.

Financial support partially provided by the School of Graduate Studies is gratefully acknowledged. Many thanks also go to Jimmy Wang, Jack Zhang, Willis Zhu and Simon 
Pang of Trane China for their support for providing all the necessary data used in my research.

I am particularly grateful for the love and encouragement of my family, my parents Gao Yin and Xu Jierui, my parents-in-law Wang Ren and Sun Fengyun, my sister-in-law Lu Fengzhu and my brother Gao Xiangrong, my brother-in-law Wang Shutian and his wife Feng Jin. They have never failed to support me in all my endeavors, and this work has been no exception.

Last but most important, I wish to express my indebtedness to my wife, Sherry Wang and my daughter, Anna, for their love, patience, continued encouragement, and understanding. Without them, I would not have been able to succeed in my master's studies. 
To Sherry Wang, Anna, and my family 


\section{TABLE OF CONTENTS}

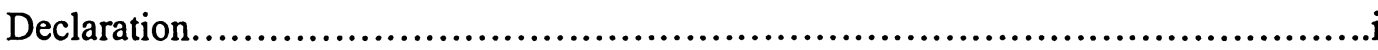

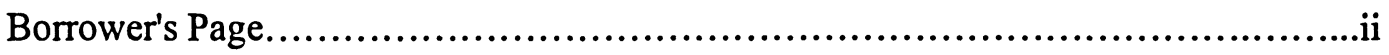

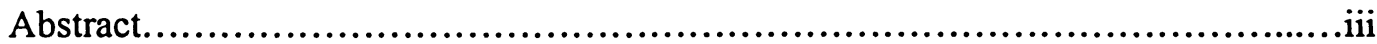

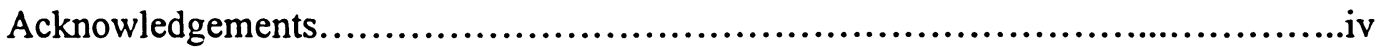

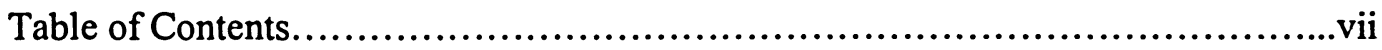

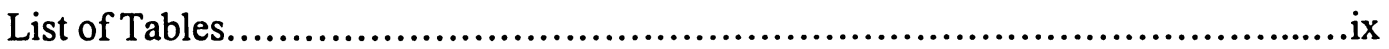

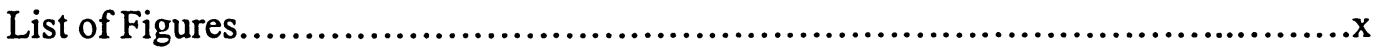

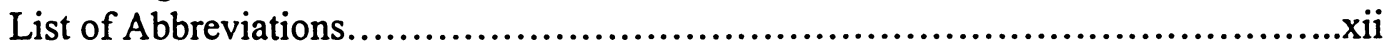

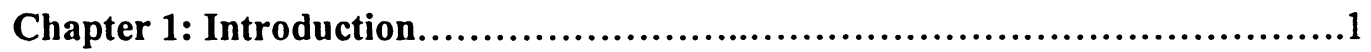

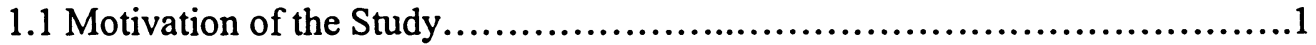

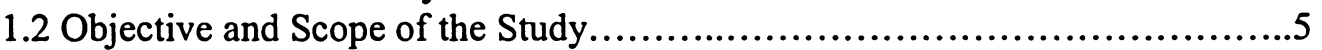

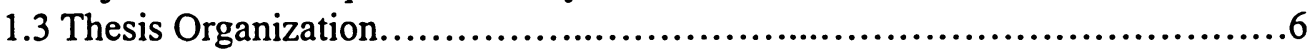

Chapter 2: Spatial Decision Approaches in Manufacturing

Environments......................................................

2.1 Spatial and Spatially Related Decisions in a Manufacturing Environment... ...8

2.2 CAD-based vs. GIS-based SDSS Approaches.... ...............................14

2.2.1 CAD-based Approach....................................................... 14

2.2.2 GIS-based Approach................................................

2.2.3 Section Summery ...................................................23

2.3 GIS Applications in SDSS in Manufacturing Environments....................24

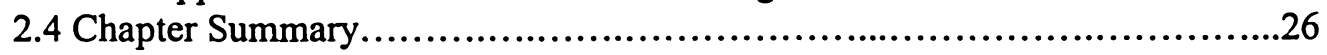

Chapter 3: Unified Process - An Systematic Approach GIS-based SDSS ........28

3.1 Object-oriented System Analysis and Design - the Unified Software

Development Process ............................................................29

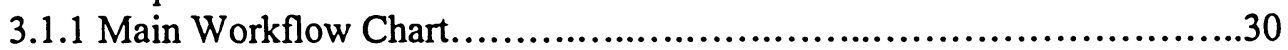

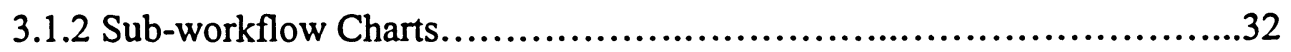

3.2 Proposed Structure and Functions of a GIS-based SDSS.......................36

3.4 Chapter Summary ..........................................................42

Chapter 4: Case Study - Trane China SDSS ...................................44

4.1 Overview of Trane China........................................................44

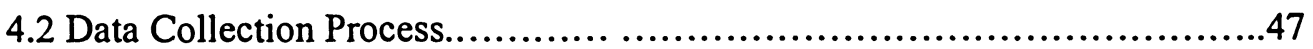

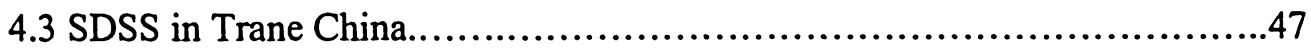

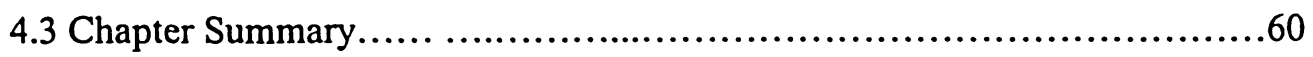


Chapter 5: Design of TCSDSS Prototype....................................62

5.1 Business Modeling....................................................62

5.2 Requirement Capturing...................................................63

5.3 Generation of Analysis Models.............................................67

5.4 Generation of Design Models.................................................69

5.5 Generation of Implementation Models...................................71

5.6 Chapter Summary.................................................... 74

Chapter 6: TCSDSS Prototype Test Results and Discussions.....................76

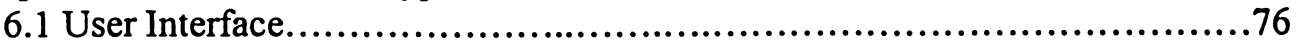

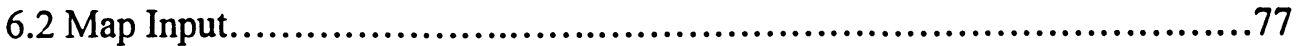

6.3 Module Function Test........................................................78

6.3.1 Test Procedure .........................................................78

6.3.2 Test Results........................................................81

6.4 Chapter Summary .....................................................98

Chapter 7: Conclusions and Recommendations................................100

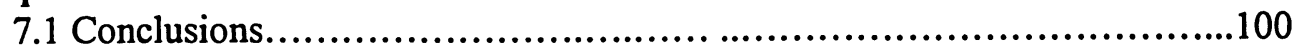

7.2 Main Issues on Future Studies.........................................102

Bibliography..............................................................106 


\section{LIST OF TABLES}

Table 2.1 Site location selection factors.. ...........................................11

Table 2.2 Similarities and differences between CAD and GIS.......................23

Table 4.1 Production line assignment..............................................46

Table 4.2 Equipment requirement list for Illusion Outdoor Line (part)..................50

Table 4.3 Hand-tool requirement list for Illusion Outdoor Line (part)...................51

Table 4.4 Equipment and facilities assessment result for Illusion Out Line (part).......52

Table 4.5 Safety risk assessment result for sheet metal area (part)....................54

Table 4.6 Production linearity index and workforce index report....................55

Table 4.7 Quality improvement candidate lines....................................57

Table 4.8 Illusion OD Line quality improvement assessment (part).................58

Table 4.9 Line average skill level survey...........................................59

Table 4.10 Sheet metal area operator training survey ..............................59

Table 4.11 Trane China SDSS status. .............................................61

Table 5.1. TCSDSS information flow table .....................................63

Table 5.2 TCSDSS Department functions and actor description. .....................64

Table 5.3 Use case descriptions for QIA. ......................................66

Table 5.4 QIA analysis description.. ...............................................69

Table 5.5 QIA design description.. .............................................70 


\section{LIST OF FIGURES}

Figure 3.1 Main workflow of unified process .......................................31

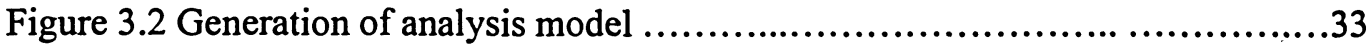

Figure 3.3 Generation of design model. ...............................................34

Figure 3.4 Generation of implementation model. ......................................36

Figure 3.5 Proposed architecture of GIS-based SDSS in manufacturing

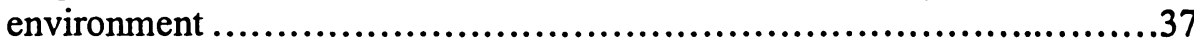

Figure 4.1 Location of Trane China and its products ................................45

Figure 4.2 Building uses for Trane China .......................................45

Figure 4.3 Trane China production lines ...........................................46

Figure 4.4 Trane China organizations chart.........................................48

Figure 4.5 Factory layout (part) .......................................................49

Figure 4.6 Geographical market segmentation......................................56

Figure 5.1 TCSDSS implementation organization chart ............................62

Figure 5.2 TCSDSS Use-case diagram ..........................................65

Figure 5.3 QIA analysis model...................................................68

Figure 5.4 QIA class diagram....................................................68

Figure 5.5 QIA collaboration diagram .............................................68

Figure 5.6 QIA design model .....................................................69

Figure 5.7 QIA design level class diagram .......................................69

Figure 5.8 QIA design level sequence diagram ...................................70

Figure 5.9 QIA implementation model and component diagram.......................71

Figure 5.10 ArcMap Editor toolbar.................................................72

Figure 5.11 Sketch tool and context menu ........................................73

Figure 5.12 Snapping environment................................................73

Figure 5.13 TCSDSS prototype system architecture ...................................74

Figure 6.1 User interface.........................................................77

Figure 6.2 User identifying........................................................77

Figure $6.3 \mathrm{Map}$ input - georeferencing............................................78

Figure 6.4 Classification - Current quality level.....................................79

Figure 6.5 Classification - Current quality level/target quality level......................8 80

Figure 6.6 Quality improvement query ( $T_{-}$sigma - C_sigma $>1.5$, Benefit cost $>5000$, High urgency) .............................................81

Figure 6.7 Lightning distribution analysis.........................................82

Figure 6.8 Noise level distribution analysis.........................................8

Figure 6.9 Indoor air quality index distribution analysis.............................83

Figure 6.10 Emergency exit accessibility within half a minute........................84

Figure 6.11 Firefight resource accessibility within half a minute.......................85

Figure 6.12 First aid resource accessibility within half a minute........................86

Figure 6.13 RONA distribution....................................................87

Figure 6.14 Linearity distribution.............................................88

Figure 6.15 Workforce utility distribution.........................................88

Figure 6.16 Query: Linearity $>0.83$, workforce utility $<1.04 \ldots \ldots \ldots \ldots \ldots \ldots \ldots \ldots \ldots \ldots . . . .89$ 
Figure 6.17 Maintenance classification by priority level........................... 90

Figure 6.18 Maintenance classification by cost..................................90

Figure 6.19 Query (Deviation index=major, impact to production=minimum, Cost<250USD)...................................................91

Figure 6.20 Market size by region.............................................92

Figure 6.21 Market size by region - pie show...................................92

Figure 6.22 Current skill level classification.....................................93

Figure 6.23 Current skill level/required skill level classification.......................93

Figure 6.24 Skill trainee selection (required skill - current skill > 5) ..................94

Figure 6.25 Space use classification.........................................95

Figure 6.26 Space use summary - tabular form................................95

Figure 6.27 Space use summary - pie form......................................96

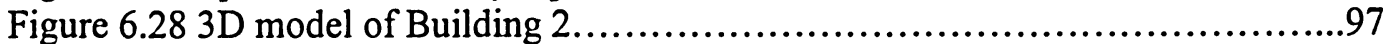

Figure 6.29 Visibility study result - ArcSecene interface...........................97

Figure 6.30 Visibility study result - ArcMap interface..............................98

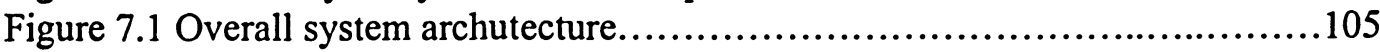




\section{LIST OF ABBREVIATIONS}

$\begin{array}{ll}\text { CAD } & \text { Computer-aided design } \\ \text { DBMS } & \text { Database management system } \\ \text { DSS } & \text { Decision support system } \\ \text { ES\&H } & \text { Environment, safety and health } \\ \text { GIS } & \text { Geographic information system } \\ \text { MBMS } & \text { Model base management system } \\ \text { MCDM } & \text { Multiple criteria decision making } \\ \text { OOAD } & \text { Object-oriented analysis and design } \\ \text { QC } & \text { Quality control } \\ \text { QIA } & \text { Quality improvement analysis } \\ \text { RONA } & \text { Return of net assets } \\ \text { SDLC } & \text { Software development life cycle } \\ \text { SDSS } & \text { Spatial decision support system } \\ \text { TCSDSS } & \text { Trane China spatial decision support system } \\ \text { UML } & \text { Unified modeling language }\end{array}$




\section{INTRODUCTION}

\subsection{Motivation of the Study}

In today's competitive world market, the management of a manufacturing enterprise faces the formidable challenge of operating a modern complex manufacturing system. The rapid advancements in manufacturing and process technologies, in product engineering designs and changes, and in market needs and requirements, have created a rapidly changing environment with a shorter product life cycle. To maintain a competitive advantage, planning and management of a manufacturing enterprise depend on computer-aided information management systems that gather and analyze information and data to provide decision support. Decision support systems (DSS) are becoming increasingly important. As defined by Power (1997), a DSS is "an interactive computer-based system intend to help managers make decisions". Many efforts have been contributed to the research of manufacturing decision support systems in the last decade (e.g., Hunkeler et al., 1999; Marinho et al., 1999; Hsieh et al., 2002; and Grabot and Letouzey, 2000).

Decisions made by a manufacturing enterprise often involve descriptive information/data with a spatial/geographical dimension. Distribution of products should consider how to set the distribution network. When the manufacturing engineers lay out the factory, they are dealing with the location of the production facility, the positions, dimensions and capacities of different facilities and equipment; later on, the maintenance people will update the status of these facilities and equipment and keep them in good conditions. Finance personnel will manage the capital investments. Quality engineers will keep track the process capacities of the facilities and equipments 
to make sure they produce the best quality products. Human resource staff members need to know where the employees are assigned to work and their skills level. Many decisions made by these departments are about locations of the spatial entities such as marketing resources locations, and manufacturing facilities and equipment location; or about treatments of the spatial entities such as equipment maintenance plans, market development plans, and quality improvement plans. These decisions need information about locations of the spatial entities and/or their attributes like sales by regions, equipment status, and quality level.

While global production is growing tremendously, there is a sense of uneasiness that the environmental burdens resulting from the uncontrolled manufacturing activities may be inflicting irreparable damage to the planet. The indicators of depleting environmental quality are conspicuously evident in many direct and indirect forms, such as the greenhouse effect, global warming, ozone depletion, loss of species and habits, and air and water pollution (Puri, 1996). In response to public demands for restoring the environment and for reducing the quantity of waste generated by industrial organizations from manufacturing processes, there has been a continuous growth in the regulations, standards and environmental management certification programs proposed and/or imposed by worldwide organizations, different countries, and different provinces of the countries (Douglas, 1995). Optimized environmental decision-making requires access to databases that are spatially comprehensive, current, relevant, and thematically detailed enough to allow the distribution and state of pollutants to be defined (Trotter et al., 2001).

Inside the manufacturing facilities, it was reported that some 50 million accidents occur every year, which is an average of 160,000 every day. Of these, around 100,000 are 
fatal. Each year, industrial accidents also disable 1.5 million workers for the rest of their lives; in addition millions suffer from disabling occupational diseases (Clerc, 1985). These human tragedies can be avoided completely that cannot be ignored. Work safety has already been drawn attention by different levels of governments, even internationally. More and more laws and regulations were imposed to ensure the employees have a safe work place by the governments. On the other hand, improving working environment does not just mean cost. Actually, the role of the physical work environments on performance and productivity has been the subject of many studies for many years. Springer et al. (2001) reviewed over 40 studies of productivity improvement and found that these studies demonstrated with great consistency that the physical place of work has a significant impact on people's performance. The three key studies in his review concluded that, with the improvements made to the lighting, spatial configuration, furniture and support equipment, and seating, employee performance and productivity improved $5 \%$ to $15 \%$. Clearly, the consistency of these results over time shows that design and management of the physical work environment is a critical contributor to the job satisfaction and safety, the performance and financial well being of the organization. Creation and improvement of a safe and comfortable work environment require related information such as equipment/facility locations, equipment/facility safety grades, and spatial distributions of lighting.

Decisions involving descriptive information/data with a spatial dimension are so important that it is necessary to study the spatial sub-set of decision support systems, or spatial decision support systems (SDSS) in manufacturing environments. An SDSS is an interactive, computer-based system designed to assist a user or a group of users in achieving a higher effectiveness of decision making while solving spatial decision problems. Typically, such a system will include spatial data relevant to the decisions, 
analytical tools to process the data in ways meaningful for decision makers, and output or display functions (Corbett et al., 2002). According to Malczewski (1997), a SDSS is made of three main components. The database management system contains the functions to manage the geographic data base; the model base management system contains the functions to manage the model base; and dialog generation and management system manages the interface between the user and the rest of the system..

Currently, most of the manufacturing enterprises are experiencing computer aided drafting (CAD) based SDSS approach, in which CAD systems are used to handle spatial data base. CAD systems are used in factory layout (Iqbal and Hashmi, 2001; Traub et al., 1998), facility/utility design and maintenance (Yu et al., 2000; Dong and Agogino, 1998; Yamada and Teraoka, 1998). Essentially developed for product designs, CAD systems have many limitations when they are applied to SDSS. First, CAD systems are typically used primarily as drawing tools, and are not used to store attribute data within the drawings (Yu et al., 2000). Second, CAD systems use connected network data model, which cannot handle areas or polygons very well (ESRI, 2003). Third, CAD systems cannot perform spatial analysis functions (ESRI, 2003) to support decision-making. On the other hand, Geographic Information Systems (GIS) provide similar graphical interfaces as $\mathrm{CAD}$, but extend the capability of associating nongraphic data with the graphics (Yu et al., 2000). As GIS systems use topological data model, they deal with polygons as well as line and point features and could easily handle more complex spatial relationships of those features (ESRI, 2003). GIS systems can also provide sophisticated spatial analysis functions to support decision-making. Thus, GIS-based SDSS approach can handle spatial databases better than CAD-based SDSS approach as well as provide some decision-making models. 
Applications of GIS in SDSSs have only been studied within 15 years (Nasirin and Birks, 2003). Most studies have just focused on individual applications. Cases are found in site selection (Church, 2002; Eck et al., 1999), resource management (McKinney and Cai, 2002; Kliskey, 1995), spatial analysis (Kluijver and Stoter, 2003;

Gualtieri and Tartaglia, 1998), facility/utility planning and management (Aldosary and Zaheer, 1996; Yeh and Chow, 1996; Berner et al., 1995), emergency response management (Cannon et al., 1998), and service network analysis (Gorr et al., 2001; Lin et al., 1996). Studies of applications of GIS in SDSS in manufacturing environments are even more limited. Cases are found in warehouse selection (Vlachopoulou et al., 2001); environment, safety and healthy (ES\&H); and facility management (Douglas, 1995). Systematic approaches to the development of GIS-based SDSS in manufacturing environments are required.

\subsection{Objective and Scope of the Study}

The objective of the study is to examine the possibility of GIS applications in SDSSs in manufacturing environments by prototyping a GIS-based SDSS in the case study of Trane, a company located in Taicang, China. Recent technological advances in software development - the object-oriented analysis and design (OOAD), unified modeling language (UML)- are utilized to prototype the Trane, China GIS-based SDSS (TCSDSS).

Two factors confine the scope of this study. First, the main purpose of this study is to examine the possibility of GIS applications in the SDSS in manufacturing environments. Thus, efforts will just be given to the prototyping of the GIS-based SDSS. Any efforts involving time-consuming algorithm research and development as 
well as coding will not be considered in the development of the prototype. Commercially available GIS software package will be considered.

Second, although a wide variety of commercial GIS packages such as MapInfo, ArcInfo, GeoMedia, ArcView, and ArcGIS exist, ArcGIS was selected in this study. As one of the pioneers of commercial GIS software developing organization, ESRI's ArcGIS should be able to represent the trend of commercial GIS software development.

\subsection{Thesis Organization}

This thesis is built over seven main chapters. After this introduction, an overview of the background and related work is provided in Chapter 2, which aims to give a description of the spatial and spatial related decisions in a manufacturing environment, a comparison between CAD-based and GIS-based SDSS approaches, a comparison between GIS and SDSS, and several studies on GIS applications in SDSS within the manufacturing environments. It supplies a reader with many references where more details can be found. This chapter is necessary to supply the reader with information on current SDSS techniques in manufacturing environments, permitting thus a better understanding about the necessity of the systematic approach to the development of a GIS-based SDSS in a manufacturing environment.

Based on overview of background and related work in Chapter 2, the proposed strategic choices, and the system architecture and main functions of SDSS in manufacturing environments are presented in Chapter 3. Recent technological advance in software development - object-oriented system development process - is also introduced into the development of GIS-based SDSS in manufacturing environments. The case study input data - Trane, China - is introduced in Chapter 4. The used spatial and attribute 
data and the existing geodatabase as well as other data sources such as plant layout are described in this chapter.

Chapter 5 describes the design of the prototype of TCSDSS, during which the objectedoriented system development process is utilized and UML is used as the modeling language.

In Chapter 6, the test results of the prototype are reported. Problems and improvement issues of the prototype are discussed. Benefits of the developed prototype are analyzed.

Chapter 7 presents conclusions about the suitability of the developed prototype and discusses the advantages, limits and perspectives of such a prototype. Main contribution of this thesis study is also concluded. Finally, recommendations for further research are given. 


\section{SPATIAL DECISION APPROACHES IN MANUFACTURING ENVIRONMENTS}

Chapter 1 discussed the necessity of building up a SDSS in a manufacturing environment. In order to have an in-depth and systematic view of this kind of SDSS, studies must be done to understand what the spatial, spatially related decisions in a manufacturing environment are, and how they are made. Section 2.1 will focus on the literature review of the related studies. Because CAD systems are so popular in manufacturing environments, it is nature to utilize CAD systems to store and retrieve spatial data. However, as presented in Section 2.2, research found that there are many limitations in the CAD-based approach to SDSSs in manufacturing environments. On the other hand, many efforts are given to the GIS-based approach to SDSSs. GIS-based approach is found to have obvious advantage over CAD-based approach although

limited study examples are found in manufacturing environments. A comparison of GIS and SDSS is also given in this section. After presenting three examples of GIS applications in the SDSS in manufacturing environments, Section 2.3 concludes that it is necessary to systematically develop manufacturing SDSSs.

\subsection{Spatial and Spatially Related Decisions in a Manufacturing}

\section{Environment}

As discussed in the previous chapter, decisions made by a manufacturing enterprise often involve descriptive information/data with a spatial dimension. Such decisions can be classified as spatial decisions that are the decisions on the dimensions of spatial features such as location and route selection, or spatially related decisions that are the 
decisions about attributes of spatial features such as prioritizing equipment maintenance plan based on the current status of the equipment. Different departments of the manufacturing enterprise perform different spatial and spatially related decisions. They need different combinations of data and decision-making models.

The marketing department needs to segment markets by geographic regions, market density, or climate. Market density is the number of people in a unit of land such as a census tract. Climate is often used to generate geographic segments because of its dramatic effect on consumers' needs and purchasing behavior. Products such as airconditioning and heating systems are those whose appeal varies sharply with climate (Lamb et al., 2002). During the setup of a physical distribution system, marketing people should balance the customer satisfaction level against the logistic costs to locate the warehouses and establish the transportation routes (Kotler et al., 1999). Quite similarly, a customer service department makes its decisions on where to set the customer service centers. Purchasing people source suppliers based on suppliers' parts price, quality, technology, management, and delivery that mainly depends on the location of the suppliers, etc. Detailed discussions on supplier selection can be found in Swift (1995) and Ittner et al. (1999).

Quality management needs to keep track of the process capabilities of each manufacturing process, which is spatially distributed, to prioritize its quality improvement efforts. One of the concerns of the finance people is the return of the capital investment. They are quite interested in how efficient the facilities and equipment making money for the company (Klammt, 1999). If the returns do not meet their expectation, this gives the manufacturing engineers a chance to conduct a cost 
reduction program. Human Resource department needs information about where the employees are assigned to work and their skill levels.

Production department performs most of the spatial and spatially related decisions in a manufacturing environment. Manufacturing engineers will first design the facilities and workplaces, layout the factory, or make the decisions on where to locate the factory, buildings, production equipment, and offices. During the operation process, facility/utility/equipment maintenance engineers will keep all the above items in good condition. ES\&H engineers mostly concern about the environmental impacts of the manufacturing processes on the employees and communities, the working environment of the employees, and the emergency response system. The detailed discussion is as follows:

\section{A. Facility Design}

According to Lee et al. (1997), there are five levels of spatial designs in the facility design process, which are global, supra, macro, micro, and sub-micro.

\section{Level I - Site Location Selection/Global Level}

At this level, the firm decides where to locate the facilities; this could be a global level selection. The proposed sites are usually showed on a map, which along with other documents, makes up the report to the management. The selection factors can be classified as external and internal. External factors exist largely outside the site boundaries while internal factors exist largely within the site boundaries. External and internal factors in turn may be classified as tangible and intangible. Tangible factors are those with physical forms such as site boundaries or soil conditions. Intangible factors 
are less definitive, and include factors like the local work ethic, government climate, or site history (Lee et al., 1997). Table 2.1 summarizes some examples of these factors.

\section{Level II - Supra-space Plan}

At this level, site planning that shows land use takes place. This includes number, size, and location of buildings; utilities such as, water, gas, communication cables, computer network cables, and power; roads; parking lots; landscape and many other site features. This is a joint effort of architects, civil engineers, and industrial engineers. The documents from a site-planning project usually include a site drawing (Lee et al., 1997). The objectives of site planning are to minimize transportation costs by improving workflow, utilize space efficiently, minimize utility material costs by minimizing utility route, ensure safety, be aware of environment, and provide scenic landscape (Lehrer, 2001).

Table 2.1 Site location selection factors

\begin{tabular}{|c|c|c|}
\hline & External & Internal \\
\hline Tangible & $\begin{array}{ll} & \text { Transportation proximity } \\
\text { - } & \text { Neighbor activity } \\
\text { - } & \text { Prevailing wind } \\
\text { - } & \text { Residential proximity } \\
\text { - } & \text { Freight transportation } \\
\text { - } & \text { Acquisition price and term } \\
\text { - } & \text {... }\end{array}$ & $\begin{array}{ll}\text { - } & \text { Topography } \\
\text { - } & \text { Soil conditions } \\
\text { - } & \text { Existing buildings } \\
\text { - } & \text { Existing traffic areas } \\
\text { - } & \text { Utility systems } \\
\text { - } & \ldots\end{array}$ \\
\hline Intangible & $\begin{array}{ll} & \text { Political climate } \\
\text { - } & \text { Police and fire protection } \\
\text { - } & \text { Manpower } \\
\text { - } & \text { Natural resource restrictions } \\
\text { - } & \text { Environmental issues } \\
\text { - } & \text { Tax exemption/local tax } \\
\text { - } & \text { Economic stability } \\
\text { - } & \text { Labor laws } \\
\text { - } & \text { Cost of living } \\
\text { - } & \ldots\end{array}$ & $\begin{array}{ll} & \text { Landscape } \\
\text { - } & \text { Security } \\
\text { - } & \text { Safety } \\
\text { - } & \text { Appearance/image } \\
\text { - } & \text { Managerial style } \\
\text { - } & \text { Tract shape } \\
\text { - } & \ldots\end{array}$ \\
\hline
\end{tabular}


Level III - Macro Space Plan

At this level, designers define and locate operating departments for each building. The fundamental organization of the factory is set at this stage (Lee et al., 1997). The major objective is to achieve the required output quantity and quality. This involves the proper process, workflow, material flow, and allocation of space and resources; the easier access to supplies and materials; the high plant efficiency; maximized space utility; safety and cost saving (Tavares et al., 1999).

Level IV, V - Micro and Sub-micro Plan

These two levels are quite similar to level 3. The main difference is the boundaries of different levels. Actually level 4 is within the boundaries of level 3 and level 5 within level 4. Level 4 locates machines, conveys, work benches, racks, and materials while Level 5 locates all the stuffs within the work station such as tools, material bins (Lee et al., 1997).

B. Maintenance

Preventive maintenance starts from condition assessment. Facilities audit is an essential tool for the determination of conditions of an organization's capital assets, including buildings, infrastructure, and major fixed and movable equipment. Companies conduct facilities audits for strategic planning purpose associated with financial planning of capital assets, for cost allocations and analyses of productivity of capital assets, and for strategic decisions on retaining or disposing of assets (Kaiser and Davies, 2001).

The facilities audits generate databases about the conditions of the facilities, such as condition deficiencies, facility condition index, quality deficiencies, facility quality 
index, facility condition/quality index, renovation/modernization/, replacement needs, prioritized projects, cost estimate, and phasing schedule (Kaiser and Davies, 2001).

By analyzing the data got from facilities auditing, working with finance people, buyers, and manufacturing engineers, maintenance engineers can make retaining/disposing decisions and establish strategic maintenance planning.

\section{ES\&H}

ES\&H effort begins with risk assessment (Dougherty, 1999; Clerc 1985), which generates the databases for ES\&H management. It is better that this job be carried out before or as soon as new plant and equipment are commissioned, since it is at these points that the necessary ES\&H measures can be taken more efficiently and at lower cost. Risk assessment systematically identifies and evaluates all obvious and hidden hazards that may occur anywhere during the operation of the undertaking. Risk assessment generally includes (Poulton, 1979; Clerc, 1985; Rush, 1986; Dougherty, 1999):

I. Machinery and plant

The safety risk of machines, workstations, racks, tools, jigs and fixers, material handling devices, vehicles, elevators, and utilities (gas and electric power) should be analyzed, categorized, and graded. Noise, heat, vibration, and radiation, gases, vapors and fumes generated by the machines and their spatial distribution should be identified. Safety conditions of premises, structures within the building, floors, access routes, and traffic aisles should also be analyzed, categorized and graded. 


\section{Harmful agents}

The pollution of the working environment by gases, vapors, fumes, dusts, and waste water is at present one of the industry's most severe problems. This pollution is not limited to the area of the undertaking; it is also a hazard for the surrounding neighborhoods, and endangers the health of the general population in large industrial centers. It is necessary to understand their spatial distribution patterns.

III. Overall working environment

Noise, illumination, temperature, and indoor air quality are indexes for working environment. The understanding of their spatial distribution will help to analyze their effects on the employees.

IV. Emergency response system

The distribution of emergency response resources such as fire fighting, first aid, and communication tools will be investigated.

Assessment results will be compared with related regulations or company standards. Degree of deficiency, cost of improvement, project priority, and material availability will be analyzed and balanced in order to set up the ES\&H strategic planning.

\subsection{CAD-based vs. GIS-based SDSS Approaches}

\subsubsection{CAD-based Approach}

Currently, most of the manufacturing companies are experiencing CAD-based SDSS approach, which a CAD system is utilized to store and retrieve spatial/geographical data. CAD systems are basically derived from the computerization of engineering 
graphics. During the product design process, different kinds of design models are generated in different design stages to facilitate the communication between different design engineers and to evaluate the periodical results (McMahon and Jimmie, 1998). This type of work used to be done manually. As computer hardware/software engineering and science improve, CAD systems were developed to automate or assist in such tasks as the production of drawings or diagrams and the generation of lists of parts in a design. As technology advances, CAD systems can not only create and modify but also analyze and optimize engineering designs. The various components of a CAD system include a graphic package for visualization, a geometry manager for maintaining data structures that contain geometric information, a numerical methods library to perform various numerical functions, an interface that connects the user and the system, and a data manager that stores and maintains the large amount of CAD data (Liu, 2003).

The use of CAD systems in SDSS started from the 1970s and early 1980s in utility companies. Linked to a separate database of textual or attribute (non-graphical) information computer graphic systems, the primary function of these systems was to record the location of geographically dispersed assets or facilities. Implementations of these systems typically had two completely separate components-a graphics "engine" and tabular record files (ESRI, 2003).

Recently, in their case study of a healthcare real estate facility management, Dechant et al. (2001) selected a CAD system to document buildings and the space uses for the accurate as-built drawings it can provide, while database systems were deployed to handle the non-geographic information. In this case, CAD drawings are not linked with the non-geographic data. Many efforts were given trying to link the geographic data 
and non-geographic data. Dong and Agogino (1998) studied the idea of "smart drawings" earlier in 1998. In such a study, a "smart drawing" is defined as a CAD drawing with external links to network-accessible relational databases and related documentation such as memos, spreadsheets and analytical results. The "smart drawing" user interface derives directly from the CAD graphics software and the CAD entities themselves. By clicking on the graphical entities, the designer can download the linked documents from the document manager and either view or edit the document. However, these documents can only be treated as external links rather than attribute data internally linked with geographic data (Dong and Agogino, 1998). In another case study, a CAD system (MicroStation) was used in a computer aided facility management (CAFM) system to maintain primarily site and building plan graphics, which represent actual building elements as well as boundaries of space use and/or ownership, locations of assets, and significant maintenance items. By linking to the space locations and asset information databases, these CAD graphics were made "smart", that is, they can provide highly accurate area measurements and graphic representations of locations, owner or occupant information, and proposed changes. The 3D function of the CAD system was also deployed for visualization and planning purposes (Barlow and White, 2001). In this study, links between geographic and nongeographic data are external as well.

At the same time, the effort of applying the 3D function of CAD to facility design was made by Traub et al. (1998) for chemical facility layout, and Iqbal and Hashmi (2001) and Zetu et al. (1998) for virtual realty factory layout.

The problem with topographical and statistical analysis function makes CAD systems hard to solve facilities layout problems (Tompkins and White, 1984). Many studies 
devoted to solve this problem. To name a few examples, Karray et al. (2000) developed computational intelligence tools; Lu et al. (1996) developed topology connectivity method; Moorthy (1999) and Eneyo and Pannirselvam (1998) tried to apply the simulation methods; Chang et al. (2002) developed a symbiotic evolutionary algorithm with a dynamic view of the facility layout; Tavares et al. (1999) tried a constraint programming approach. Different packages of commercial software were developed decades ago, such as CRAFT, COFAD, PLANET, CORELAP, and ALDEP (Tompkins and White, 1984). However, the results of all these efforts are just the representative diagrams that describe the topological relations among the departments. Accurate final designs still have to be achieved by CAD systems.

The practice of CAD-based SDSS finds that CAD systems cannot generate direct links between graphic and attribute data and perform spatial analysis. Their ability to handle spatial information and support decision-making is limited.

\subsubsection{GIS-based Approach}

Parallel to the development of CAD systems, another type of computer graphic system was emerging that handled geographic areas or coverages as their primary component. These also linked graphic entities to non-graphic information stored in flat files or databases. They differed from CAD systems in that they dealt with the underlying geography directly, rather than as simply a means to display facilities. These systems are called geographic information systems (ESRI, 2003).

A GIS is "a system of hardware, software, and procedures designed to support the capture, management, manipulation, analysis, modeling, and display of spatially referenced data for solving complex planning and management problem" (Rhind, 1989). As for the spatially referenced data, it implies that all data in the system are pertinent to 
Earth's features and resources, including human activities based on or associated with these features and resources. It also means that the commonality of both the data and the problems that the systems are developed to solve is geographic space, i.e., location, distribution, pattern, and relationship within a specific spatial referenced framework. This focus in spatial/geographic data and their applications for spatial problem solving makes GIS unique among information systems (Lo and Yeung, 2002).

Although few literatures are found in the applications of GIS in SDSS in manufacturing environment, many GIS applications are found in other areas such as urban planning, utility management, transportation, environment protection, and service industries. These applications perform similar functions required by manufacturing enterprise such as location decision, facilities management, and environment protection.

\section{Location decision,}

Yeh and Chow (1996) integrated GIS and a location-allocation model to find the best sites for public facilities. In this study, they tried to identify the optimal sites for open space and to evaluate the location of existing open space in Hong Kong. Eck et al. (1999) discussed different methods to construct an accessibility surface, which was a map showing the general pattern of accessibility or expected market size for a new facility on any location in the area, as a tool for facility location planning with special reference to shops. Lin et al. (1996) presented an efficient method to determine the substation siting and feeder planning based on the shortest path for the Taiwan Power Company. In their study, a GIS provided an environment for building a database that contains both graphic information and non-graphic facility data. Church (2002) summarized that because GIS can be used to assemble data from various sources involving 
different map scales and transformations, it can be a significant aid to the location analyst. Even though location studies need not involve the use of GIS, there is much to be gained by taking advantage of the functions that are available in GIS software, and available in databases that can be purchased. First, some of the software features support is needed for operations in a location model application. These may include: data entry, mapping, solution presentation, output, spatial data organization, and spatial measurement (e.g., distance matrix). In many cases, it would not be cost effective to independently develop such software functions for a location study. It is possible, for example, to develop a system that can generate a view-shed for a cellular telephone location study, but it could be a far simpler task to integrate GIS system to provide such functionality when needed. Second, a growing data development industry supported primarily by GIS users now makes or packs a number of data products that could have significant value in location studies. Third, GIS software often uses state-of-the-art database engines and is designed to handle large volumes of data. Such software can obliviate the need to independently develop a spatial database engine. On the negative side, there are actually costs to both software and data acquisition. Such costs may not be justified in terms of an isolated project; but, in any circumstance where the costs of the GIS and needed expertise can be averaged over multiple uses, GIS may be the costeffective alternative. As new software is brought on-line and expertise is developed among location scientists, it is hard to imagine that GIS will provide only a supporting role in location research, as many new models become possible when viewed from a GIS perspective. In fact, demand for better location model functionality in GIS software will grow. It is easy to conclude 
that the success of many location applications in the future may be intimately tied to GIS.

II. Environment protection,

Gualtiert and Tartaglia (1998) set up a comprehensive GIS-based simulation model for predicting and evaluating air pollution due to road traffic in urban areas. Different models were integrated in a GIS, which allowed the use of spatial coordinates to describe the structure of urban areas, road networks, and pollutant distribution in the atmosphere. These models were aimed at reproducing traffic behavior, emission and dispersion scenarios. The application of GIS makes it suitable for use by the local administration in order to forecast alert pollutant levels in urban atmosphere, integrate existing monitoring network measurements, and estimate the sensitivity of pollution levels to such variables as traffic flow distribution and atmospheric conditions. Jensen et al. (2001) found that the current Danish urban air quality management systems had low spatial resolutions, crude exposure assessment and did not take full advantage of GIS and administrative databases. They set up a model called AirGIS that was able to estimate ambient air pollution levels at high temporal and spatial resolutions. The new model enabled mapping of traffic emissions, air quality levels and human exposures at residence addresses, at workplace addresses and in street. Mapping and scenario results were compared with air quality limits. Impact assessment of traffic air pollution abatement measures was also carried out. Kluijver and Stoter. (2003) found that to quantify and visualize noise effects an extended spatial database, spatial tools and computation force were needed. For that reason, GIS was used in studies on the 
environmental impact of noise. Noise levels were computed in specially developed simulation computer models and GIS tool was used to quantify and visualize noise effects based on these noise levels. An appropriate use of GIS in mapping noise effects made it possible to optimize quality, accuracy and efficiency of noise effect studies, improve data management and presentation. Standardization benefited from the possibility of automating the noise mapping process in GIS. Furthermore, GIS can play an important role in estimating and exposing uncertainties.

III. Facility management,

Berner et al. (1995) developed an integrated computer system for urban facilities maintenance and alarm management to perform five major tasks. These five tasks were processing of the geographical and attributive information about town area and urban systems, simulations of the facilities and calculations, simulation results and current facilities status analysis and decision-making, real-time process monitoring, and marketing and accounting with gas, water and heat consumer. In the system they developed, a GIS was adopted to combine different graphical/geographical and attribute information, which includes town maps with administrative districts borders, buildings, roads, urban facilities arrangement; reference attributes tied; current measurement data; alarms and process violation information; and process circuits (graphical representation of gas, water, sewage or heat network topology and interaction between equipment units). GIS was also used to produce reports, requests and measurement, etc. Considering the vast applications of GIS, Aldosary and Zaheer (1996) thought the maintenance was also a potential application area. They tried to develop an 
application mechanism for a GIS-based maintenance system taking the case of the Maintenance Department at the King Fahd University of Petroleum and Minerals in Saudi Arabia. They found that GIS not only enhanced the quality of maps produced, but also to a large extent improved the maintenance process, services to the community members, increased the efficiency and enhanced the decision-making process. In addition to these, GIS had provided the cutting edge in term of cost-effectiveness. Jordani and Gondeck-Becker (2001) conducted a case study of space management at the University of Minnesota. They selected a commercial "off-the-shelf" GIS system for the following reasons:

a) GIS can manage the full spectrum of spatial data management issues from the site to a room; the wide range functions include utility management, capital projects, master planning, inventory services, and infrastructure management services.

b) GIS data models are geographically continuous.

c) GIS offers a more open architecture that would better facilitate the customer's customization requirements.

d) The concept of "thematic maps" makes GIS more powerful for display and data analysis.

e) The spatial analysis function of GIS is unique.

The practice of GIS-based SDSS finds that GIS systems have the ability to link graphical and non-graphical data directly. Their built-in models can perform spatially 
related analysis functions. Thus, their ability to handle spatial information and support decision-making is better than that of CAD systems.

\subsubsection{Section Summary}

In summary, the similarities and differences between CAD and GIS are presented in Table 2.2. It can be concluded that in order to handle spatial information better, make better use of spatial information, and to support better spatial/attribute decisions, GIS systems are more suitable than CAD systems for SDSS development.

Table 2.2 Similarities and differences between CAD and GIS

\begin{tabular}{|c|c|l|}
\hline & CAD & \multicolumn{1}{|c|}{ GIS } \\
\hline $\begin{array}{c}\text { Similarities } \\
\text { (Hanna and } \\
\text { Culpepper, } \\
1998)\end{array}$ & \multicolumn{1}{|c|}{$\begin{array}{l}\text { Use of layers } \\
\text { Diverse and high quality data output }\end{array}$} \\
\hline \multirow{2}{*}{$\begin{array}{c}\text { Easy scale handling ability } \\
\text { Flexible data storing and transportation }\end{array}$} \\
\hline & $\begin{array}{l}\text { Attribute data stored within maps } \\
\text { Polygons, line and point features } \\
\text { Precision - Coordinate entry, } \\
\text { snapping, ortho } \\
\text { Reporting ability } \\
\text { Statistical analysis models } \\
\text { Visualization (thematic maps...) }\end{array}$ \\
\hline
\end{tabular}

The most recent commercial GIS packages such as ArcGIS 8.3 version provide GIS systems more advanced drawing functions such as snapping, angle and length setting to make the drawings more precise (Booth and Andy, 2001). This provides one more reason for manufacturing enterprises to shift from CAD-based to GIS-based SDSS.

It should be mentioned that although a GIS has its own database, model base, and user interfaces, it could not be considered as an SDSS. Corbett et al. (2002) listed two main differences between a GIS and a SDSS.

First, Daniel (1992) noted that many of the distinction between GIS and SDSS are derived from the differences in their target audiences. While a GIS is typically operated 
by technicians focusing on details on database and tool development, the user of an SDSS seeks only a handful of intuitive operations that yield quick and effective answers.

Second, a GIS is often defined as having four major capabilities: data entry, data management, analysis, and presentation of outputs. A multiuse SDSS differs from a GIS in that data entry is deemphasized, analytic tools are given powerful goal-specific capabilities, and presentation of outputs is restricted to the basic needs of decision makers. This view assumes that users of an SDSS will be able to access full GIS capabilities as needed. Furthermore, some decisions may require outputs from decision models that are too complex to run within a GIS. Thus, a more functional view is to recognize an SDSS as an information system that combines selected functions of a GIS with software tools specifically designed to support decision-making.

\subsection{GIS Applications in SDSS in Manufacturing Environments}

Very limited studies have been found in the applications of GIS SDSS in manufacturing environments. The following paragraphs present four examples of these studies.

A. Murphy (1994) discussed key philosophical, data, and design issues for the use of GIS for combined manufacturing-environmental modeling. She explored the potential for GIS to improve the understanding of the impact of manufacturing scenarios on the environment and, vice versa, to assess the impact of potential environmental constraints on manufacturing plans.

B. Douglas (1995) described the application of information technology to address ES\&H and facilities management in an integrated manner, in which GIS played 
a very important role. He believed that "Emerging GIS technology is being applied with increasing frequency to manage industrial facilities. This tool will become a standard in the 21 century for dealing with information. Those organizations who adapt and take advantage of the power of GIS will find applications transcend the traditional facility management role."

C. Vlachopoulou et al. (2001) found that GIS can support logistic and marketing managers to evaluate placement options for warehouse stores, based on costs (transport, labor, utilities, etc.), and on customers and competitors demographics. They pointed out that the factors to be considered during the warehouse site selection include customer population of the surrounding area, spending power of this population, quality of transport links to site, competition, possible store size, parking facilities, proposed in-store facilities, warehouse management cost, and distribution cost. By integrating GIS with a Multiple Criteria Decision Making (MCDM) model in a decision support system, they classified the proposed warehouse sites and found the best site.

D. Holl (2001) tried to solve the manufacturing facility location problem in terms of its relation with the road transport infrastructure. He tried to link road network with transport cost and potential market size. In his study, he used GIS to handle graphic data such as road network and community map, and attribute data such as population, average income and potential supplier qualification. GIS was also used to calculate the accessibility of the potential manufacturing facility, potential costumers, and potential suppliers to the road network, and the accessibility of potential costumers and supplier to the potential manufacturing facility. 
The above four examples illustrate that current applications of GIS in SDSSs in manufacturing environments are not systematic. Although effective within their specific areas, these applications address limited parts of a SDSS in a manufacturing environment. Actually, the quantities of spatial data, spatial feature attribute data, and spatial decision models in a manufacturing environment are vast. However, the assembly of these data and models into a systematic and powerful SDSS is just at its beginning stage. A systematic approach to SDSSs in manufacturing environments is required.

\subsection{Chapter Summary}

Spatial/attribute decisions occur everyday in manufacturing environments in order to provide customer on time, high quality and reasonable priced products; generate profit for the company by increasing sales, reducing cost and improving productivity; be responsible for the environment we live in; and provide job safety and satisfaction to the employees. To make these decisions effective and efficient, a well-organized SDSS that contains vast spatial/attribute data and decision models is required.

The unique functions that GIS can provide - direct link with non-graphical attributes, spatial analysis, statistical analysis, visualization, reporting, and open software architecture for integration with other software packages - and the improved drawing functions of the most recent commercial GIS packages make GIS system a better choice than CAD system for the development of SDSSs in manufacturing environments.

Although effective within their specific areas, current applications of GIS are limited in isolated parts of a SDSS in a manufacturing environment. A systematic approach to SDSSs in manufacturing environments is required. 
Systematic approach needs appropriate method. SDSS development can be considered as a kind of information system development. In the next chapter, recent development in the information technology - the object-oriented analysis and design process will be introduced as the methodology in the development of SDSS in the manufacturing environment. The structure of the proposed SDSS in manufacturing environment will also be presented, as well as the important data and decision models in each module of the system. 


\section{UNIFIED PROCESS - A SYSTEMATIC}

\section{APPROACH TO GIS-BASED SDSS}

As discussed in previous chapters, there exist a lot of improvement space in a CADbased SDSS. First, graphical data and attribute data should be linked together. When changes are made, such as a move of a machine or a production line, the related attribute data change simultaneously. Thus, the opportunities of making mistakes are reduced. Second, in order to predict the effect of a spatially related activity, proper spatial analysis is required before the activity is taken. Third, in order to have more effective and efficient communication, better and faster reporting methods are needed. On the other hand, the unique functions provided by GIS make it a better choice than CAD system to develop SDSSs in manufacturing environments.

Based on the conclusion drawn in Chapter 2, there is a need for a systematic way to develop SDSS in manufacturing environments because current applications of GIS are limited in parts of a SDSS in a manufacturing environment.

In this chapter, focus will first be placed on the recent development in information technology (see Section 3.1). The object-oriented analysis and design process (OOAD) will be introduced as the methodology in the development of SDSS in the manufacturing environment.

In Section 3.2, the structure and functions of the proposed SDSS in a manufacturing environment will be presented based on the studies on the spatial and spatial related decisions in the manufacturing environment, e.g., what these decisions are and how they are made. 


\subsection{Object-oriented System Analysis and Design - the Unified}

\section{Software Development Process}

As a SDSS can be considered as a kind of information systems, methodologies utilized in information system development by information technology industry can also be utilized in the development of GIS-based SDSSs in manufacturing environments.

Currently, the most popular information systems development methodology utilized is the systems development life cycle (SDLC) (Shelly et al., 2001; Hoffer et al., 1999). The problem with this approach is as requirements change (and they will) and the system grows (and it will), systems built with an algorithmic focus turn out to be very hard to maintain (Booch et al., 1999). A more recent approach to systems development that is increasingly popular is object-oriented analysis and design (Hoffer et al., 1999; Duckham, 2001; Aggarwal, 2002). This approach combines data and process into single entities called objects, which correspond to the real things such as customers and suppliers an information system deals with, thus makes its product more close to the real world. There are three main techniques about OOAD. Encapsulation is the technique of hiding the internal implementation details of an object from its external view. Objects are organized into object classes, which are groups of objects sharing structural and behavioral characteristics. Inheritance is the technique that allows the creation of new classes that share some of the characteristics of existing classes. Polymorphism is the technique used to apply the same operation to two or more classes in different ways. These three techniques make system elements more reusable, thus improving system quality and maintainability, and the productivity of system analysis and design (Hoffer et al., 1999). 
Many object-oriented methods have been developed (Graham, 1994). Among these, the Unified Modeling Language (UML) resulted from the unification of the Booch, OMT, and OOSE methods has become the de facto standard for object oriented system analysis and design (Saleh, 2002; Shelly et al, 2001; Bennett et al., 2001; Booch et al., 1999; Hoffer et al., 1999).

The object-oriented software development cycle developed by Jacobson et al. (1999) has been widely used in the object-oriented software development. This software development cycle adopts UML and is called the unified software development process or unified process. The following paragraphs give a brief introduction of the unified process.

\subsubsection{Main Workflow Chart}

The main workflow of the unified process is described in Figure 3.1. The business modeling describes the structure of the organization and information flow inside the organization. The organization chart, the functions of each department, and the information flowchart or table are generated. Requirements capturing has two objectives: (1) to find the true requirements and (2) to represent them in a suitable way for the users, customers, and developers. Normally, a system has many users. Each type of user is represented as an actor. Actors use the system as they interact with use cases. A use case is a sequence of actions that the system performs to offer some results of value to an actor. All the actors and the use cases of a system make up a use-case model, which is described by a use-case diagram. The use cases and actors are described in detail by text. 


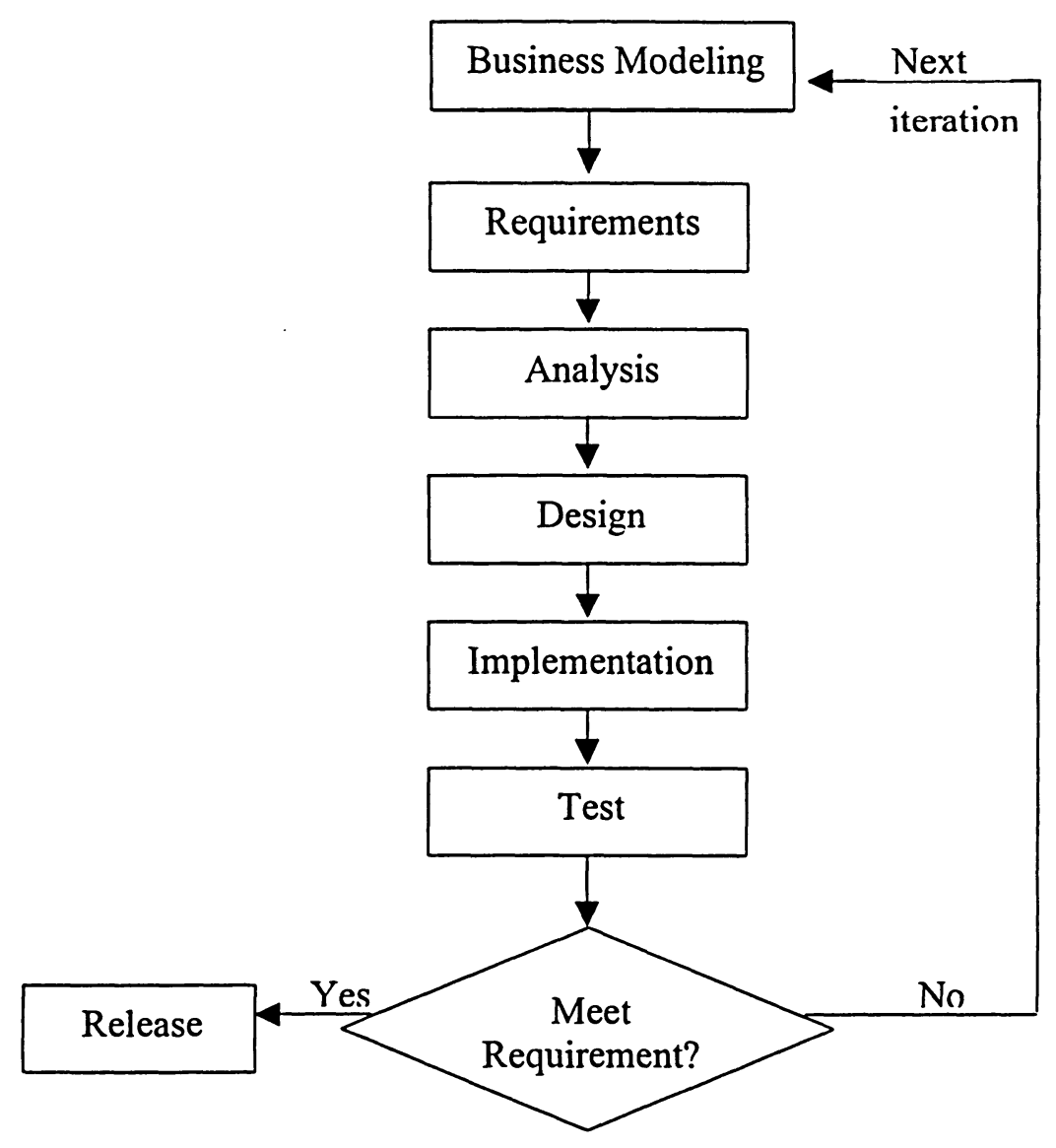

Figure 3.1 Main workflow of unified process

The analysis model is a detailed specification of the requirements and work as a first cut at a design model, although it is a model of its own. It is used by developers to understand more precisely the use cases as described in the requirements workflow by refining them as collaborations among conceptual classifiers. The developers create an analysis model that uses the use-case model as input. Each use case in the use-case model will be realized as a use-case realization in the analysis model.

The developers then design the classes and use-case realization to take better advantage of the products and technologies (e.g., GUI construction kits and database management systems) used to implement the system. The design classes are grouped into subsystems, and interfaces may be defined between those subsystems. 
Next, the developers implement the designed classes as a set of file components (core code and/or commercial software packages) in the implementation model, from which the applications can be produced. The use cases help the developers determine the order in which to implement and integrate the components.

Finally, during the test workflow the testers verify if the system implements functions described in the use cases and satisfies the system requirements.

However, this is only one iteration. Considering the periodical achievements, the unified process groups several iterations into different phases, which are inception, elaboration, construction, and transition phases.

During the inception phase, a good idea is developed into a vision of the end production and the business case for the product is presented. It is common to create an executable prototype that serves as a proof of the concept. Most of the product's use cases are specified in detail and system architecture is designed during the elaboration phase. In the construction phase, the product is built - completed software is added to the architecture. The transaction phase covers the period during which the product moves into release. Defects and deficiencies are reported, and improvements are made.

\subsubsection{Sub-workflow Charts}

More details are needed to describe the analysis, design, and implement processes.

A. Analysis model (Figure 3.2) 
The analysis model grows incrementally as more and more cases are analyzed. For each iteration, a set of use cases is selected to be realized. The system is built as a

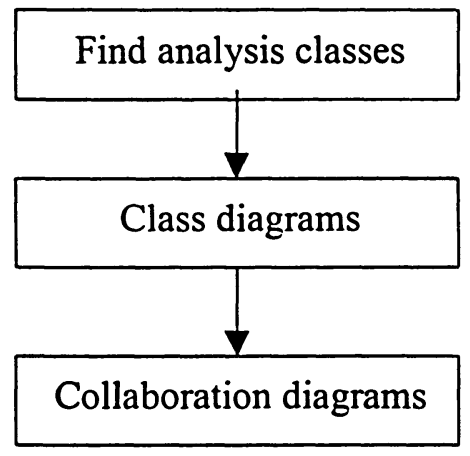

Figure 3.2 Generation of analysis model

structure of classifiers (analysis classes) and relationships between those classifiers. The collaborations that realize the use cases, i.e., the use-case realizations are also described.

A practical way to generate an analysis model is to first identify and describe the use cases for one iteration, then read through the description of each use case, and suggest what classifiers and associations are needed to realize the use case. Each classifier role specifies the responsibilities, attributes, and so on that the classifier must have to participate in realizing a use case. Then the structure of the system is modeled in a class diagram. Class diagrams are generally used to show classes and their relationships. At last, the interactions among the objects of the analysis classes that must take place in realizing the use cases are identified in detail, which are modeled by collaboration diagrams. A collaboration diagram shows how objects interact sequentially or in parallel by numbering the exchanged messages. As a complement to a collaboration 
diagram, developers may also use text to explain how the objects interact to perform the flow of events of the use case.

\section{B. Design Model (Figure 3.3)}

The design model is created using the analysis model as the input. Similar to the analysis model, the design model also defines classifiers (classes, subsystems, and interfaces), relationships between those classifiers, and collaborations that realize the use cases (i. e., the use-case realizations). However, the design model is more "physical" in nature, whereas the analysis is more "conceptual".

When the analysis classes are designed, they all specify and give rise to more refined classes that are adapted to the implementation environment. The class diagram introduces more detail than the class diagram does in the analysis model. This detail is needed due to the adaptation of the design model to the implementation environment.

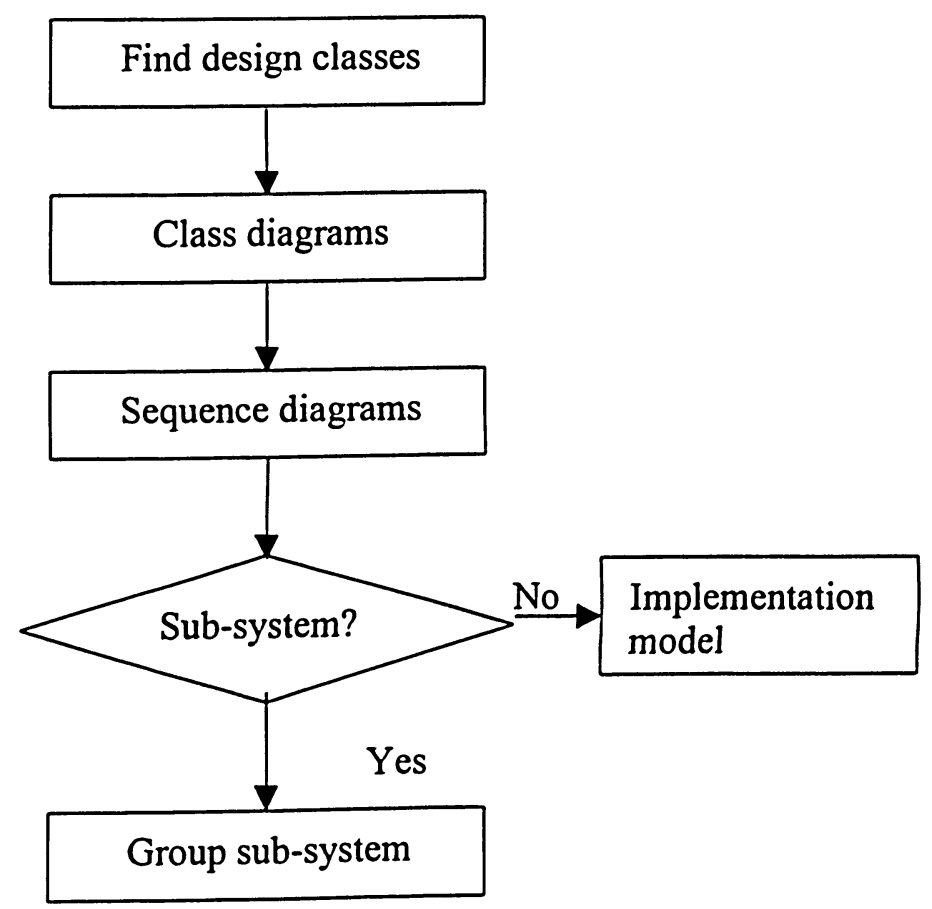

Figure 3.3 Generation of design model 
Similar to that in analysis model, the interaction among design objects, which takes place when the use case is realized in the design, must be identified. A sequence diagram is used to model interactions among objects in design. The sequence diagram shows how the focus - starting at the upper left corner-moves from object to object as the use case is performed and messages are sent between objects. A message sent from one object triggers the receiving object to take over focus and to carry out one of the operations of its class. As in collaboration diagrams, developers may also use text to complement the sequence diagram - explaining how the design objects interact to perform the flow of events of the use case.

For a large system with hundreds or thousands of classes, using only classes to realize use cases would not be possible: The system is too large to grasp without a higher-order grouping. The classes are grouped in subsystems. A subsystem has a set of interfaces that it provides and uses. These interfaces define the context of the subsystem.

\section{Implementation Model (Figure 3.4)}

During the implementation workflow, everything needed to produce an executable system is developed: the executable components (either self-developed or commercial packages), software components (source code, shell scripts, etc.), table components (database elements) and so on. A component is a physical and replaceable part of a system that conforms to and provides the realization of a set of interfaces. Components implement design classes from the design model. The implementation model is made up of components, which include all executables.

A component diagram is used to model the relationships between the components. Components diagrams are used to model the static implementation view of a system. 
This involves modeling the physical things that reside on a node, such as executables, libraries, tables, files, and documents.

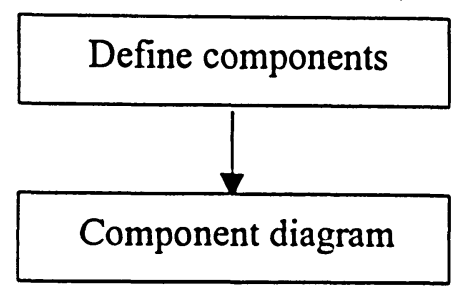

Figure 3.4 Generation of implementation model

\subsection{Proposed Structure and Functions of a GIS-based SDSS}

A traditional SDSS architecture, as a sub-set of a DSS, considers the interaction of three main components: interface, database and model base (Densham and Goodchild, 1990). The interface interacts with a database management system (DBMS), which manipulates data, and a model base management system (MBMS), which manipulates models to be applied on these data.

To deliver it to a wide, non-technical target audience, this traditional construct is expanded by object modules to create a more flexible and less hierarchical architecture, which provides systematic mechanisms to deliver an open, flexible design to SDSS users.

As discussed in Chapter 2, some decisions may require outputs from decision models that are too complex to run within a GIS. Thus, besides the built-in models in a GIS, such as spatial analysis and statistical analysis, a SDSS needs to incorporate other models specifically designed to support decision-making such as MCDM.

In addition, there often are large sets of auxiliary data and information that are loosely linked to locations to be incorporated into a GIS but that still hold interest for decision 
makers using an SDSS. An objected-oriented design and open structure of the SDSS should allow its users to access to a wide range of databases and documents in electronic formats in their decision-making process.

Based on the above discussions, a proposed architecture of GIS-based SDSS in manufacturing environment is given by Figure 3.5.

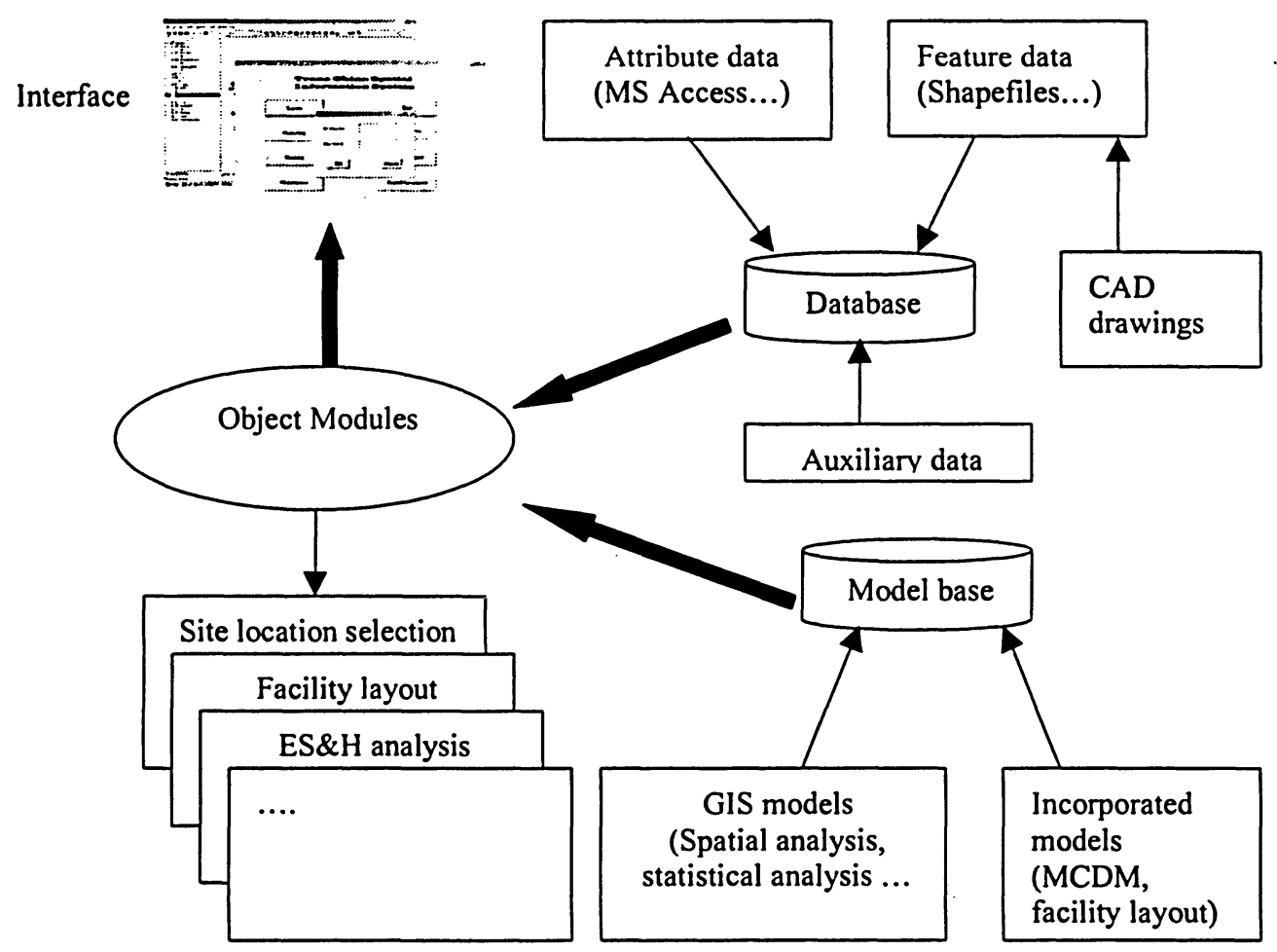

Figure 3.5 Proposed architecture of GIS-based SDSS in a manufacturing environment

The database consists of feature data, attribute data and auxiliary data. Feature data are stored in geographic "flat files/data layers such as ESRI shapefiles". They record the geographical information of the spatial entities inside the manufacturing environment, such as boundary of the facility, location of the equipment, marketing network. They answer the question "Where are these entities?" or "How are these entities distributed spatially?". Attribute data are stored in database software packages such as Microsoft 
Access. They are used to describe the feature data, such as length of the line, area of the polygon, status of the equipment, safety level of the equipment, skill level of the employee. They normally answer the question "What are these entities?" Auxiliary data are data loosely linked to locations. These data may used to describe the features or the attributes of features. They exist in large variety kinds of electronic formats such as text files, spreadsheet files, and graphic files, which can be a purchasing contract, equipment operation manual, picture of the building, and priority level of the attributes, etc.

The model base consists of the models that are embedded in the typical commercial GIS package such as feature query/classification, spatial analysis, and network analysis; and the models such as MCDM and facility layout models. The GIS embedded models help to make the decisions about features based on their locations and/or attributes, such as prioritizing the equipment based on the safety level, provide noise protection devise based on noise distribution pattern. The models that are independent on GIS package use specially developed algorithms to generate new attributes of the features based on the existing attribute data and/or auxiliary data to help make spatial decisions. For example, the MCDM model defines value functions (algorithms) for each attribute to set values for each feature (new attribute). It then weights each attribute (algorithm, auxiliary data) and calculates total value (new attribute) for a specific feature.

The interfaces consist of a main menu that is used to identify users and activate the system. GIS interfaces that are used to input feature data, attribute data and some auxiliary data, conduct GIS-embedded model functions, visualize results and generate reports. Non-GIS interfaces are used to input auxiliary data, conduct non-GISembedded model functions, and generate reports as well. 
An object module incorporates data and models in one or more interface boundaries to perform particular functions. A manufacturing enterprise SDSS mainly consists of the following object modules:

- New facility site selection

This module helps to select a new facility site. Examples of feature data and attribute data are show by Table 2.1. Auxiliary data are the data used to determine the weights of each attribute, such as weights given by experts. The models used could be MCDM, query, and classification models.

- Facility layout

This module helps to lay out the facilities. The feature data include facility boundaries, and the points, lines, or polygons information of the features. Attribute data include areas of the boundaries and polygons, length of the lines, and usage of the feature. Auxiliary data may include travel distances between each feature and the travel costs. Models used could be facility layout and classification models.

- Facility maintenance analysis

This module helps to generate facility maintenance plan. The feature data includes all the facilities. They could be points such as valves, lines such as utility lines, and polygons such as equipment and building. Attributes data could be the status of the facility, cost of maintenance, and impact level on production. Auxiliary data are the data used to determine the weights of each attribute, such as weights give by experts. The models used could be MCDM, query, and classification models. 
- ES\&H analysis

This module helps to generate ES\&H improvement action plan. The feature data includes all the facilities and environmental sample points. Facilities could be points such as valves, lines such as utility lines, and polygons such as equipment and building. Attribute data could be the safety level of the facility, cost of improvement, estimated project time, and values of the sample points such noise, temperature, air quality, and density of harmful agents. Auxiliary data are the data used to determine the weights of each attribute, such as weights give by experts. The models used could be MCDM, query, and classification models.

- Market geographical segmentation

This module helps to generate market development plan. Feature data could be sales regions. Attribute data could be sales volumes, average income, population, and climate. Decision models could be query and classification models.

- Warehouse site selection

This module is quite similar with the facility selection module. They use the same models except different kinds of data.

- Shortest transportation route analysis

This module helps to set up the transportation routing plan. Feature data include transportation networks. Attribute data include travel distances and cost. The model used is network based. 
- Supplier selection

This module can be considered as having the same situation as warehouse site selection in terms of the decision-making process.

- Production control performance analysis

This module is used to evaluate production line performance. Feature data are the production line. Attribute data include all production line performance assessment criteria. Models used are classification and query based.

- Quality improvement analysis

This module helps to generate quality improvement plan. Feature data include production lines and quality control points. Attribute data could be required quality level, current quality level, project time, project cost, and impact on production. Auxiliary data are the data used to determine the weights of each attribute, such as weights given by experts. The models used could be MCDM, query, and classification based.

- Training requirement analysis

This module helps to generate training schedule. Feature data include production lines and assigned employee workplace. Attribute data could be required skill level, current skill level, and employee available date. Auxiliary data could be planned training courses and instructor available time. Models used are query and classification based.

- Capital investment return analysis 
This module helps to decide whether to dispose, retain, or improve the facility/equipment. Feature data include all capital investment facilities. Attribute data could be investment value and investment return. Models used could be query and classification based.

\subsection{Chapter Summary}

In this chapter, GIS approach is chosen to set up SDSS in manufacturing environment. To ensure a systematic approach, current development of information technology is utilized. The object-oriented software development cycle using UML as the systemmodeling tool called unified software development process or unified process is used to develop the GIS-based manufacturing enterprise SDSS.

A proposed architecture of the GIS-based manufacturing enterprise SDSS is also presented in this chapter. This architecture includes four main component. The interface interacts with database and model base. The database includes feature data, attribute data and auxiliary data. The model base include GIS models and specially designed models. Finally, the object module incorporates data and models in one or more interface boundaries to perform particular functions.

In today's complex world, every manufacturing enterprise has its own special workflow. The development of GIS-based SDSS requires the integrating of data, models, interfaces and object modules into a well-organized system. Different manufacturing enterprise requires different kinds of information, models, interfaces, and object modules. Customization is necessary for each specific GIS-based manufacturing enterprise SDSS project. For this reason, a case study - Trane China will be introduced in next chapter. 


\section{CASE STUDY - TRANE CHINA SDSS}

As stated in previous chapter, different manufacturing enterprise requires different data, models, interfaces, and modules. Each GIS-based manufacturing enterprise SDSS must be customized particularly. In order to fully demonstrate the methodology presented in Chapter 3, it is necessary to conduct a case study. Thus, in this chapter, a case study Trane China is introduced. Section 4.1 gives an overview of Trane, China. Detailed introduction is given to its current SDSS, which is CAD-based, in Section 4.2. The summary section gives a brief assessment of the current SDSS.

\subsection{Overview of Trane, China}

The Trane Company is a leading manufacturer and distributor of air-conditioning systems in the world. Being aware of the huge potential market in China, it invested 50 million U. S. dollars and established a manufacturing facility in 1995 in China. The manufacturing facility is located in small city, Taicang, around 50 kilometers north from Shanghai, which produces air handler units which include DWAA, CLCP, HFCA, and HCCA; unitary products which include Illusion, Insight, Cassette ceiling, Impression, and Odyssey; and water-cooled products which include Koolman, Aquassey, Diamond, and Aquastream (Figure 4.1). 

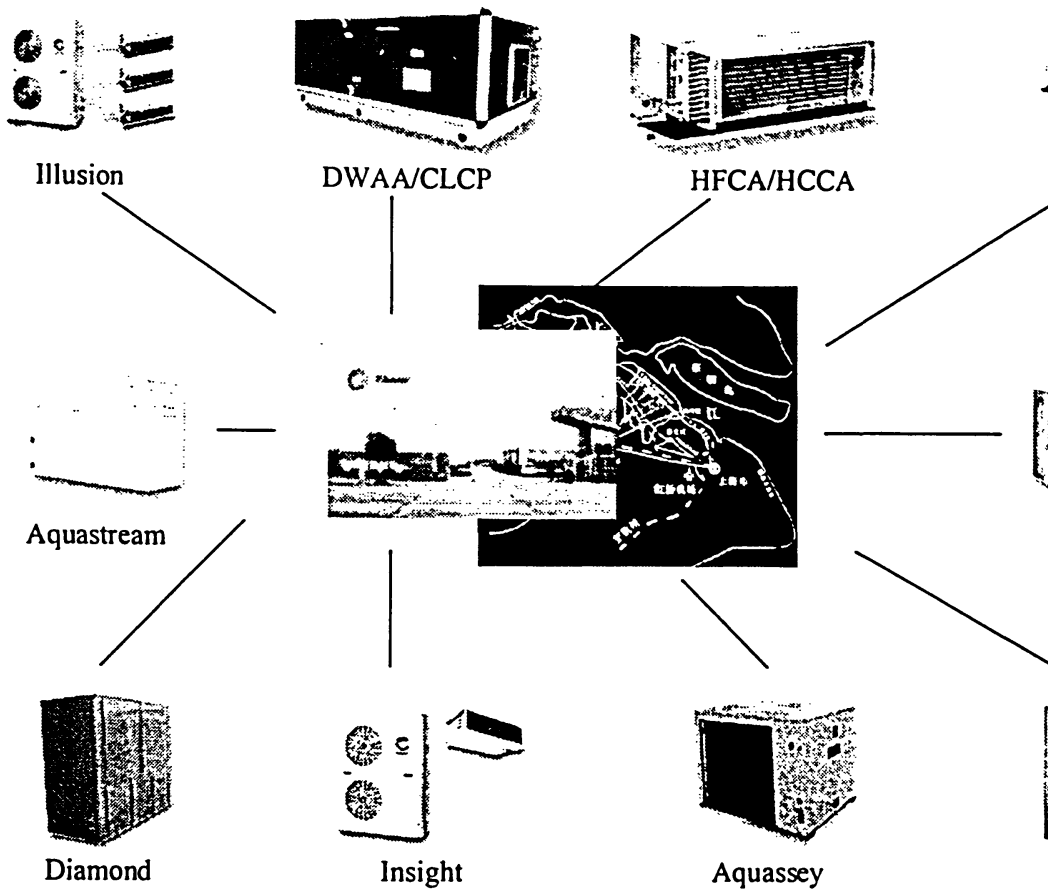

Aquastream
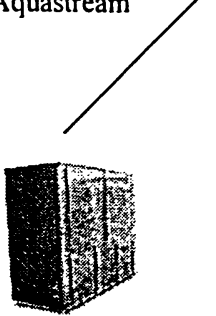

Diamond

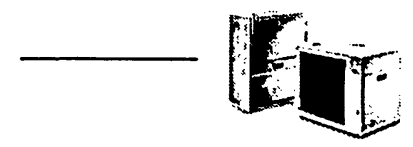

Odyssey

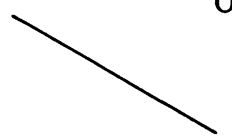

Figure 4.1 Location of Trane China and its products

The total area of the factory is about 100,000 square meters, with half of that dedicated to current production and the rest for future development. Figure 4.2 shows some details for building uses. Building 1 through 3 are for production purposes while the other buildings are for production support purposes.

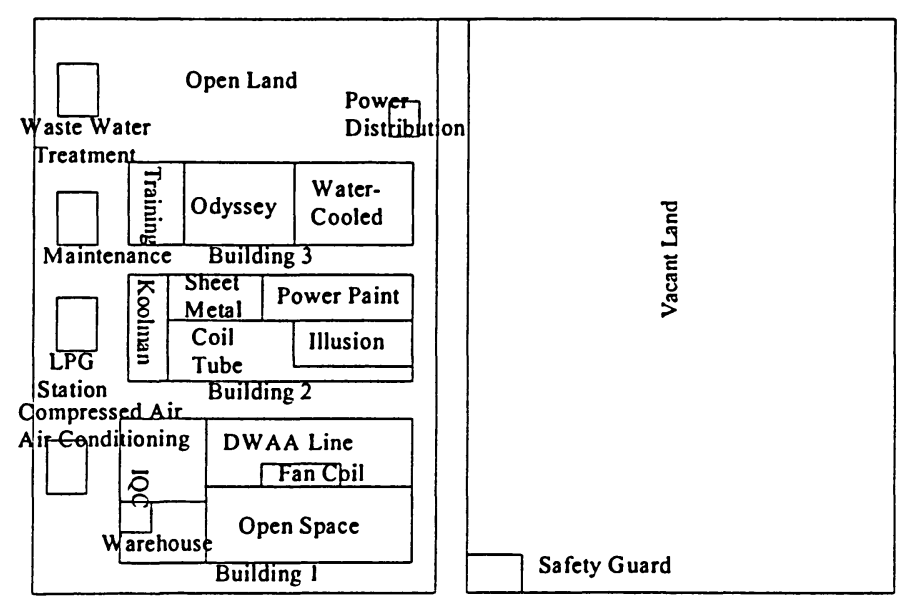

Figure 4.2 Building uses for Trane China 
There are 12 production lines in Trane China, in which 10 lines are used for final assembly, two lines for coil and tube, one area for sheet metal, and one line for power paint. Figure 4.3 shows the overview of the production lines and Table 4.1 explain the products each line is assigned.

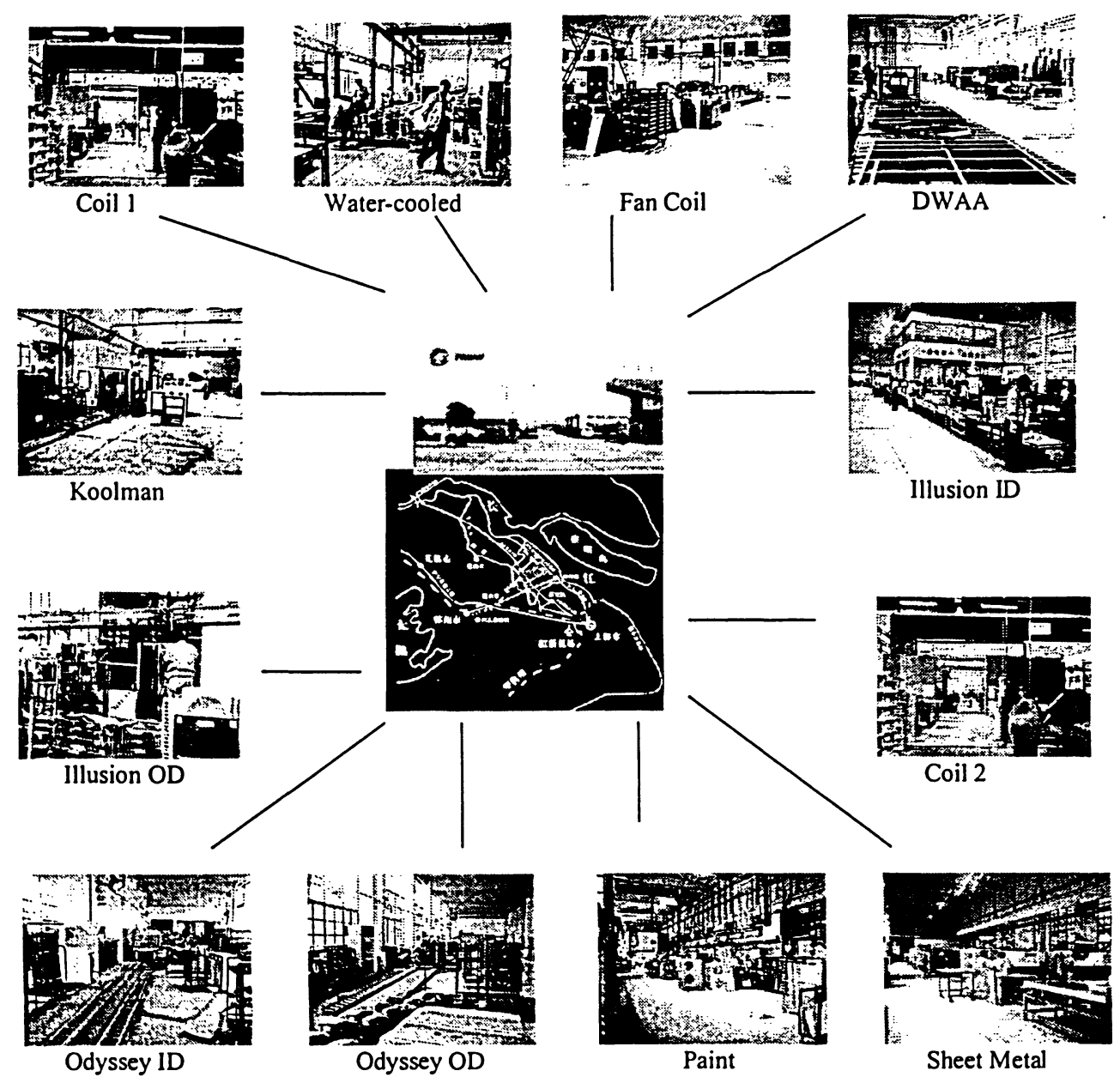

Figure 4.3 Trane China production lines

Table 4.1 Production line assignments

\begin{tabular}{|c|c|c|c|c|c|c|}
\hline Lines & Coil 1 & Water-cooled & Fan Coil & DWAA & Koolman & Illusion ID \\
\hline Products & $<=5$ ton & $\begin{array}{c}\text { Aquassey } \\
\text { Diamond } \\
\text { Aquastream }\end{array}$ & $\begin{array}{l}\text { HFCA } \\
\text { HCCA }\end{array}$ & $\begin{array}{l}\text { DWAA } \\
\text { CLCP }\end{array}$ & Koolman & $\begin{array}{l}\text { Illusion ID } \\
\text { Insight ID } \\
\text { Cassette ID }\end{array}$ \\
\hline Lines & Illusion OD & Coil 2 & Odyssey ID & Odyssey OD & Paint & Sheet Metal \\
\hline Products & $\begin{array}{l}\text { Illusion OD } \\
\text { Insight OD } \\
\text { Cassette OD }\end{array}$ & $>5$ ton & Odyssey ID & Odyssey OD & All products & $\begin{array}{c}\text { Self-made } \\
\text { parts }\end{array}$ \\
\hline
\end{tabular}


Last year the company's sales revenue was about 150 million U. S. dollars with nearly 15 million U.S. dollars of profit. It has 50 sales offices around China. With these great achievements, the company has a very ambitious plan. First, it is going to open 10 more offices and 6 more product centers to expand its distribution network. Considering the market size, delivery, and production cost, the management is also planning to set up a new factory in the south part of China. Besides these, the company is also planning to expand their product lines, the centrol air conditioning systems with much larger capacity are to be introduced to the market late next year, which means the management is considering use the use of the vacant land. Many decisions are going to be made this year.

\subsection{Data Collection Process}

Trane China is an ISO9001 registered organization. It has a well-developed document control system. The historical data related to its spatial decisions are all documented. To obtain these data, an official process that is defined by its ISO9001 system should be passed. For commercial reasons, the data are partially provided and obtained in electronic formats instead of hard copies.

\subsection{SDSS in Trane China}

To explain the status of the SDSS in Trane China, it is better to start with the company organization chart (Figure 4.4). Several departments are involved in the spatial information system, which are M.E. (manufacturing engineering), maintenance, ES\&H, production planning, sourcing, warehouse, marketing, financial analysis, quality control, training, and after-sales service. Details on what kind of spatial information the after-mentioned departments are dealing with and 


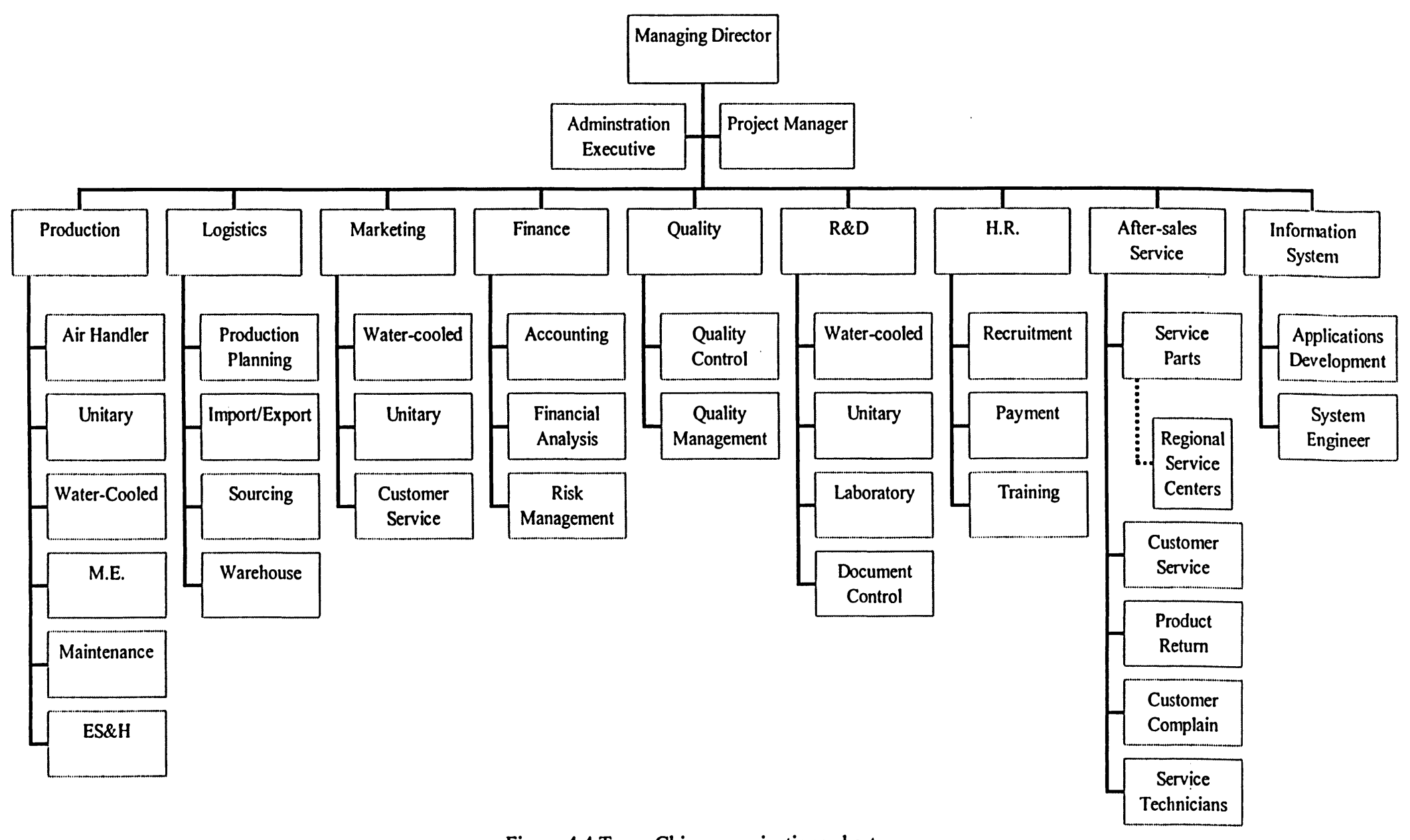

Figure 4.4 Trane China organizations chart 
how they are dealing with the information are explained as follows:

A. M. E.

Manufacturing engineers are responsible for the proposals of new factory site selection and factory layout, which includes supra-macro, macro, micro, and submicro space planning. Deliverables for site selection are an analysis report, which analyzes the internal and external factors of the candidate sites and grades for each potential site, and a site map. Deliverables for factory layout are a factory layout graphic (CAD files), an equipment/facility requirement list and a hand-tool requirement list (Microsoft Excel files). Figure 4.5 shows part of Trane China's factory layout. Tables 4.2 and 4.3 show examples of an equipment requirement list and a tool requirement list.

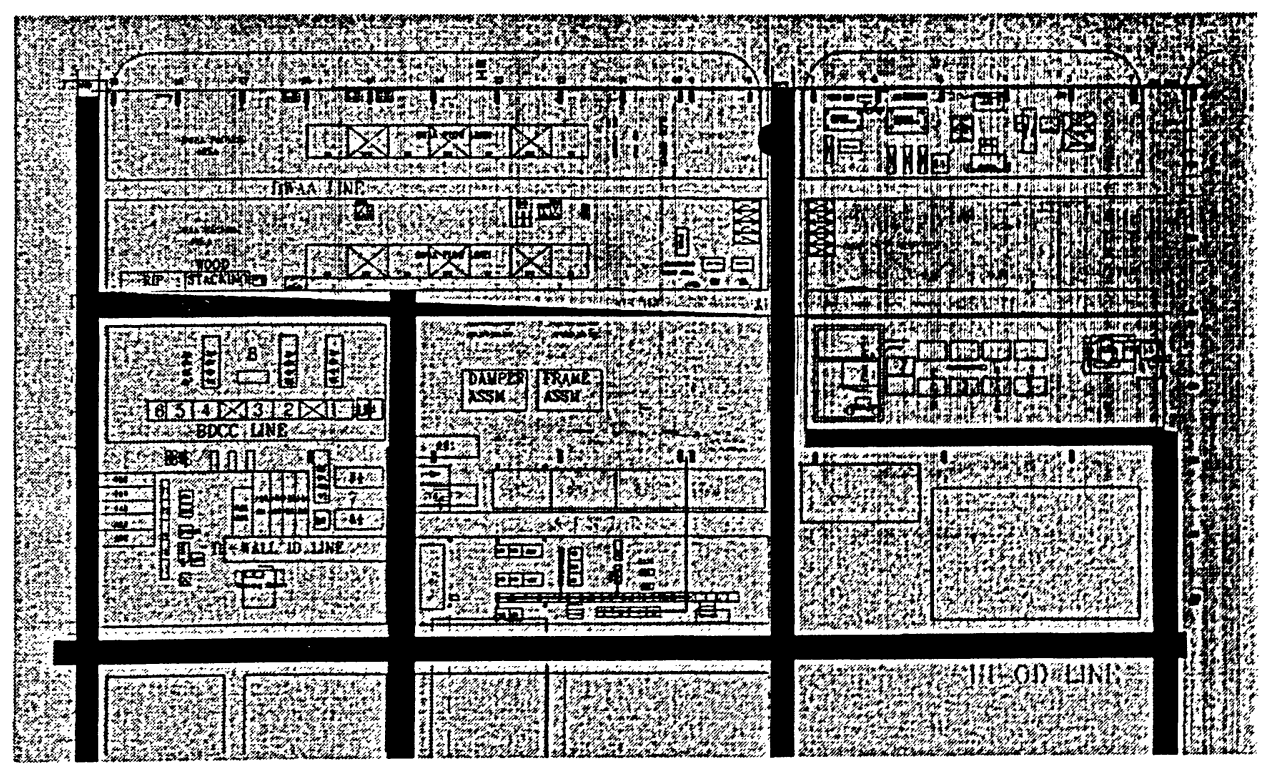

Figure 4.5 Factory layout (part) 
Table 4.2 Equipment requirement list for Illusion Outdoor Line (part)

\begin{tabular}{|c|c|c|c|c|c|}
\hline Name & General Description & Dimension (m) & Quantity & EST. Unit Price (USD) & Status \\
\hline Conveyer & Move products & $65 * 1.5 * 0.5$ & 1 & 10,000 & Exist \\
\hline Crane & Lift compressors and finished products & See drawings & 2 & 1,000 & Exist \\
\hline Vacuum pump & System vacuum (8L) & See product description & 6 & 650 & Exist \\
\hline Leak tester & System leak check & See product description & 1 & 25,000 & Exist \\
\hline Freon charger & Charge freon & See product description & 1 & 50,000 & Exist \\
\hline Performance test unit & Check system performance & See drawings & 1 & 10,000 & Exist \\
\hline Electric safety test unit & Check product electric safety & See drawings & 1 & 10,000 & Exist \\
\hline Packing machine & Pack finished product & See product description & 1 & 8,000 & Exist \\
\hline Rack & Material racks & See drawings & 12 & 100 AVG. & Exist \\
\hline Work bench & Work stations & See drawings & 4 & 100 AVG. & Exist \\
\hline & $\ldots \ldots$ & & & & \\
\hline Compressed air line & Low pressure compressed air (1/4") & 65 & 1 & 100 & Contract \\
\hline LPG line & Provide LPG for brazing (1/4") & 45 & 1 & 100 & Contract \\
\hline Oxygen line & Provide oxygen for brazing (1/4") & 45 & 1 & 100 & Contract \\
\hline Water pipe line & Cool switch valve while brazing (1/4") & 30 & 1 & 50 & Self-made \\
\hline Electric cable & Provide power (40A) & 65 & 1 & 100 & Self-made \\
\hline
\end{tabular}


Table 4.3 Hand-tool requirement list for Illusion Outdoor Line (part)

\begin{tabular}{|c|c|c|c|}
\hline General Description & Quantity & Est. Unit Price & Status \\
\hline Normal use & 23 & 30 & Exist \\
\hline Compressor assembly & 1 & 350 & Exist \\
\hline Crate package & 2 & 800 & Exist \\
\hline Normal use & 3 & 100 & Exist \\
\hline 1 ton & 1 & 250 & Exist \\
\hline Control box assembly & 4 & 30 & Exist \\
\hline Motor assembly & 1 & 350 & Exist \\
\hline Freon charge & 2 & 10 & Exist \\
\hline Switch valve, see drawings & As required & 30 & Make as required \\
\hline$\ldots . .$. & & & \\
\hline
\end{tabular}

B. Maintenance

Every year during the budget period, maintenance people in Trane China conduct company wide equipment and facilities condition assessment. They will check out the deviations for each equipment and facility; grade the deviation index, degree of impact to production, and priority level; estimate project time and cost; and check parts lead time (Table 4.4). Based on these studies, they generate a maintenance master plan. Every month, they will check the main equipment and facilities, update equipment and facilities status and make monthly maintenance plan. They use CAD files to tell them the location information for the equipment and facilities coupled with Microsoft Excel files for the non-spatial data. A coding system is used to identify equipment and facilities.

\section{ES\&H}

The ES\&H officers in Trane China are mainly responsible for the machinery and plant safety risk assessment, harmful agents analysis, work environment assessment, emergency response system assessment, and community environment 
Table 4.4 Equipment and facilities assessment result for Illusion Out Line (part)

\begin{tabular}{|c|c|c|c|c|c|c|c|}
\hline Name & ID No. & Deviation Index & Impact to Production & Priority Level & EST. Time (hr.) & Est.Cost (USD) & Parts Leadtime (day) \\
\hline Conveyer & 10001 & Minor & Major & 2 & 4 & 100 & 0 \\
\hline Crane & 10004 & Minor & Minor & 3 & 2 & 100 & 0 \\
\hline Vacuum pump & 10037 & Major & Medium & 2 & 2 & 100 & 3 \\
\hline Leak tester & 10025 & Major & Major & 5 & 8 & 700 & 30 \\
\hline Freon charger & 10042 & Medium & Major & 5 & 2 & 350 & 30 \\
\hline Performance test unit & 10051 & Perfect & No & 0 & 0 & 0 & N.A. \\
\hline Electric safety test unit & 10052 & Perfect & No & 0 & 0 & 0 & N.A. \\
\hline Packing machine & 10074 & Major & Minor & 2 & 1 & 100 & 7 \\
\hline Rack & 10100 & Minor & No & 1 & 0.5 & 30 & 0 \\
\hline Work bench & 10121 & Minor & No & 1 & 0.5 & 30 & 0 \\
\hline \multicolumn{8}{|l|}{$\ldots \ldots$} \\
\hline Compressed air line & 10082 & Perfect & No & 0 & 0 & 0 & N. A. \\
\hline LPG line & 10083 & Perfect & No & 0 & 0 & 0 & N. A. \\
\hline Oxygen line & 10084 & Perfect & No & 0 & 0 & 0 & N. A. \\
\hline Water pipe line & 10085 & Minor & Minor & 2 & 0.5 & 30 & 0 \\
\hline Electric cable & 10086 & Perfect & No & 0 & 0 & 0 & N. A. \\
\hline
\end{tabular}


impact assessment. Quite similar to the maintenance department's equipment and facilities condition assessment, ES\&H officers champion a company wide machinery and plant assessment activity each year. They will check out the deviations for all the machines, buildings, and facilities; grade the deviation index, risk level/priority level, and degree of impact to production; estimate project time and cost; and check part available date (Table 4.5). Based on these data, they generate a safety improvement master plan. Every month, they will check the main items, update safety status and make monthly safety action plan. They also use $\mathrm{CAD}$ files to tell them the location information for the machines, buildings, and facilities coupled with Microsoft Excel files for the non-spatial data. Several kinds of harmful agents are produced during the manufacturing processes such as brazing and welding, aluminum bar cutting, Freon charging, coil and tube degreasing, system rework, and powder paint. Currently, Trane China does this in a very simple way - the ES\&H officers identify the location of these processes, provide ventilations and work protection devices, but they do not have a clear idea if the ventilation is enough and if enough number of operators get protected. Same situation exists in the work environment assessment and community environment impact assessment processes. They know where they should make improvement and the means of improvement. However, because they do not know how the work environment factors and community environment impact are distributed spatially, they are not sure if their improvement activities cover enough area. Thus, they can only rely on the local government's periodic assessment activity to check if they provide enough protection to the community and annual employee physical test to check if the employees are well protected. Similar situation with the emergency response system, such as fire fighter and first 
Table 4.5 Safety risk assessment result for sheet metal area (part)

\begin{tabular}{|c|c|c|c|c|c|c|c|}
\hline Name & ID No. & Dev.Index & Impact to Pro. & Risk Level & EST. Time (hr.) & Est.Cost (USD) & Parts Leadtime (day) \\
\hline $2.5 \mathrm{~m}$ shear & 02002 & Minor & Medium & High & 3 & 200 & 7 \\
\hline $1.8 \mathrm{~m}$ shear & 02003 & Perfect & No & No & 0 & 0 & N.A. \\
\hline $63 \mathrm{~T}$ turret punch & 02004 & Medium & Medium & High & 2 & 50 & 5 \\
\hline CNC punch & 02006 & Minor & Medium & Medium & 8 & 1000 & 30 \\
\hline CNC punch & 02007 & Perfect & No & No & 0 & 0 & N.A. \\
\hline $2.5 \mathrm{~m} \mathrm{CNC} \mathrm{brake}$ & 02008 & Minor & Minor & Medium & 6 & 100 & 10 \\
\hline $2.5 \mathrm{~m} \mathrm{CNC} \mathrm{brake}$ & 02009 & Minor & Minor & Medium & 6 & 100 & 10 \\
\hline Power cable & 02013 & Minor & Major & Medium & 1 & 60 & 1 \\
\hline Compressed air line & 02014 & Perfect & No & No & 0 & 0 & N.A. \\
\hline Raw material racks & 02015 & Medium & Minor & Minor & 1 & 20 & 1 \\
\hline
\end{tabular}


aid, ES\&H officers in Trane China do not have a clear idea if sufficient resources are provided for employees to react in a certain short period of time in case that accidents happen.

D. Production planning

Production planning people assign production plans to each production line. In Trane China, they make production plans in strict accordance with the confirmed sales orders, so they require their production lines strictly follow the production plans every day, no more and no less. They call this as production linearity. Trane China also has its own work force management system, which is called "one-upone-down", by which the number of operators put in a line is not fixed and varies everyday according to the production plan. So another job the production planner does in Trane China is to recommend number of operators being put on a line everyday. At the end of each month, production planners generate a production linearity index and workforce utility index to assess the performance of each production line in a Microsoft Excel file (Table 4.6).

Table 4.6 Production linearity index and workforce index report

\begin{tabular}{|c|c|c|c|c|c|c|}
\hline Lines & Coil 1 & Water-cooled & Fan Coil & DWAA & Koolman & Illusion ID \\
\hline Linearity & $83 \%$ & $90 \%$ & $92 \%$ & $87 \%$ & $95 \%$ & $96 \%$ \\
\hline Labor Utility & 1.04 & 1.1 & 1.03 & 1.2 & 1.1 & 1.03 \\
\hline
\end{tabular}

\begin{tabular}{|c|c|c|c|c|c|c|}
\hline Lines & Illusion OD & Coil 2 & Odyssey ID & Odyssey OD & Paint & Sheet Metal \\
\hline Linearity & $91 \%$ & $80 \%$ & $89 \%$ & $90 \%$ & $75 \%$ & $79 \%$ \\
\hline Labor Utility & 1.02 & 1.15 & 1.2 & 1.1 & 1 & 1.1 \\
\hline
\end{tabular}




\section{E. Sourcing}

Buyers are responsible for the sourcing of suppliers. They will conduct the potential supplier surveys and collect related information about the candidate suppliers. The supplier selection report is quite similar with the manufacturing facility site selection report.

F. Warehouse

Warehouse Manager has two responsibilities in terms of using spatial information: transportation network development and warehouse selection. Currently, Trane China is using third party to contract the delivery of their products. The warehouse selection report is quite similar with the manufacturing facility site selection report.

G. Market analysis

The marketing department needs to segment markets geographically by region of the country or world, market size, market density, or climate in order to find potential market. Currently, Trane China is using pie chart and bar chart to make their report (Figures 4.6).

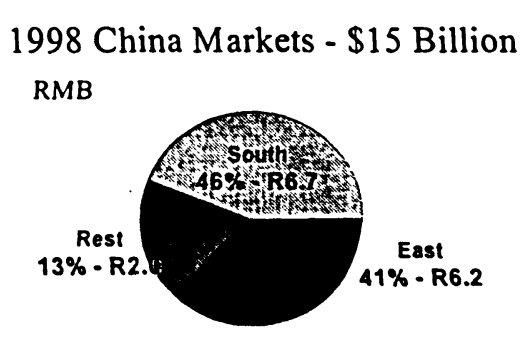

China Air Conditioning Markets 2002 without window units

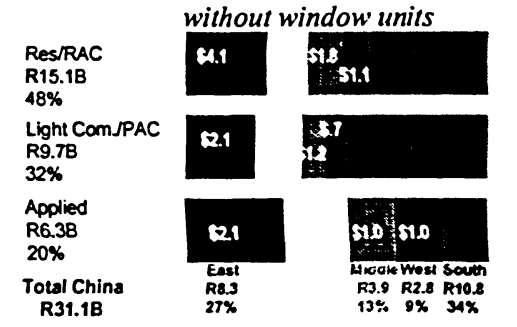

Figure 4.6 Geographical market segmentation 
H. Capital Management

Trane China uses RONA (return of net assets) to describe how efficiently its capital investment makes money. The financial information system it is using now is Platinum. The financial system generates a report each month.

I. Quality control (Q. C.)

Trane China is now implementing the six sigma program. To find a new quality improvement opportunity, the quality engineers will do a lot of surveys first. They normally list all the production lines, the products those lines produce, and quality levels of each production line. They then choose some candidate lines. For each candidate line, they list all the control points in that line, check their quality levels, estimate the improvement activity cost and benefit, estimate the time needed for the improvement activities, and the importance index for each control point. They can then prioritize their quality improvement efforts. The report they are using is Microsoft Excel file (Tables 4.7 and 4.8).

Table 4.7 Quality improvement candidate lines

\begin{tabular}{|c|c|c|c|c|c|c|}
\hline Lines & ron & Water-cooled & Fan Coil & DWAA & Koolman & Illusion ID \\
\hline Current sigma & 栵 & $\begin{array}{l}2.60 \\
\end{array}$ & 3.20 & 2.75 & \begin{tabular}{|l|}
2.60 \\
\end{tabular} & \begin{tabular}{|l}
3.20 \\
\end{tabular} \\
\hline Target sigma & 400 & 3.00 & 4.50 & 3.00 & 3.00 & 4.50 \\
\hline Lines & Illusion OD & Coil 2 & Odyssey ID & Odyssey OD & Paint & Sheet Metal \\
\hline Current sigma & Nown & 2.50 & 2.80 & 2.50 & 4.00 & \begin{tabular}{|l|}
4.00 \\
\end{tabular} \\
\hline Target sigma & 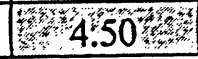 & 2.75 & 3.00 & 3.00 & 4.50 & 4.30 \\
\hline
\end{tabular}


Table 4.8 Illusion OD line quality improvement assessment (part)

\begin{tabular}{|c|c|c|c|c|c|c|}
\hline Q/C points & Current sigma & Target sigma & Cost (RMB) & Benefit (RMB) & Time (day) & Urgency \\
\hline Compressors & 4.2 & 4.5 & 2000 & 25000 & 5 & Medium \\
\hline Check valves & 4.2 & 4.5 & 1500 & 5000 & 5 & Medium \\
\hline Leak test 1 & 3 & 4.5 & 5000 & 75000 & 21 & High \\
\hline Motor & 4.2 & 4.5 & 1500 & 10000 & 5 & Medium \\
\hline Control box & 3 & 4.5 & 2500 & 20000 & 5 & High \\
\hline Vacuum & 4.2 & 4.5 & 5000 & 40000 & 14 & Medium \\
\hline Freon charge & 3.8 & 4.5 & 800 & 25000 & 3 & High \\
\hline Performance & 2.5 & 4.5 & 20000 & 100000 & 30 & High \\
\hline Safety & 3.9 & 4.5 & 40000 & 250000 & 30 & Urgent \\
\hline Leak test 2 & 2.5 & 4.5 & 1000 & 5000 & 3 & Low \\
\hline Appearance & 2.5 & 4.5 & 1000 & 5000 & 3 & Low \\
\hline Package & 3 & 4.5 & 2000 & 3000 & 3 & Low \\
\hline
\end{tabular}

J. Training

Training officer is responsible for the employee-training program. The "one-upone-down" work force management system requires "multi-skilled" employees. Skill training is an ongoing program. To generate a training plan, the training officer first calculates the average skill level of each production line to find some candidate areas. Then he/she goes through each employee of each candidate line to check the employee's current skill level and compare to the skill requirement of the employee's main work station, one-up and one-down station to find out the candidate employees. After checking with these employees and their supervisors to confirm the three best available dates, the training officer finally generates the training schedule. The Microsoft Excel file is also used in the process (Tables 4.9, and 4.10). 
Table 4.9 Line average skill level survey

\begin{tabular}{|c|c|c|c|c|c|c|}
\hline Lines & Coil 1 & Water-cooled & Fan Coil & DWAA & Koolman & Illusion ID \\
\hline Current Level & 10 & 8 & 8 & 10 & 12 & 9 \\
\hline Required Level & 15 & 15 & 10 & 15 & 15 & 10 \\
\hline
\end{tabular}

\begin{tabular}{|c|c|c|c|c|c|c|}
\hline Lines & Illusion OD & Coil 2 & Odyssey ID & Odyssey OD & Paint & Sheet Metal \\
\hline Current Level & 10 & 12 & 10 & 10 & 8 & 8 \\
\hline Required Level & 12 & 18 & 12 & 15 & 10 & 15 \\
\hline
\end{tabular}

Table 4.10 Sheet metal area operator training survey

\begin{tabular}{|c|c|c|c|c|c|c|}
\hline Operator & Operation & Current Level & Required Level & $1^{\text {st }}$. date & $2^{\text {nd }}$. date & $3^{\text {rd }}$. date \\
\hline 02001 & Shear & 15 & 15 & & & \\
\hline 02002 & Shear & 12 & 15 & & & \\
\hline 02003 & Punch & 20 & 20 & & & \\
\hline 02004 & Punch & 20 & 20 & & & \\
\hline 02005 & Punch & 15 & 20 & & & \\
\hline 02006 & Punch & 10 & 20 & & & \\
\hline 02007 & Brake & 17 & 17 & & & \\
\hline 02008 & Brake & 15 & 17 & & & \\
\hline 02009 & Spot weld & 7 & 12 & & & \\
\hline 02010 & Runner & 4 & 10 & & & \\
\hline 02011 & Runner & 6 & 10 & & & \\
\hline
\end{tabular}

\section{K. Service}

Service people are in charge of establishment of new service center. This is quite similar with warehouse selection. 


\subsection{Chapter Summary}

In summary, the status of the SDSS Trane China is described by Table 4.11. The Trane China SDSS is CAD-based. It has to use Excel files to store attribute data. Feature data cannot be linked directly to attribute data. There is also no decision model to facilitate decision making. The functions of the current SDSS are very limited. To improve this situation, considering the results got from the previous chapters, a GIS-based SDSS is chosen. The prototype of Trane China GIS-based SDSS (TCSDSS) will be developed in next chapter. 
Table 4.11 Trane China SDSS status

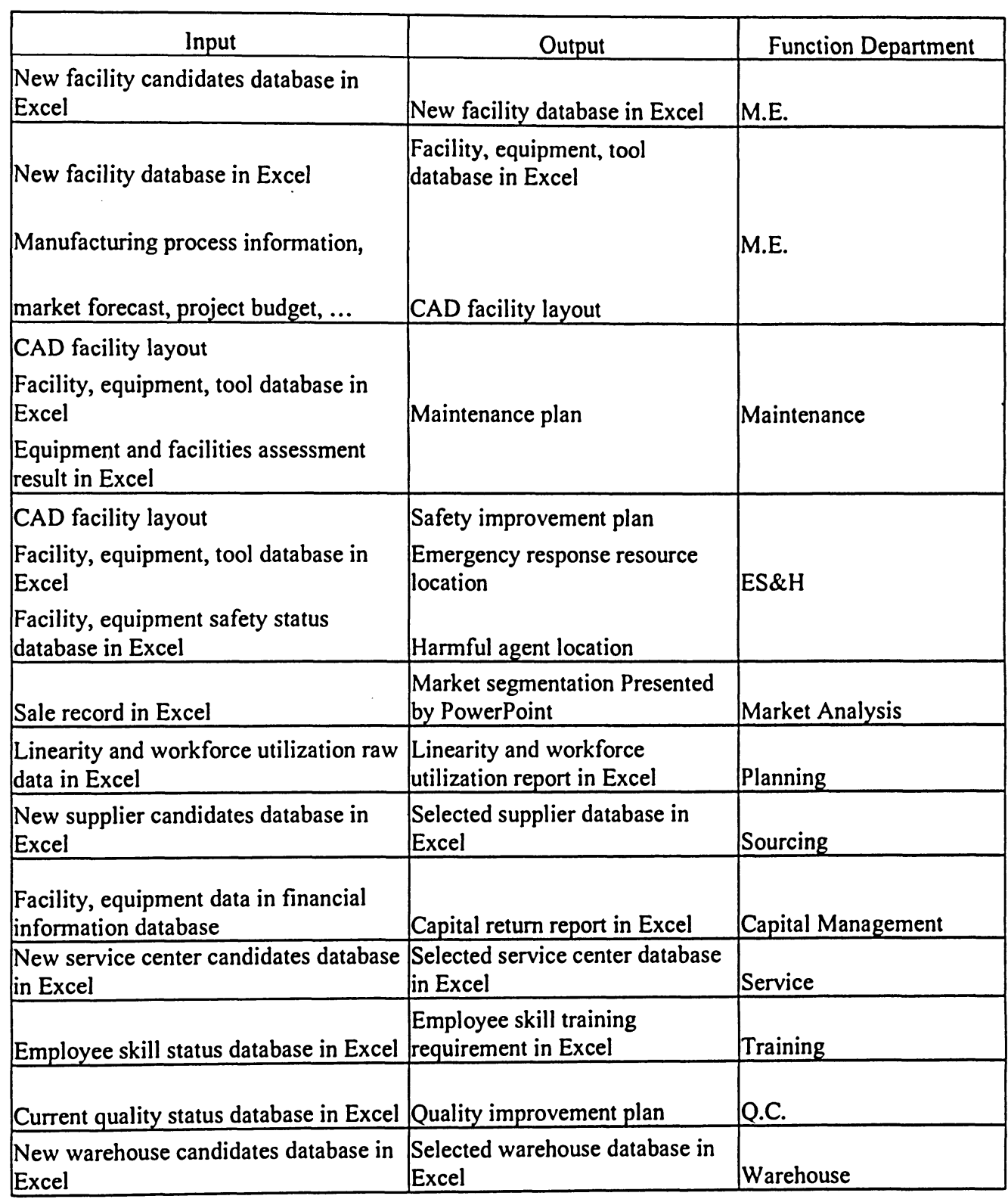




\section{DESIGN OF TCSDSS PROTOTYPE}

In this chapter, TCSDSS prototype will be designed using unified process introduced in Chapter 3. Section 5.1, business modeling, gives out the implementation organization chart, department functions, and information flow table. Use case diagrams are introduced in Sect 5.2. Examples of analysis models, design models, and implementation models are shown in Section 5.3, 5.4, and 5.5 respectively. Finally, the system architecture is presented in the summary section.

\subsection{Business Modeling}

As discussed in Section 4.1, the organization chart for TCSDSS implementation (Figure 5.1) and information flow table (Table 5.1) are developed. Functions of each department are summarized in Table 5.2

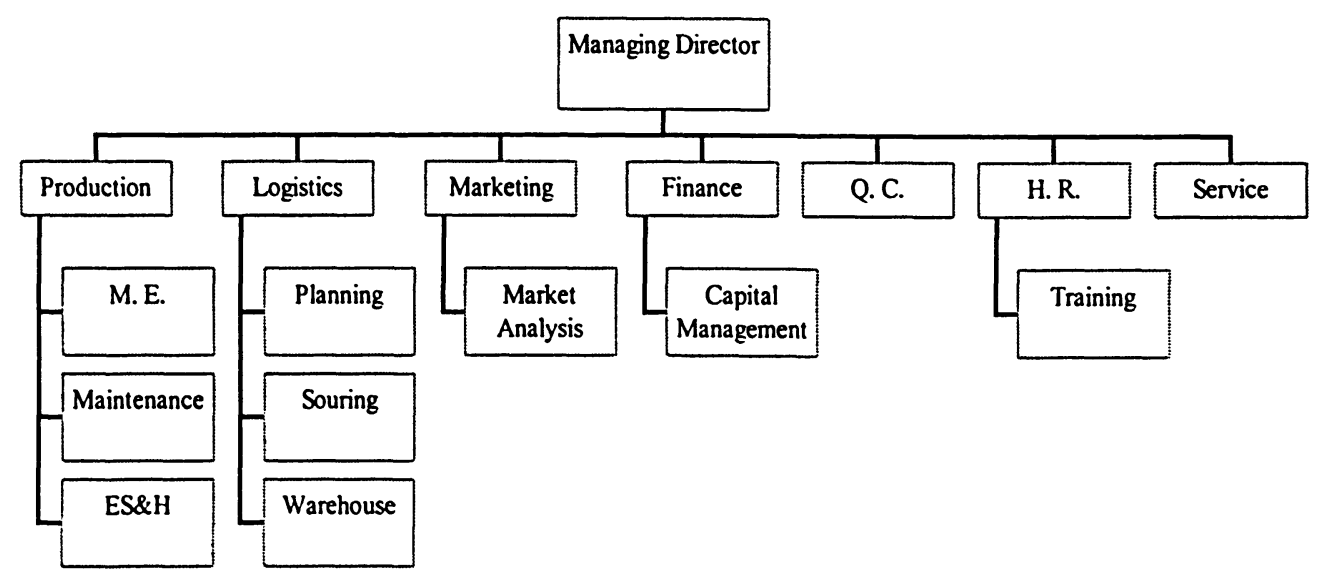

Figure 5.1 TCSDSS implementation organization chart 


\subsection{Requirements Capturing}

Requirements are modeled by a use-case diagram. Each department is defined as an actor of TCSDSS. Description of each actor is showed in Table 5.2. By breaking down functions of each department, TCSDSS use cases are generated. The use-case diagram is showed in Figure 5.2 .

Table 5.1 TCSDSS information flow table

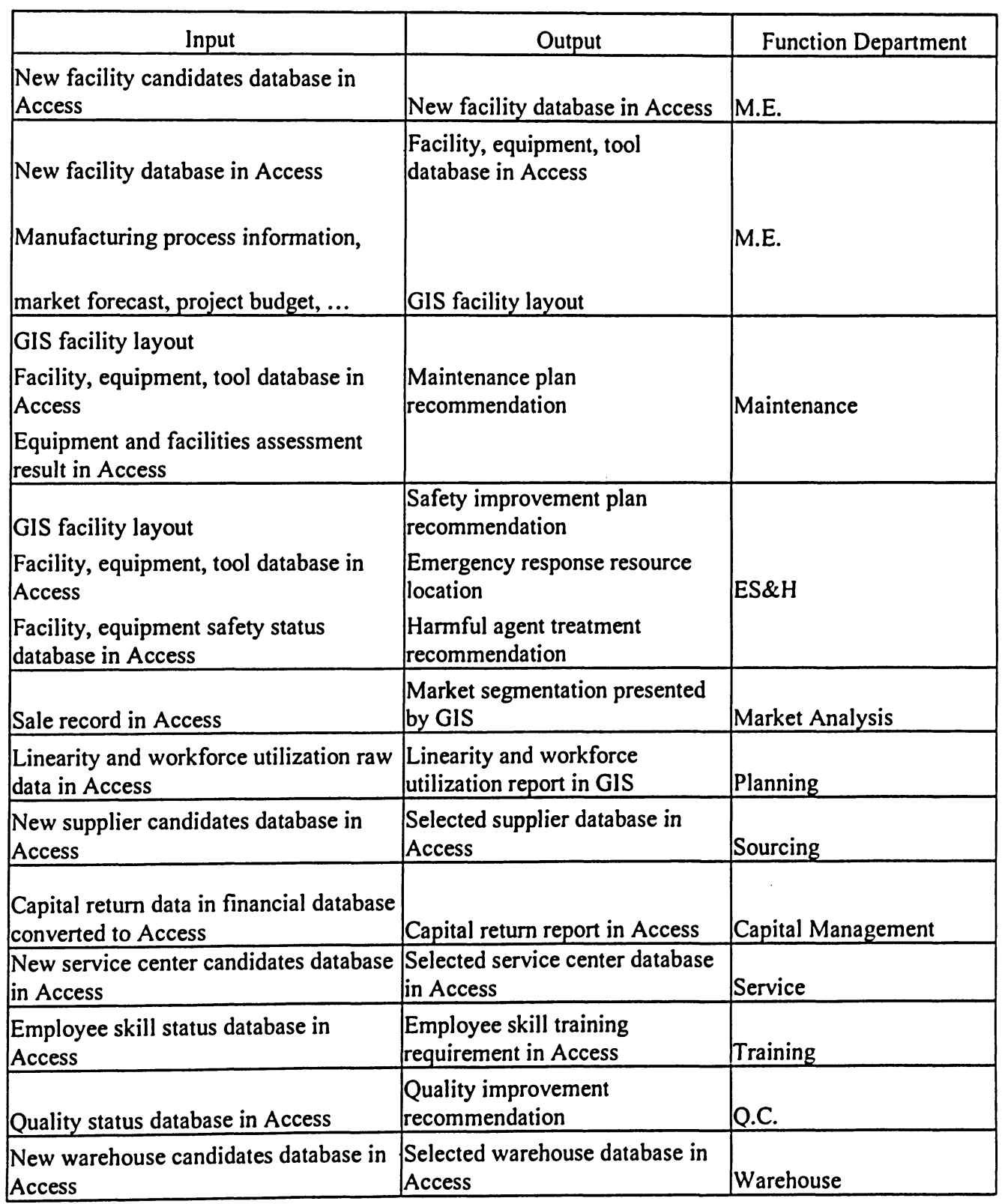


Table 5.2 TCSDSS Department functions and actor description

\begin{tabular}{|c|l|l|}
\hline Department/Actor & \multicolumn{1}{|c|}{ Functions } & \multicolumn{1}{|c|}{ Description } \\
\hline M.E. Dept. (ME) & $\begin{array}{l}\text { New site selection, facility layout design } \\
\text { and analysis }\end{array}$ & $\begin{array}{l}\text { Maintain the equipment and facilities in good } \\
\text { Input facilities design data }\end{array}$ \\
\hline Maintenance Dept. (M) & Facility status update, maintenance planning & anditions \\
\hline ES\&H Dept. (ESH) & $\begin{array}{l}\text { ES\&H assessment, ES\&H improvement } \\
\text { planning }\end{array}$ & $\begin{array}{l}\text { Ensure work places safe and healthy, be } \\
\text { environment awareness }\end{array}$ \\
\hline Planning Dept. (P) & Linearity and work force index report & Assess line performance \\
\hline Sourcing Dept. (S) & Supplier selection & Find suppliers \\
\hline Warehouse Dept. (W) & Warehouse selection & Find warehouse \\
\hline Market analysis Dept. (MA) & Market geographical segmentation & Find potential market \\
\hline Capital management Dept. (CM) & RONA report & Analyze investment return \\
\hline Q.C. Dept. (QC) & $\begin{array}{l}\text { Quality analysis, quality improvement } \\
\text { planning }\end{array}$ & Ensure product quality \\
\hline Training Dept. (T) & Employee skill analysis, training planning & Upgrade employee skill \\
\hline Service Dept. (SER) & Service center selection & Locate new service center \\
\hline
\end{tabular}




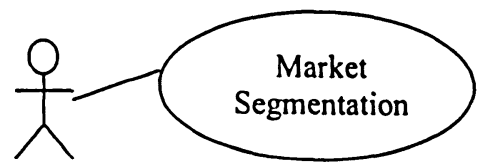

Market

analysis Dept.

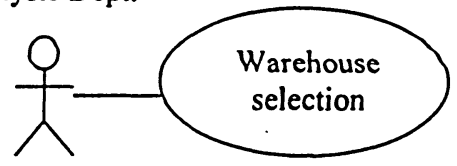

Warehouse Dept.
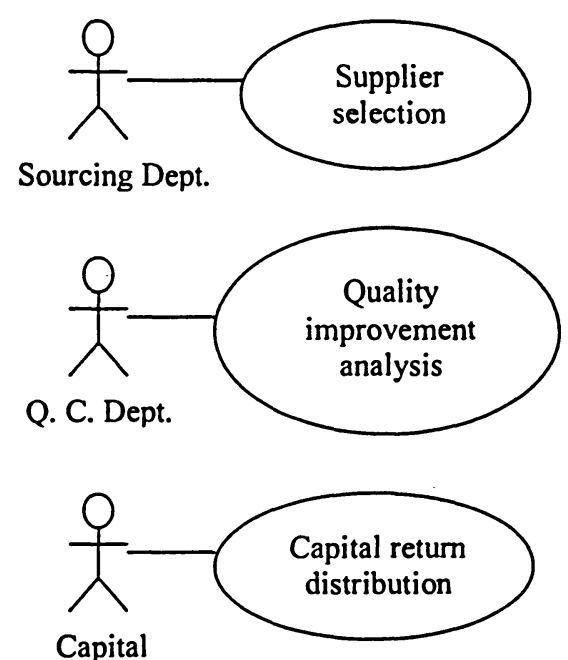

Management Dept.

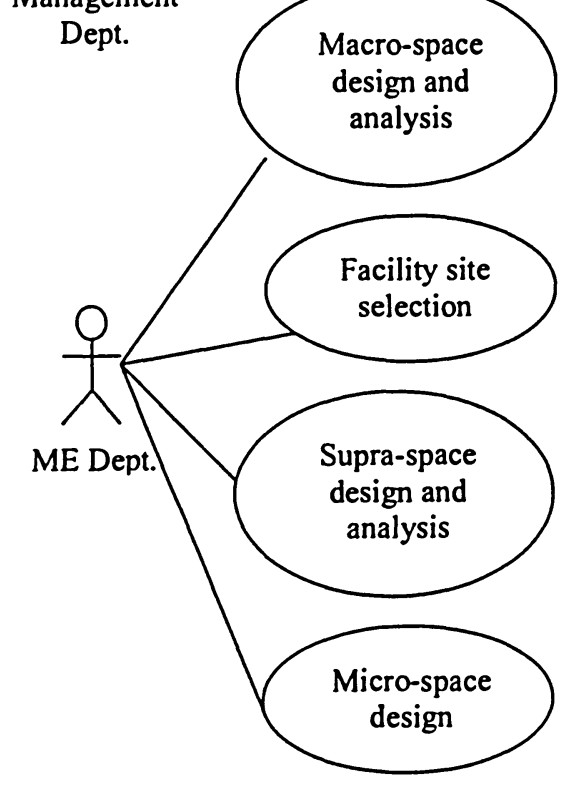

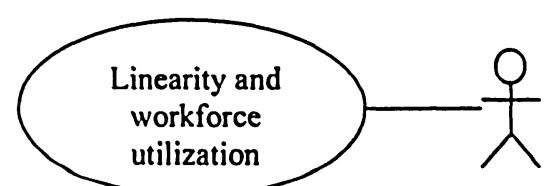

Planning Dept.

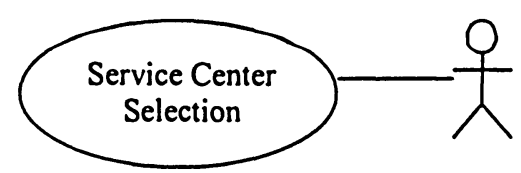

Service Dept.

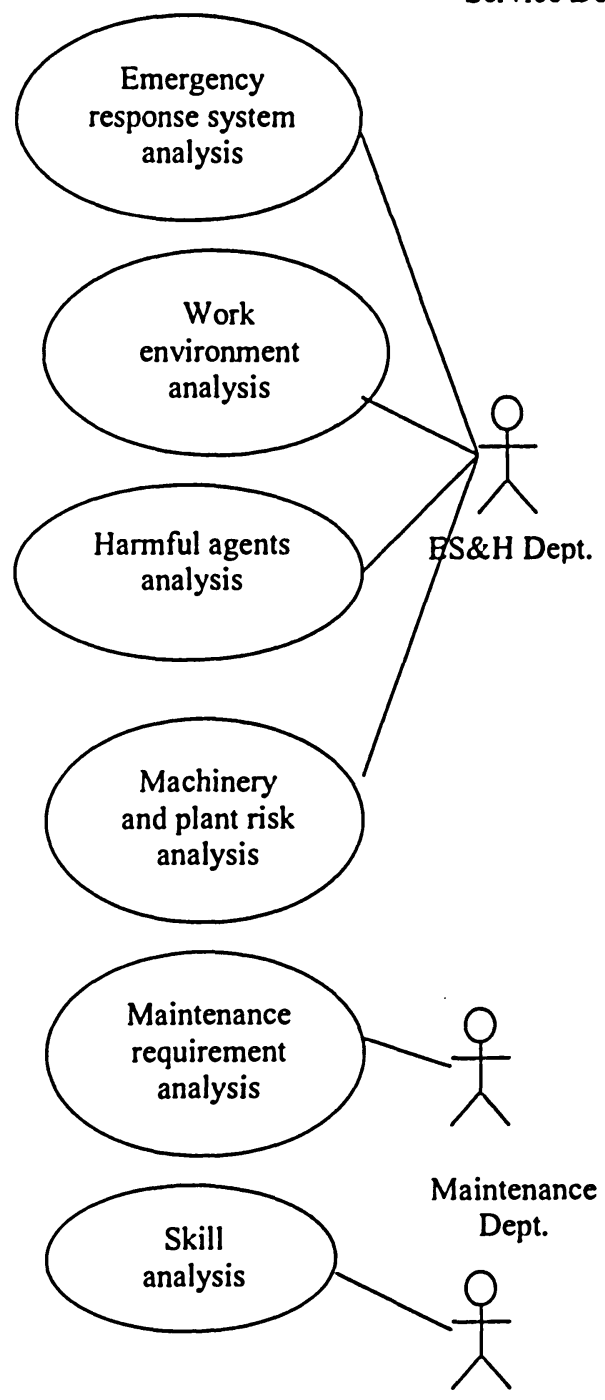

Training Dept.

Figure 5.2 TCSDSS Use-case diagram

As an example, the use case description for Quality Improvement Analysis (QIA) is shown in Table 5.3. 
Table 5.3 Use case descriptions for QIA

\begin{tabular}{|l|l|l|}
\hline & \multicolumn{1}{|c|}{ Actor } & \multicolumn{1}{|c|}{ System } \\
\hline 1 & $\begin{array}{l}\text { The user click on the related button in } \\
\text { the main menu interface }\end{array}$ & $\begin{array}{l}\text { The system opens register interface, asking } \\
\text { for user ID (user name and password) }\end{array}$ \\
\hline 2 & The user input user name and password & $\begin{array}{l}\text { The system confirms the user and opens } \\
\text { the "quality improvement analysis" } \\
\text { interface }\end{array}$ \\
\hline 3 & $\begin{array}{l}\text { The user activates the classification } \\
\text { function }\end{array}$ & $\begin{array}{l}\text { The system prompts the user to input } \\
\text { criteria }\end{array}$ \\
\hline 4 & The user input classification criteria & $\begin{array}{l}\text { The system make the classification and } \\
\text { output the results }\end{array}$ \\
\hline 5 & The user activates the query function & $\begin{array}{l}\text { The system prompts the user to input } \\
\text { riteria }\end{array}$ \\
\hline 6 & The user input query criteria & $\begin{array}{l}\text { The system makes the query and output } \\
\text { results }\end{array}$ \\
\hline
\end{tabular}

A decision has to be made at this time that is how to proceed with the analysis model. Should they be developed for all the use cases or just a part of them? It is realized that the goal of the prototype is to check the feasibility of TCSDSS. So decision is made to select samples of use cases that can prove GIS is able to:

(a) Solve problems that cannot be solved currently. The "Harmful agents analysis", "Work environment analysis", and "Emergency response system analysis" use cases are found to be good candidates to sample. However, the "Harmful agents analysis", "Work environment analysis" are quite similar because they all deal with the distribution of something, so it is enough to select just one of them.

(b) Meet the design precision requirement. The "Micro-space design", "Macrospace design and analysis", and "Supra-space design and analysis" use cases look like good candidates to start. The last two are quite similar - all dealing with the assignment of a block of space, thus only one of them can be selected. 
(c) Provide better space analysis functions. "Market Segmentation", "Quality improvement analysis", "Skill analysis", "Maintenance requirement analysis", and "Machinery and plant risk analysis" are good candidates. The last two deal with functions regarding equipment and facilities. By considering their similarity, only one is selected.

(d) Provide better visualization and reporting functions. "Warehouse selection", "Supplier selection", "Facility site selection", "service center selection", "Capital return distribution", and "Linearity and workforce utilization report" use case are good candidates. The first four all relate to site decision. Considering simplicity, "Warehouse selection" use case is selected.

As a result, the use cases "Work environment analysis", "Emergency response system analysis", "Micro-space design", "Macro-space design and analysis", "Market Segmentation", "Quality improvement analysis", "Skill analysis", "Maintenance requirement analysis", "Warehouse selection", "Capital return distribution", and "Linearity and workforce utilization report" are selected.

In order to get a fast result, complicated algorithms and coding will not be developed in the prototyping stage; "off-the-shelf" commercial software packages will be considered if the price is reasonable.

\subsection{Generation of Analysis Models}

For the analysis, design, and implementation models, the QIA use case will be used as an example to explain how these models are developed. 
Figure 5.3 describes how the QIA use case is realized by collaboration (i.e., a use-case realization) with a $<<$ trace $>>$ dependency between them, and that two classes participate and play roles in the use-case realization.

The structure of the classes is modeled in a class diagram shown in Figure 5.4. The collaboration diagram (Figure 5.5) shows the interaction between these two classes. The text explanation is presented by Table 5.4.

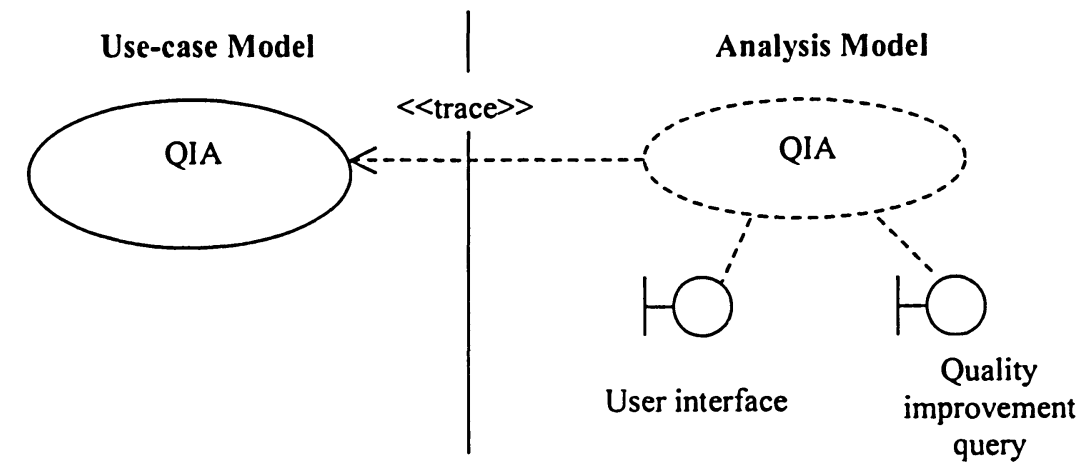

Figure 5.3 QIA analysis model

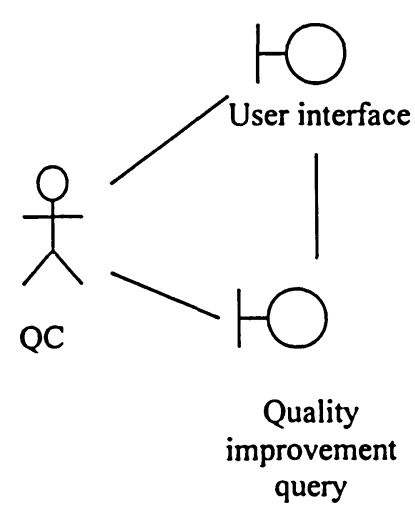

Figure 5.4 QIA class diagram

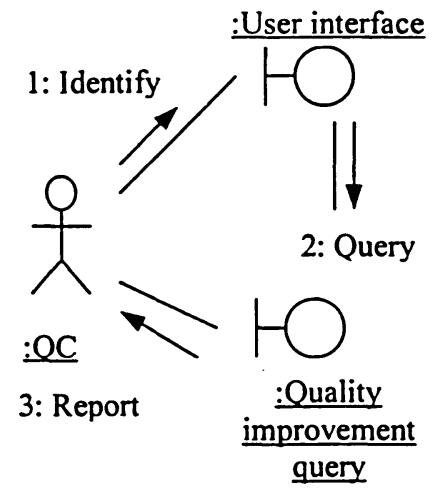

Figure 5.5 QIA collaboration diagram 
A QC chooses to conduct QIA and activates the user interface object. The QC identifies him/herself, conducts a quality improvement query, and generates a report. The User interface verifies the QC's identity and activates the Quality improvement query object.

\subsection{Generation of Design Models}

The QIA analysis model is then refined to a design model shown in Figure 5.6. The class diagram and sequence diagram are shown in Figures 5.7 and 5.8. Some text explanations are represented in Table 5.5.

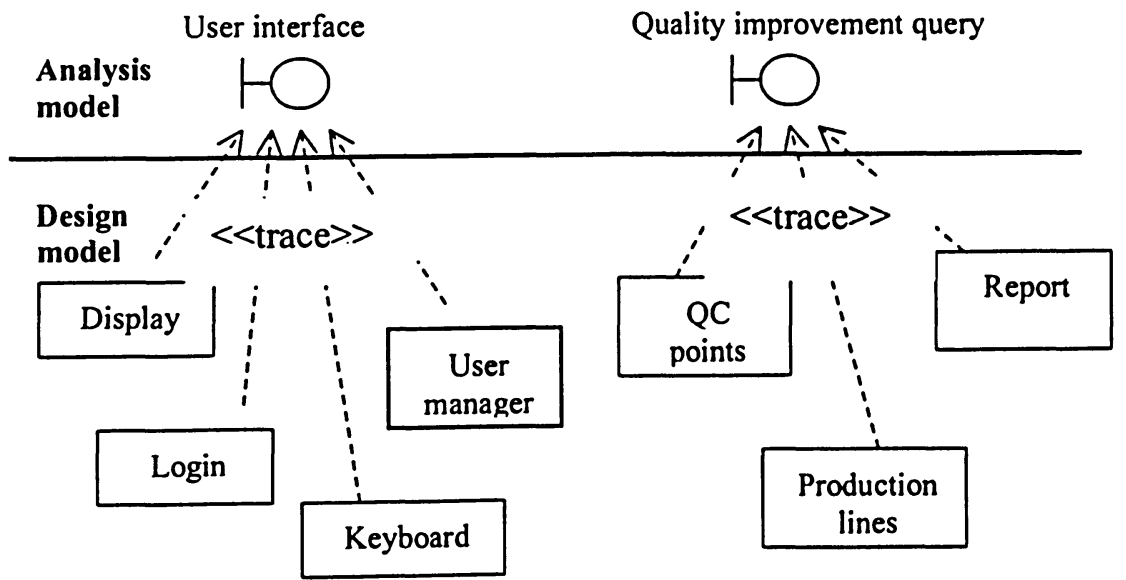

Figure 5.6 QIA design model
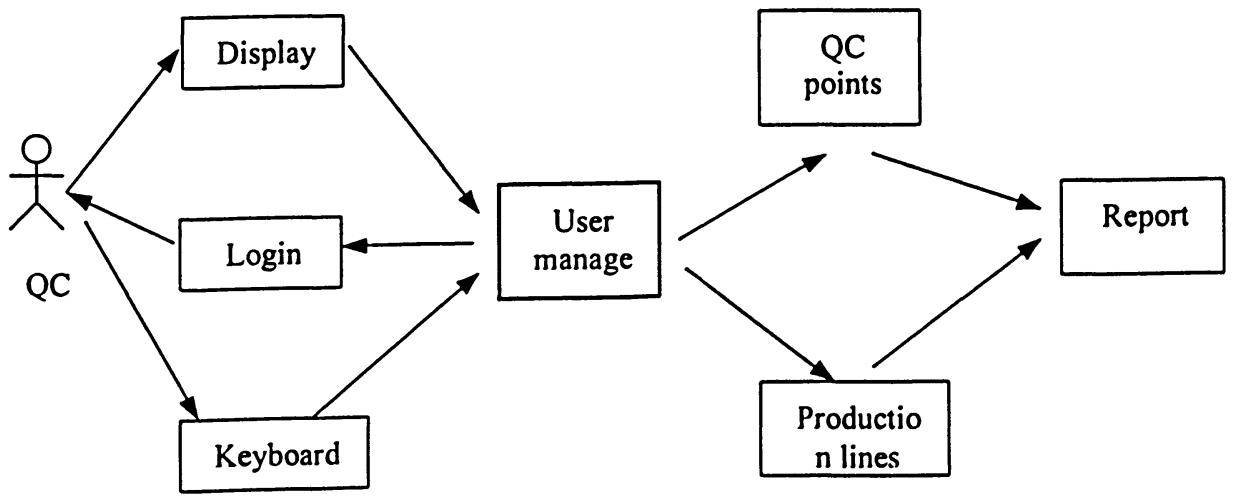

Figure 5.7 QIA design level class diagram 

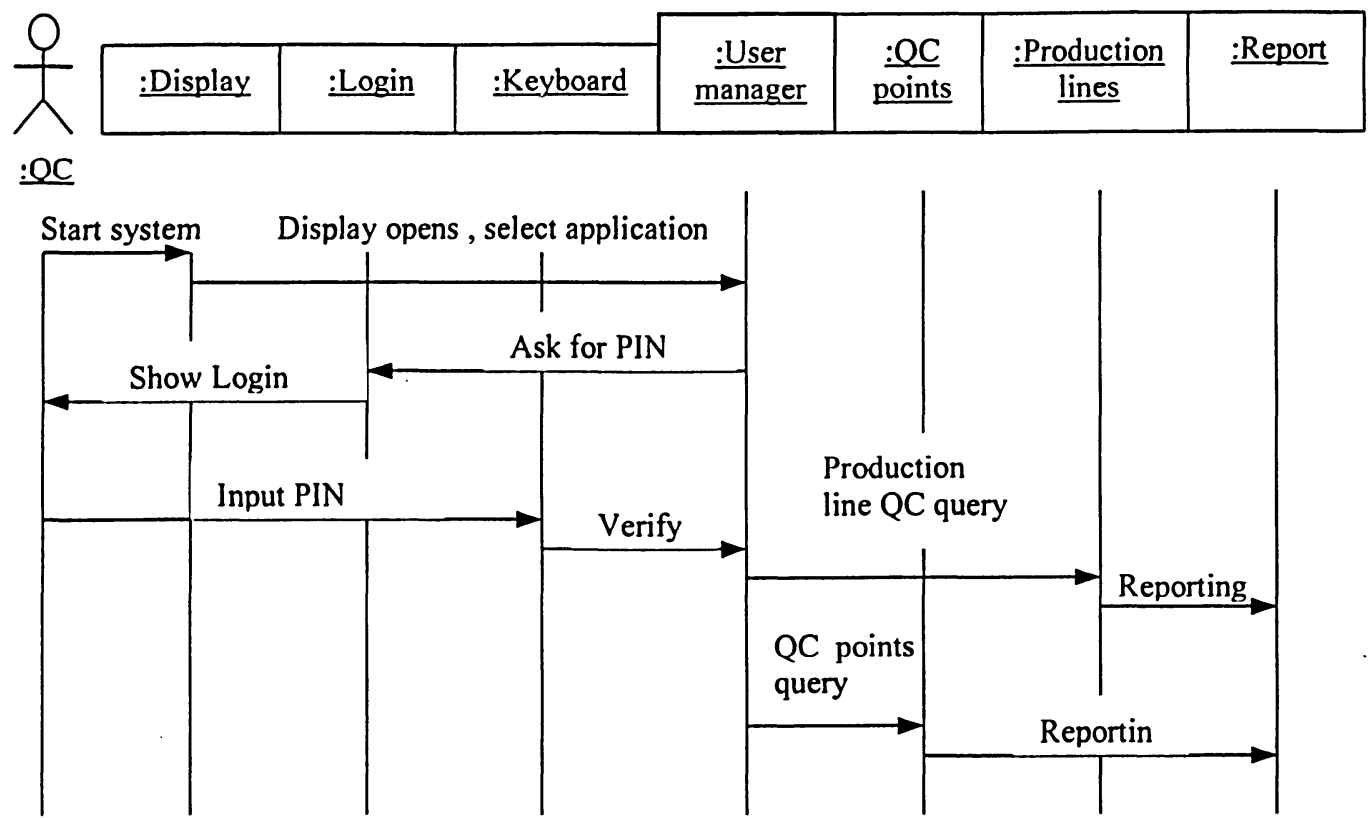

Figure 5.8 QIA design level sequence diagram

Table 5.5 QIA design description

The QC starts the system, and the Display interface opens. The QC then pushes the QC button, sending a message to the User manager object that activates the Login interface asking the $\mathrm{QC}$ to input user name and PIN. After verifying the right user, the User manager activates the $\mathrm{QC}$ points (a point theme) and Production line (a polygon theme) objects that supposed to be in a GIS software package. The QC then performs query operations on the Production line and QC points objects and generates some reports. Attributes and operations for the $\mathrm{QC}$ points and Production classes are as follows (* stands for primary key, $s$ for string, $i$ for integer, $f$ for float, $\mathrm{m}$ for money, $\mathrm{t}$ for time):

\begin{tabular}{|l|l|c|}
\hline \multicolumn{1}{|c|}{ Objects } & \multicolumn{1}{|c|}{ Attributes } & Operations \\
\hline $\begin{array}{l}\text { Production } \\
\text { lines }\end{array}$ & $\begin{array}{l}\text { Line name(s), Line code*(i), Current sigma(f), } \\
\text { Target sigma(f) }\end{array}$ & PLQC_Classify( ) \\
\hline QC points & $\begin{array}{l}\text { Point code*(i), Q/C points(s), Current sigma(f), } \\
\text { Target sigma(f), Cost(m), Benefit(m), Time(t), } \\
\text { Urgency(s) }\end{array}$ & QCP_Query ( ) \\
\hline
\end{tabular}




\subsection{Generation of Implementation Models}

The implementation model for QIA is shown in Figure 5.9. The user.c software contains the source code and thus implements the classes Display, Login, Keyboard, and User manager. This file component is then compiled into the Usreinter.exe component, which is executable. While the GIS package implements the classes QC points, report, and production line.

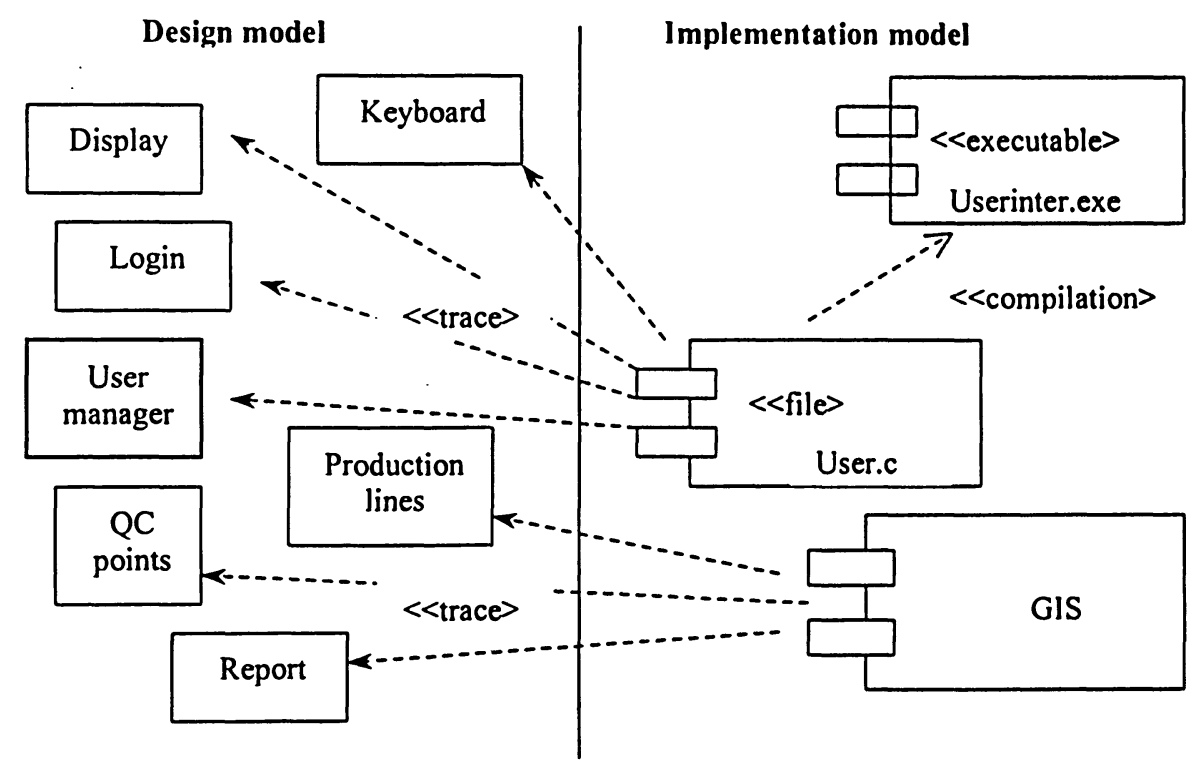

Figure 5.9 QIA implementation model and component diagram

The TCSDSS prototype contains two blocks of software packages, the user interface package and the GIS package. The first one is used to identify users and activate the GIS package if the user is identified. A commercial product is considered for the GIS package. ArcGIS 8.3 was selected in this study for two reasons.

1. The drawing functions that ArcGIS provides are precise enough for line layout requirements. This is accomplished by ArcGIS's Editor (see Figure 5.10). The Editor can achieve the functions such as creating new features, selecting features using a line, and cutting polygon features. 


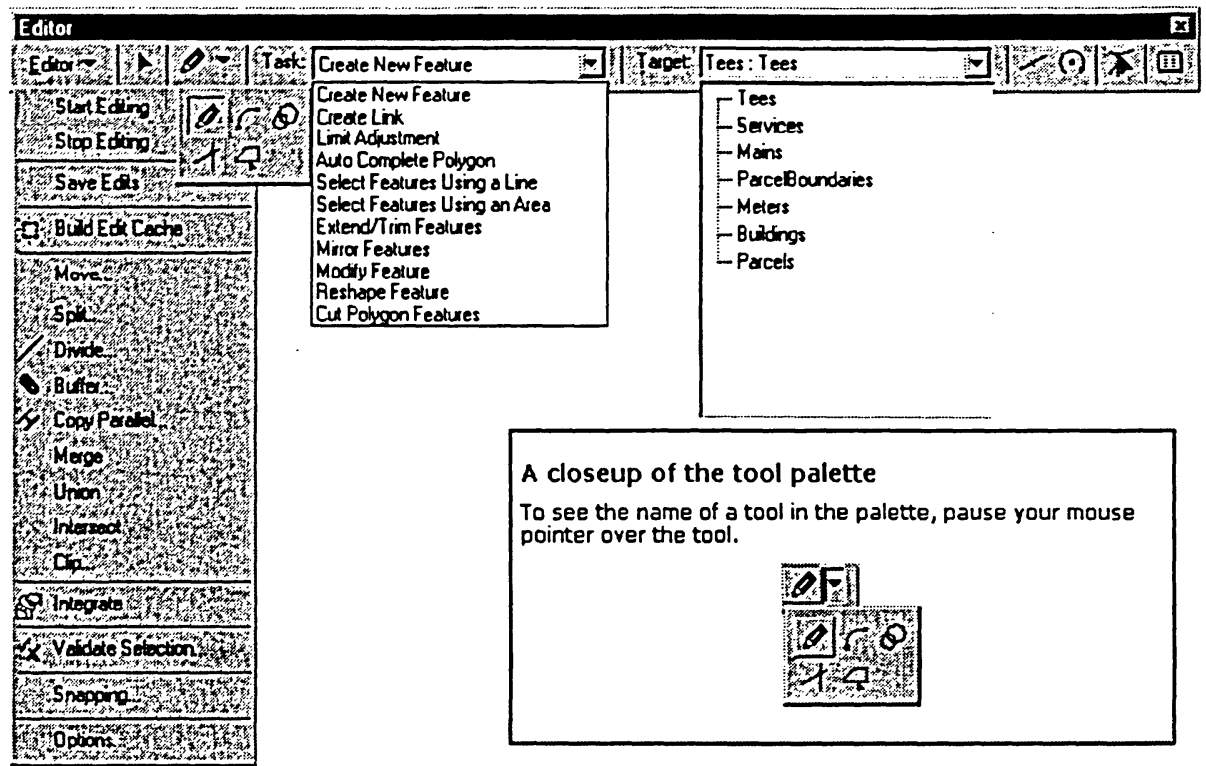

Figure 5.10 ArcMap Editor toolbar

The Editor can create three main types of features: points, lines, and polygons. To create a line or polygon, a sketch must be created first. A sketch is composed of all the vertices and segments of the feature. Vertices are the points at which the sketch changes direction, such as corners; segments are the lines that connect the vertices. A sketch can be created by creating the vertices and segments that make up the features.

The sketch tool (see Figure 5.11) is the tool used most often to create a sketch. It has an accompanying context menu (see Figure 5.11) that helps to place vertices and segments more accurately. For example, a vertex can be created at a specific $x, y$ coordinate location and set a segment can be set a certain length and/or angle. The Arc tool, the Distance-Distance tool, and the Intersection tool also help to create vertices and segments using other construction methods. 


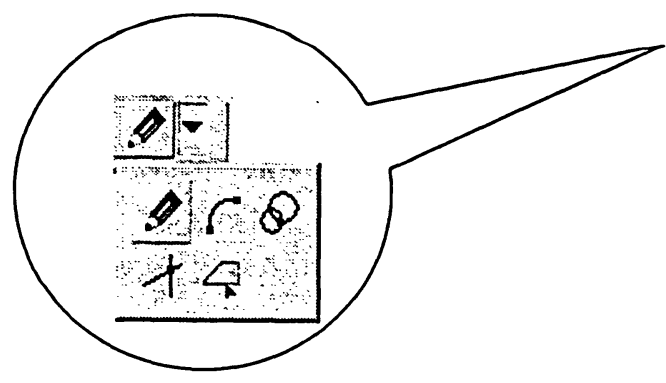

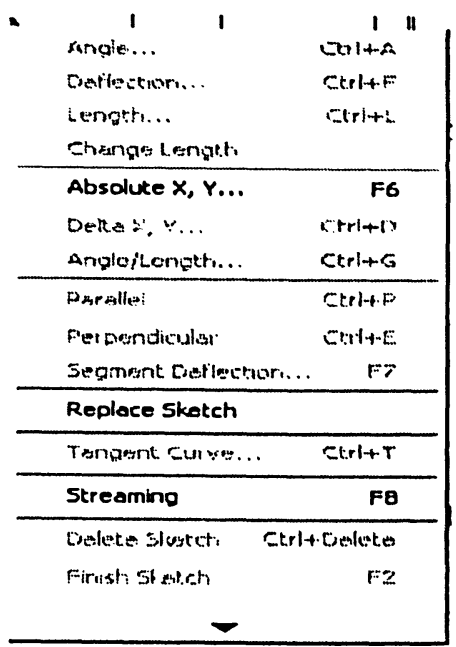

Figure 5.11 Sketch tool and context menu

The snapping environment (Figure 5.12), which is similar to CAD's object snapping function, can help establish exact locations in relation to other features. The snapping environment can also be used to move a feature (newly created or copied) to a precise location in relation to another feature.

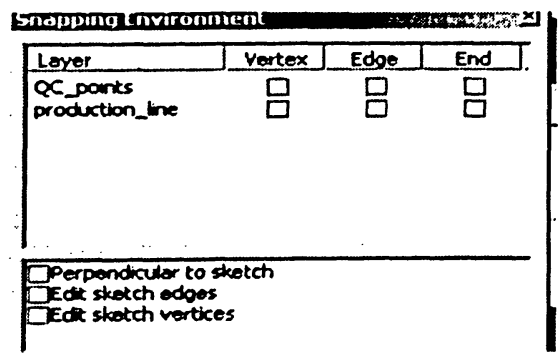

Figure 5.12 Snapping environment

ArcGIS 8.3 can provide precise drawing functions quite similar to what a $\mathrm{CAD}$ system can provide regarding to points, straight lines, and polygons. As for arcs and circles, ArcGIS is not so precise as CAD - it cannot snap the center and define radius precisely. However, it can show the center of a circle and the diameter can be roughly measured by its distance measurement function. 
2. For the extensions, Spatial Analyst, 3D Analyst, and Network Analyst are thought to provide enough functions for what the prototype needs, which the ArcGIS 8.3 has all of them.

The prototype is also considered to implemented on a single desktop although the local network and Internet implementation is considered if the prototype is tested successfully.

\subsection{Chapter Summary}

The architecture of TCSDSS prototype is shown in Figure 5.13.

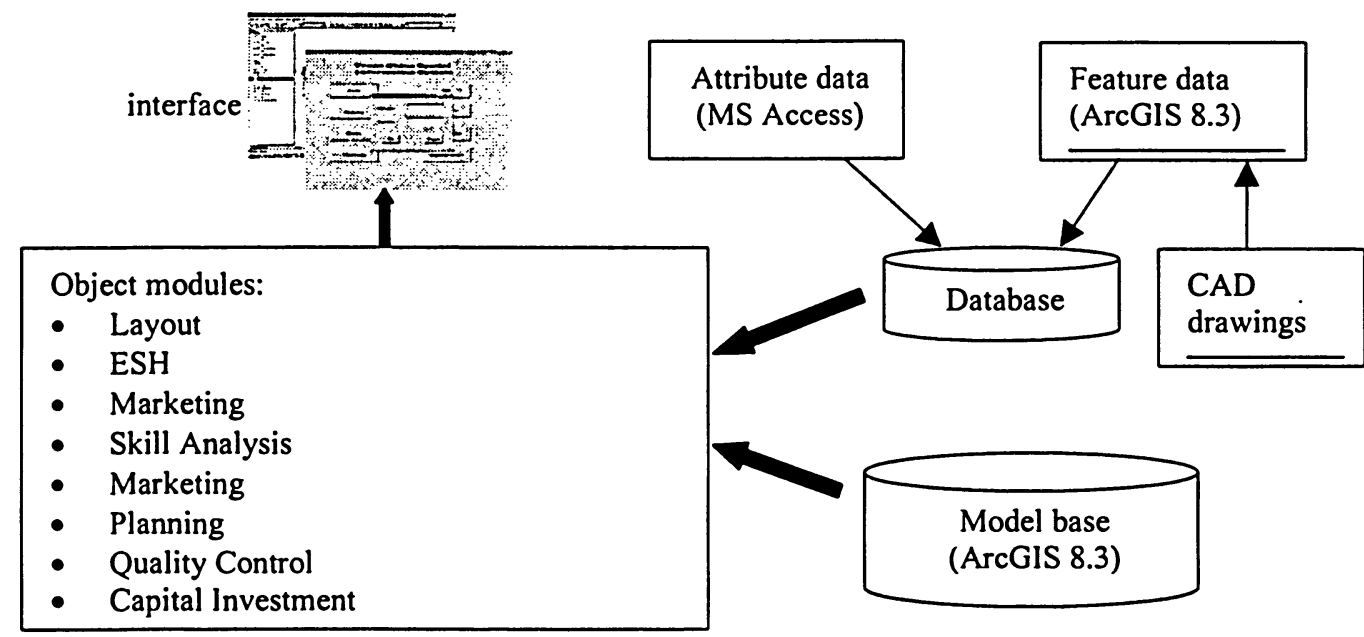

Figure 5.13 TCSDSS prototype system architecture

The interfaces contain user interface and ArcGIS 8.3 interface. Database includes feature data that are stored in ArcGIS 8.3 and MS Access attribute data. Model base contains models imbedded in ArcGIS 8.3, such as 3D Analyst, Georeferencing, and Spatial Analyst. The object modules consist of use cases. The ESH module contains Work environment analysis and Emergency response system analysis use cases. The Layout module contains Micro-space design and Macro-space design and analysis use 
cases. The Marketing module contains Market Segmentation use case. The Skill Analysis module contains Skill analysis use case. The Planning module contains Linearity and workforce utilization report use case. The Quality Control module contains Quality improvement analysis use case. The Capital Investment module contains Capital return distribution use case. Finally, the Maintenance module contains Maintenance requirement analysis use case.

To assess the performance of the prototype, each object module is tested. Test results will be presented in Chapter 6 . 


\section{TCSDSS PROTOTYPE TEST RESULTS AND}

\section{DISCUSSIONS}

The test procedures and results for the TCSDSS prototype are presented in this chapter. Section 6.1 introduces the test of user interface. Section 6.2 shows the input of feature data and georeference results of Trane China on the Taicang City map. Section 6.3 introduces the test procedure of object module by using Quality Control object module as an example and gives out the test results of each object module. Discussions in this section are focused on the benefit GIS can bring. Major findings are given in the summary section.

\subsection{User Interface}

The user interface is used to identify authorized users and activate GIS interfaces for different users. For example, if a quality control engineer wants to conduct a work environment analysis, she/he first clicks the Quality Control button on the user interface (Figure 6.1); a message box (Figure 6.2) then pops out to ask the quality control engineer to input the user name and password. After checking the right identification, the user interface then opens the GIS interface especially for quality control engineer. 


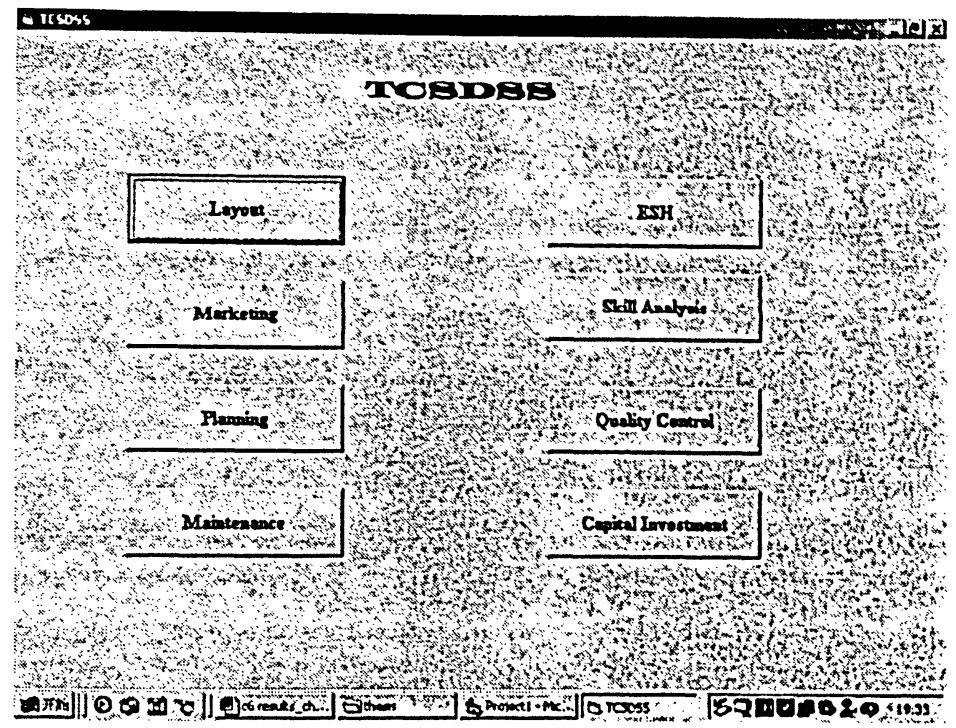

Figure 6.1 User interface

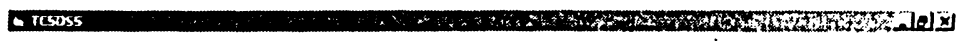

ICETDEE

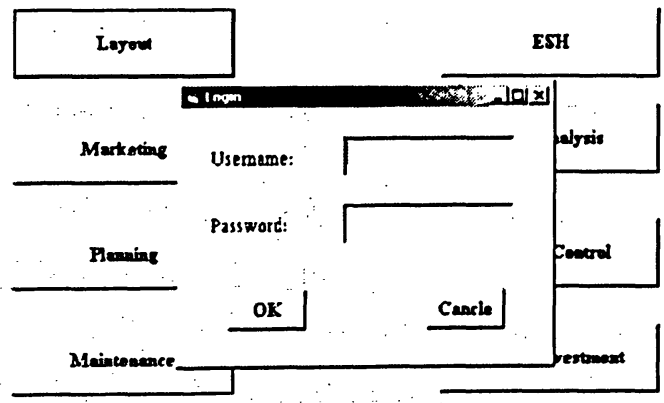

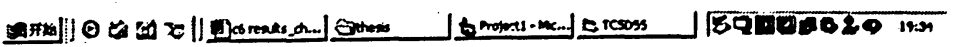

Figure 6.2 User identifying

\subsection{Map Input}

A raster map of Taicang City and the CAD drawing of Trane China are input as two background layers by using the georeferencing function of ArcGIS 8.3 (Figure 6.3). 


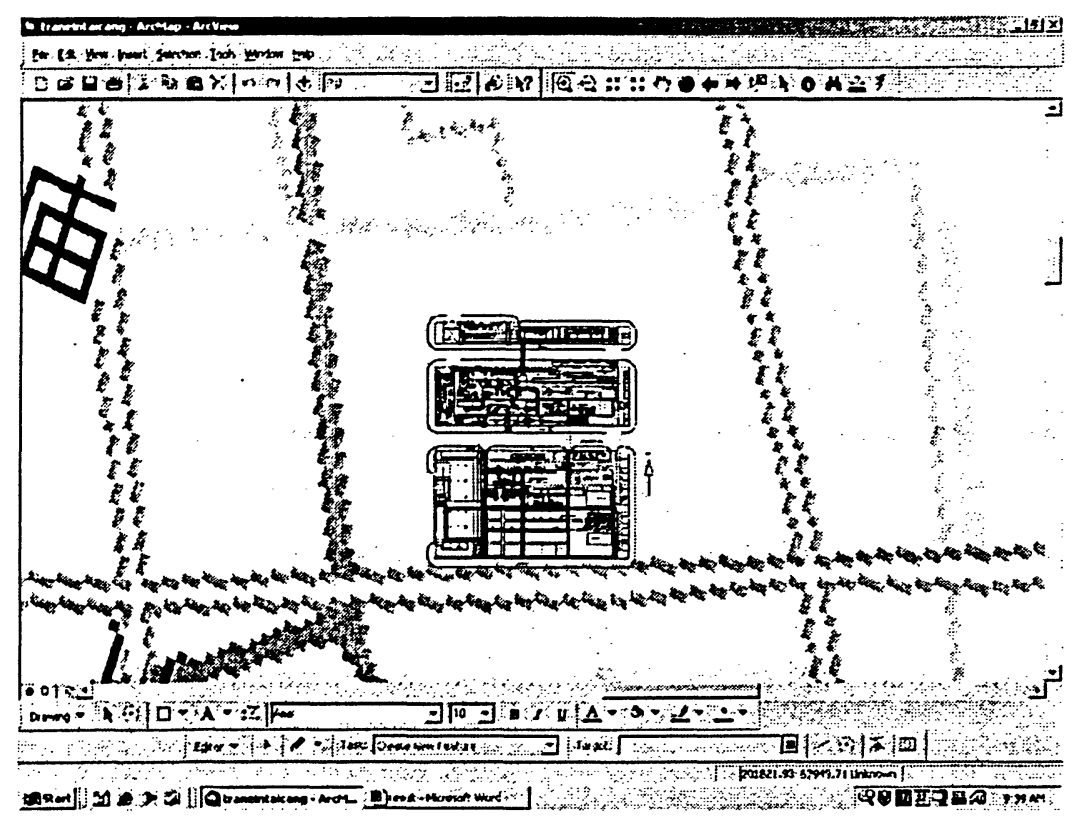

Figure 6.3 Map input - georeferencing

\subsection{Module Function Test}

The eight object modules developed in the prototype are tested with real data to check if GIS package is suitable for SDSS in a manufacturing environment such as Trane China.

\subsubsection{Test Procedure}

To test an object module, each use case it contains should be tested. The test procedure should follow the use case descriptions developed in Chapter 5. The Quality Control object module that contains the QIA use case is used as an example here to explain the test procedure. Use case description can be found in Table 5.3.

1. User identification

This step contains the first two rows in use case description. Details have been introduced in Section 6.1. 


\section{Classification function test}

This step contains the third and fourth rows in the use case description. As found in Table 5.5, this test is performed on the Production line objects. Input of feature is introduced in Section 6.2. Attribute data need to be input into the system are described in Table 5.5. Values of each object data and related attribute data for Trane China can be found in Table 4.7. After data are input, the PLQC_Classify() operation stated in Table 5.5 is performed on the objects. Two criteria are used in this operation, which are "current quality level" and "current quality level/target quality level".

Figure 6.4 shows the classification of production lines for the current quality level. Deeper color means higher quality level. Figure 6.5 shows the classification of production lines based on the ratio of current quality again target quality. The smaller the ratio is, the lighter the color is in Figure 6.5, the higher quality improvement priority the related lines will get. Thus, in this case, Coil 1 line gets the highest priority. Inside the lines, quality points are selected according to some specific criteria given by quality engineers.

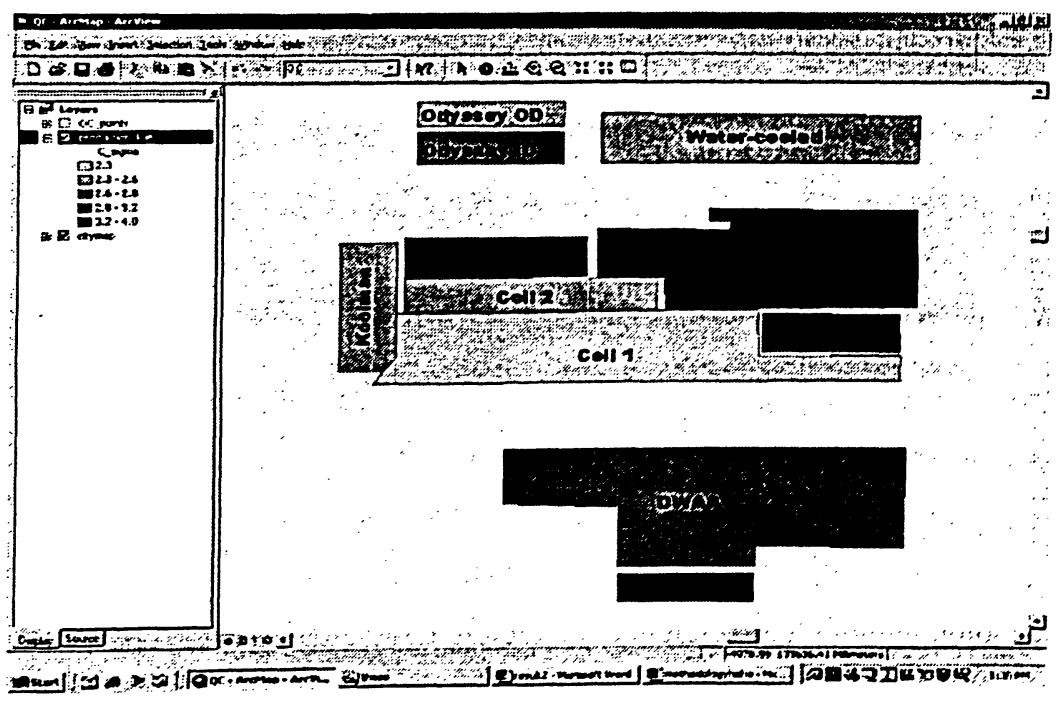

Figure 6.4 Classification - Current quality level 


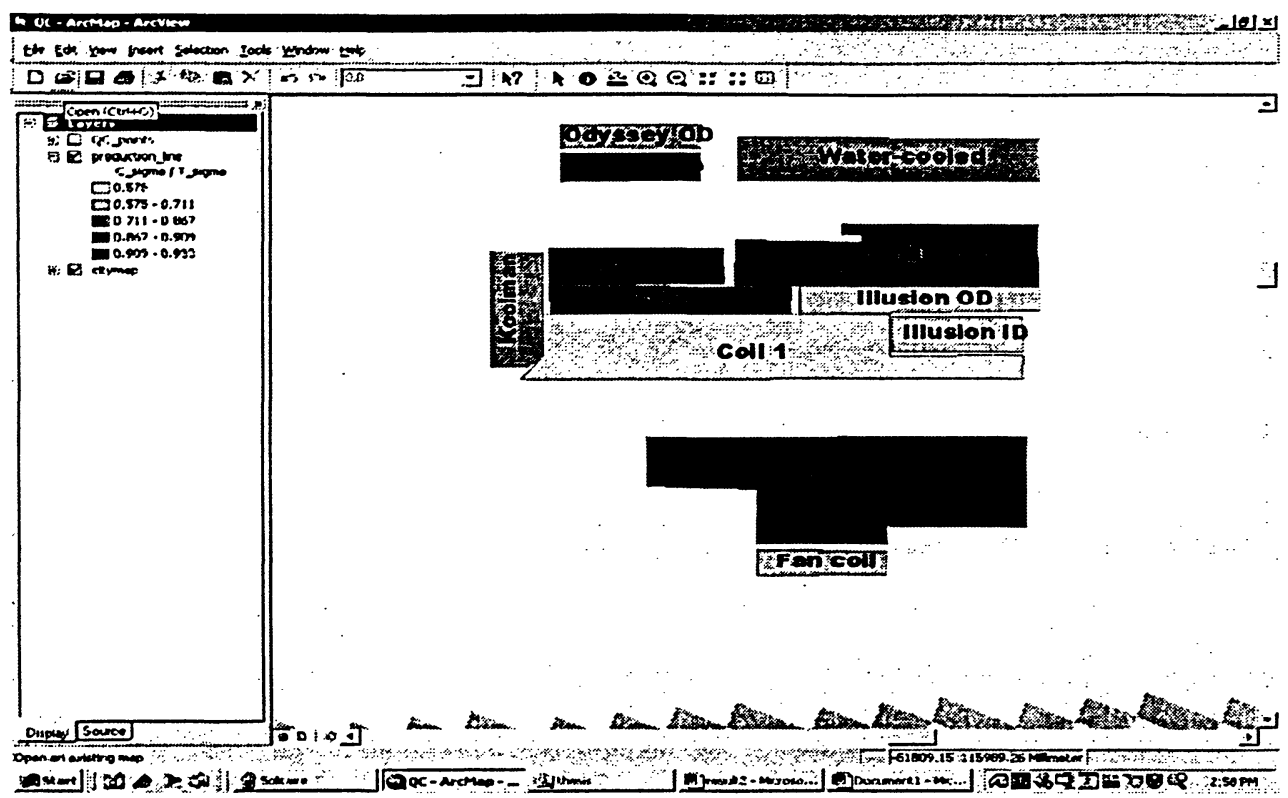

Figure 6.5 Classification - Current quality level/target quality level

3. Query function test

This step contains the last two rows in the use case description. As found in Table 5.5, this test is performed on the QC point objects. Input of feature data is introduced in Section 6.2. Attribute data need to be input into the system are described in Table 5.5. Values of each object data and related attribute data for the example of Illusion OD line in Trane China can be found in Table 4.8. After data are input, the QCP_Query ( ) operation stated in Table 5.5 is performed on the objects. Figure 6.6 gives an example in the Illusion OD line for the criterion of target sigma is 1.5 more than current sigma (biggest difference); net benefit (benefit - cost) is 600 USD (highest net benefit); and with high urgency level. After the operation is performed, the result is highlighted in light blue. 


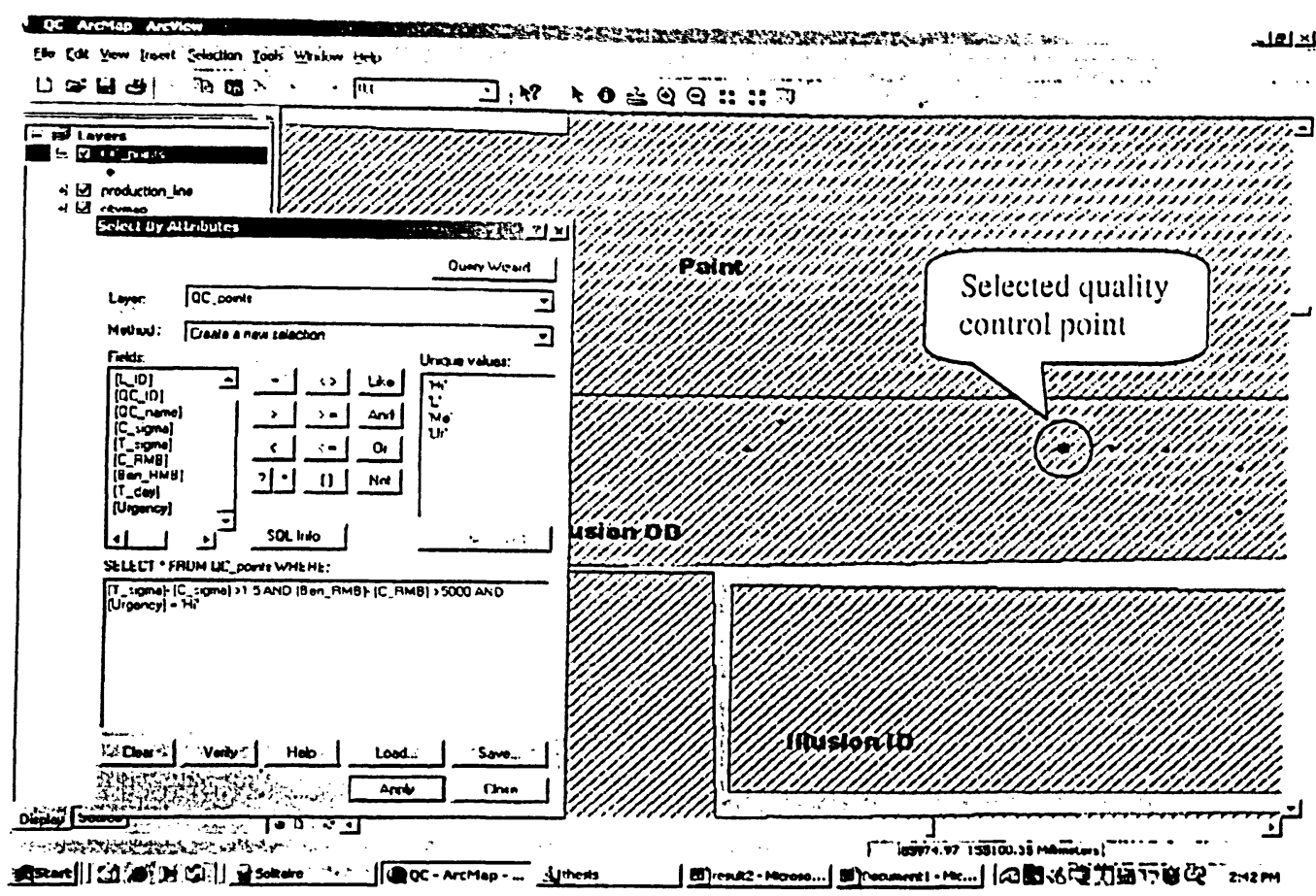

Figure 6.6 Quality improvement query

(T_sigma - C_sigma $>1.5$. Benelit -cos $>60)$. High urgency)

\subsubsection{Test Results}

Test results for the rest object modules are presented in the following paragraphs.

\section{A. ESH}

ESH module in this prototype has two main functions: work environment analysis and emergency response system simulation. Building 2 of Trane China is used as the study area.

Noise, lighting, and indoor air quality levels are used to describe the working environment. Sample points are selected at $10 \mathrm{~m} * 10 \mathrm{~m}$ grid to gather related data. The results are shown in Figures 6.7, 6.8, and 6.9, respectively. The red solid polygons in the figures present the facilities in Building 2. 


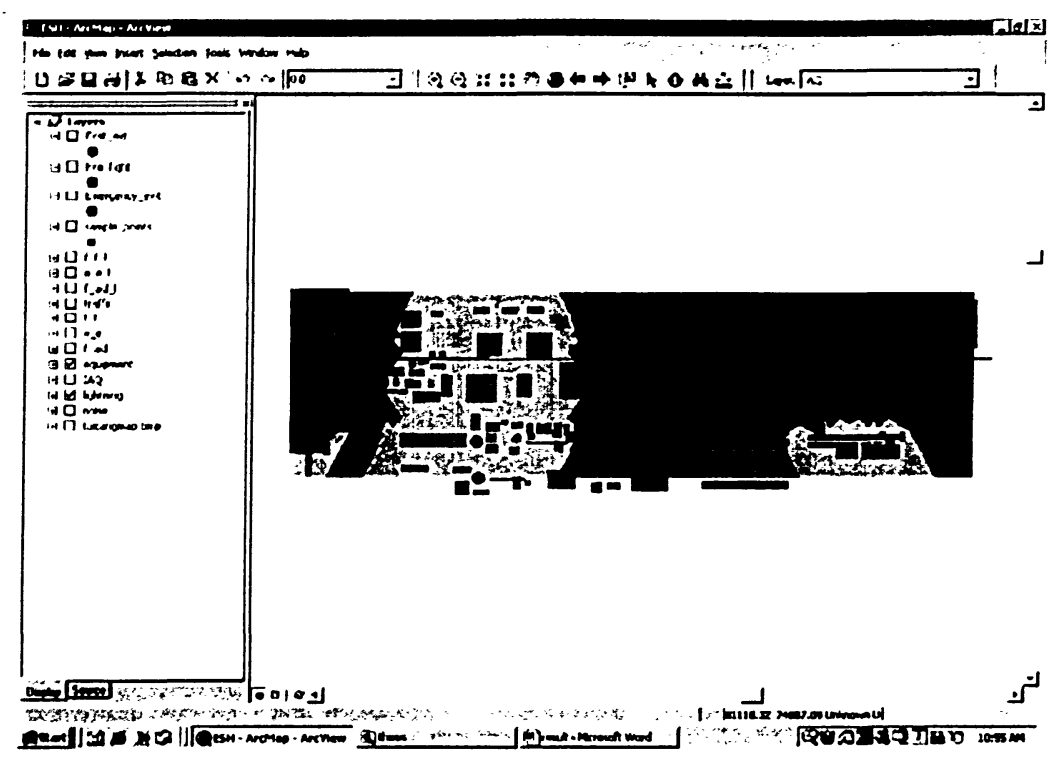

Figure 6.7 Lighting distribution analysis

As the color getting darker, the lighting situation is getting worse. This helps figure out where in this building needs more lighting.

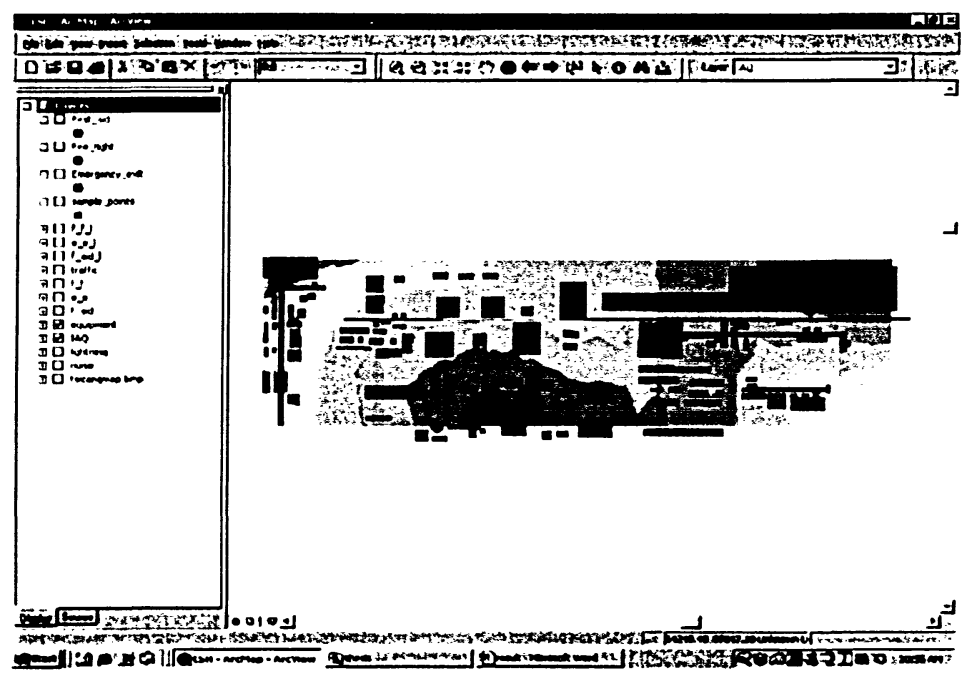

Figure 6.8 Noise level distribution analysis

As the color getting redder, noise level increases. The power paint area and fin press area are found to generate the most noise. Because there are only two operators in the power paint area. which is in a semi-enclosed area, noise protective 
device is chosen to overcome this problem. However. most of the operators are working around the fin press area that is quite open, proper treatment should be to build noise-insulating booths around the fin presses.

In Figure 6.9. as the color getting redder. indoor air quality is getting worse. Indoor air quality is the worst in the power paint area and coil degreasing area. It is quite reasonable because there is a lot of paint power in the paint area. As for the coil degreasing area. the chemicals used to degrease the coils contribute most to the problem, as well as the brazing process comes right after the degreasing process. Masks are provided to the power paint operators, as mentioned early, because there are only two operators working in this semi-closed area. Better ventilation system should be installed in the degreasing area. However, the best way is to eliminate the chemical degreasing method. Best choice is to use evaporative oil during coil manufacturing and adopt heating degreasing process to eliminate the use of chemicals.

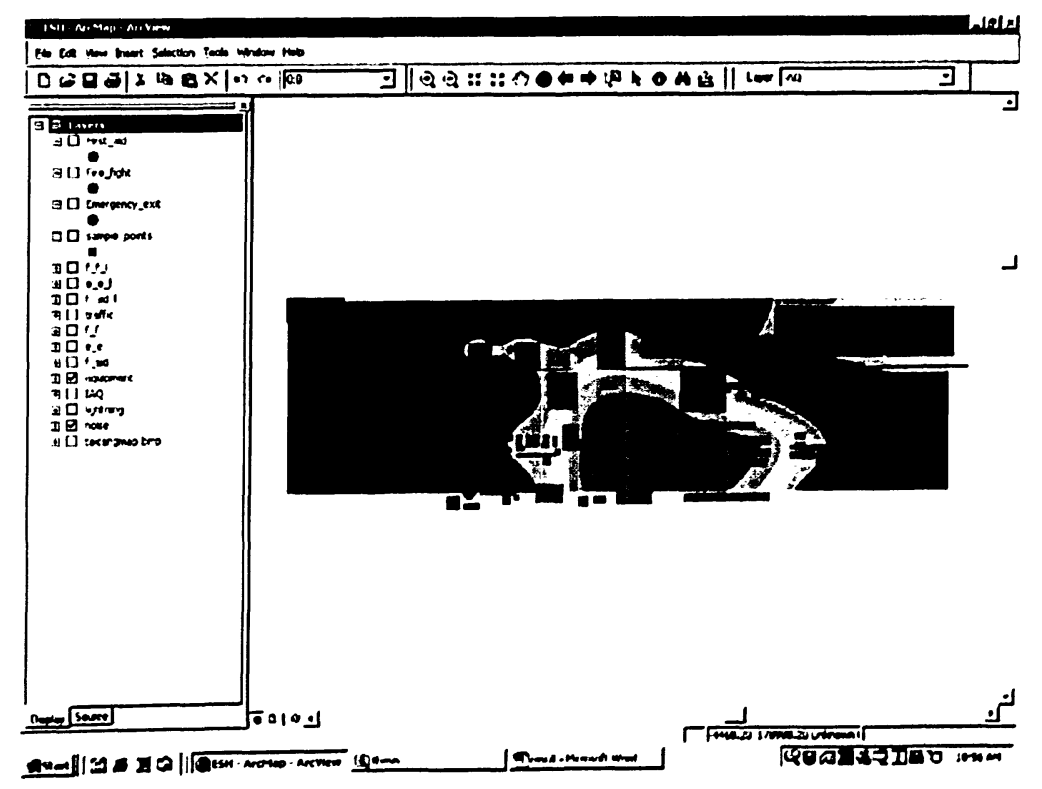

Figure 6.9 Indoor air quality index distribution analysis 
It is found that, by adopting the GIS spatial analysis function, work environment analysis is much easier. Starting from just a few sample points, the ES\&H officer is now able to predict the reasonable spatial distribution of the work environment indexes and give trustable and systematic recommendations to the management on how to improve the work environment, such functions are what CAD is not capable of. However, the selection of the sample points needs to be further studied. As found in Figures 6.7, 6.8, and 6.9. with the current sample points, the distribution of the work environment indexes in some places are not shown. This should be fine tuned in the following detailed system development.

As for the emergency response system simulation, first aid, emergency exit, and fire fight resources accessibility analysis is conducted, running speed of human being is considered in this case $(15 \mathrm{~km} / \mathrm{hr})$. Results are shown in Figures 6.10, 6.11, and 6.12.

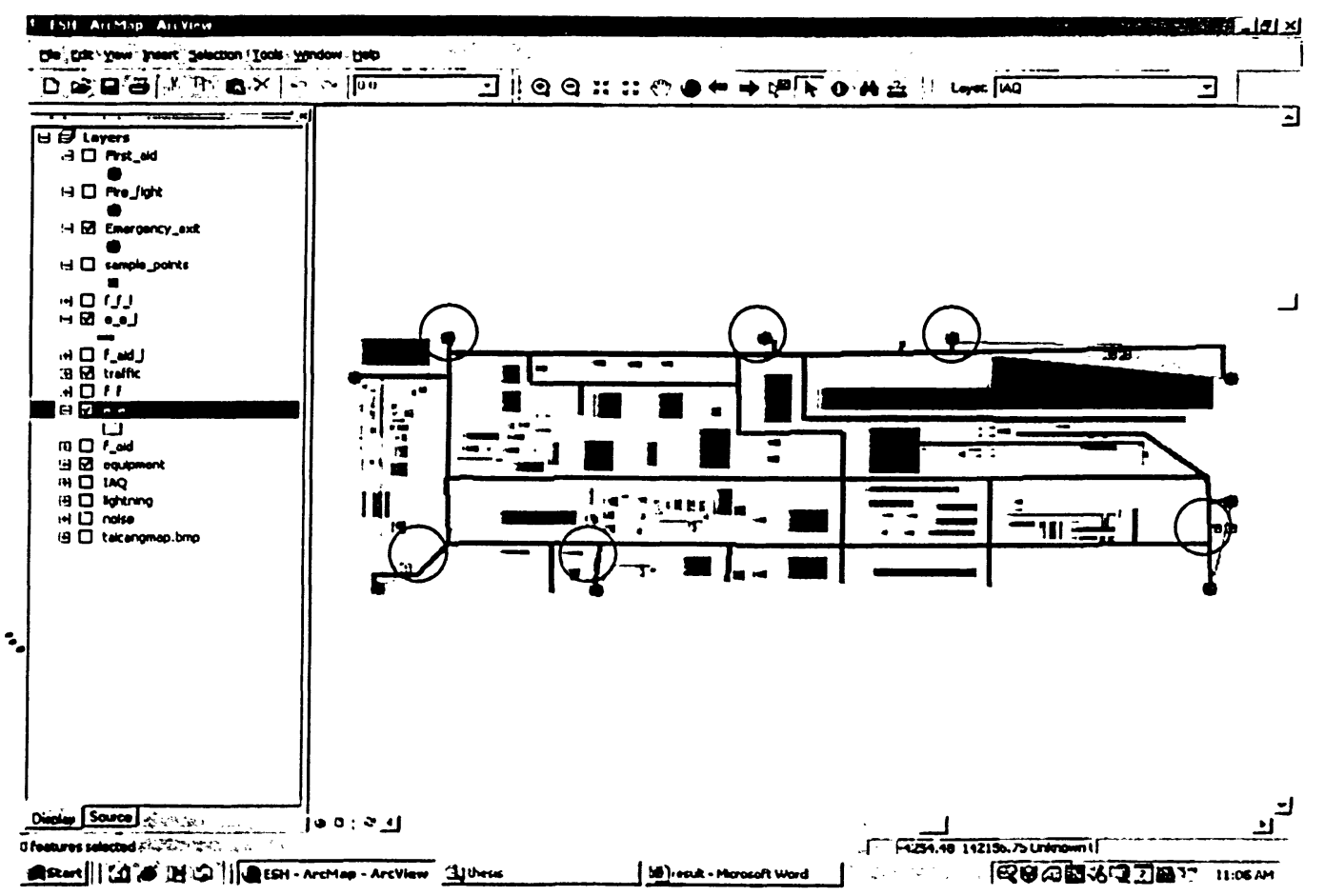

Figure 6.10 Emergency exit accessibility within half a minute 
The red lines and light blue areas in Figure 6.10 show that employees within these places can leave the building within half a minute if an emergency situation occurs. It shows a big problem in this figure because this only covers a very small part of the building. Facility layout needs to be reconsidered to add more aisles and emergency exit doors.

The red lines and brown areas in Figure 6.11 show that the above areas can get firefighting resources in half a minute if fire occurs. The situation is much better than the emergency exit system. However, improvements are still needed for the circled areas where a lot of brazing work is performed.

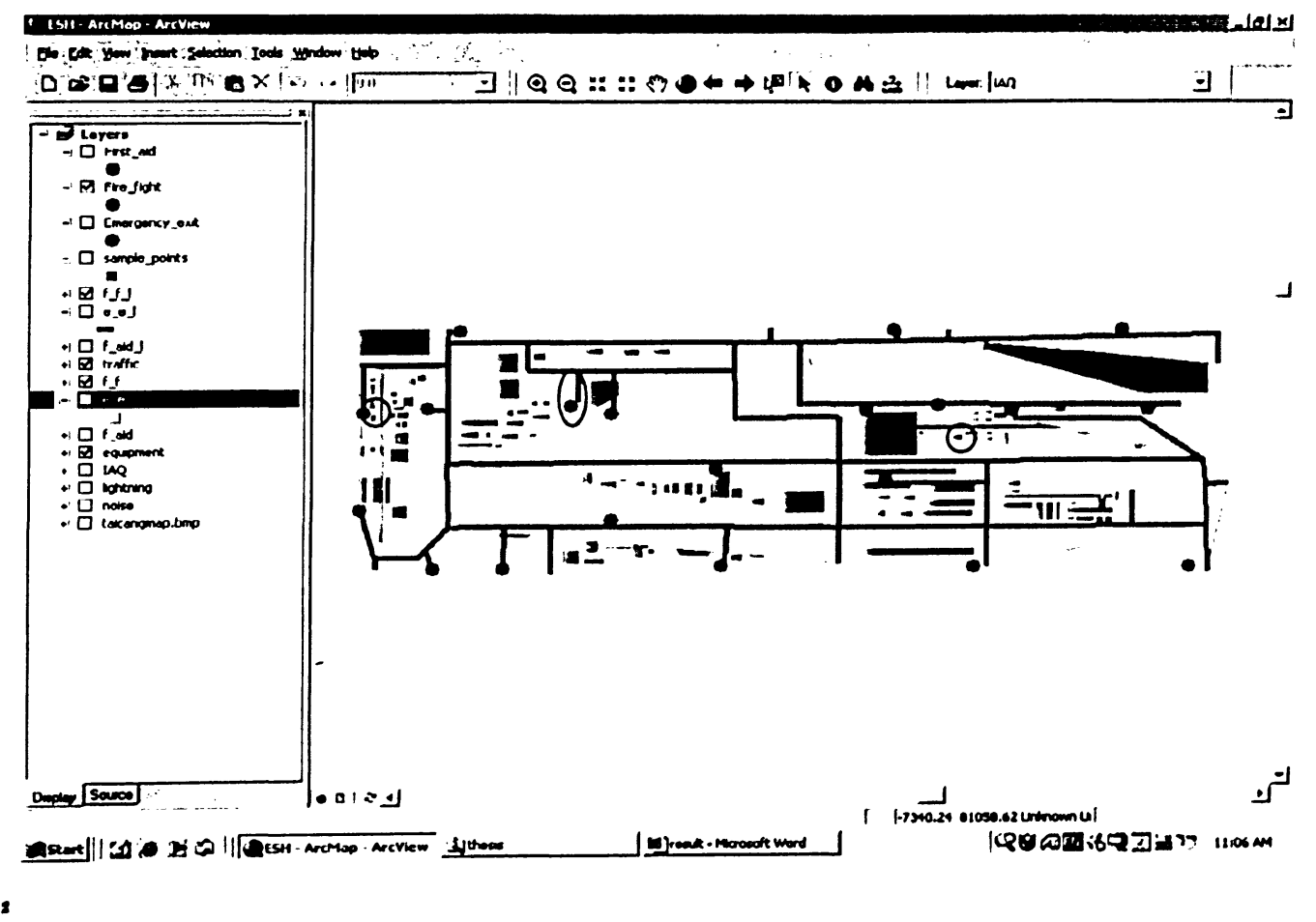

Figure 6.11 Firefight resource accessibility within half a minute 


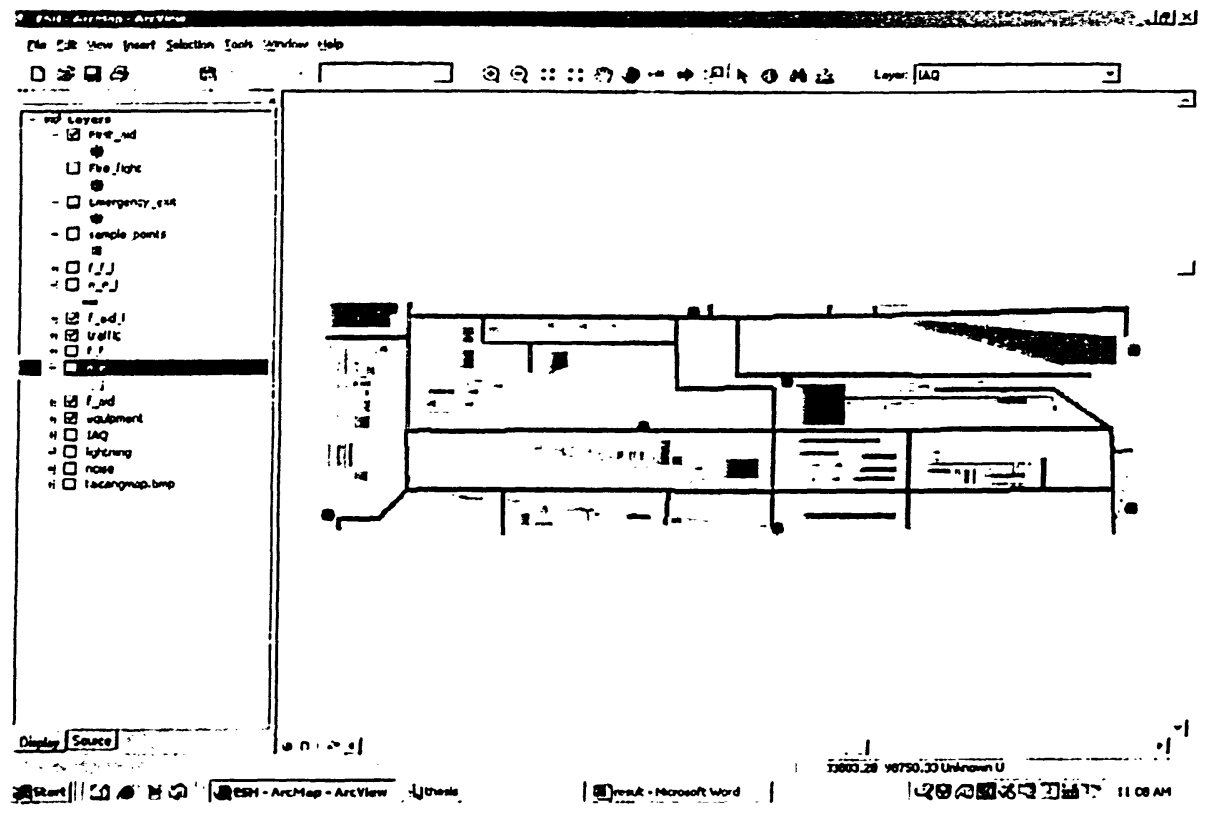

Figure 6.12 First aid resource accessibility within half a minute

The red lines and brown areas in Figure 6.12 show the areas first-aid resources can be reached when operator gets hurt. Half of the building is covered; improvement is needed.

The results are also overwhelming for the emergency system. With the help of GIS, it makes the ES\&H officer very easy to find if the resources are enough and distributed reasonablely. In this case, although the cost savings cannot be calculated directly, the risk of running the facility and human life are greatly reduced by sound reasonable approach. The benefit of GIS in this case is no doubt.

B. Capital Investment

It is not fully necessary to use GIS to analysis the RONA, Excel is good enough by its sorting function, but if a GIS is already in place, why not take the full advantage of it? In fact, the colors are much easier to be distinguished and remembered by human beings than just the numbers. In this case, as showed in Figure 6.13 for the 
capital investment in Building 2, the capital investment analyst can easily tell the manufacturing engineer what kind of equipment (red color) needs to be improved because they are not making money efficiently, and where these machines are. Communications are greatly improved in this way.

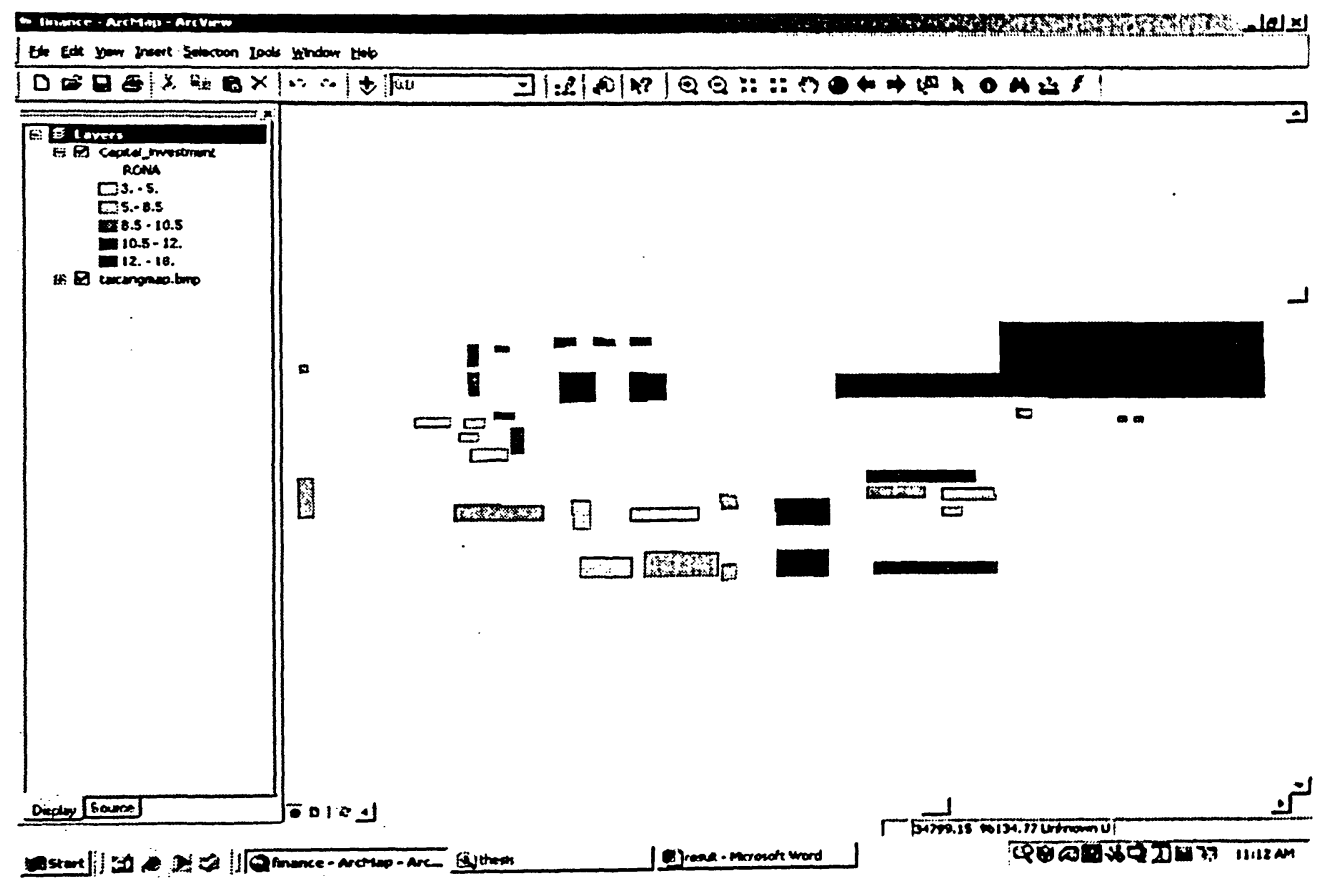

Figure 6.13 RONA distribution

C. Planning

Figure 6.14 shows the classification of linearity, when the color getting redder, linearity improves, which means production plan is better implement and customer requirements are better fulfilled. 


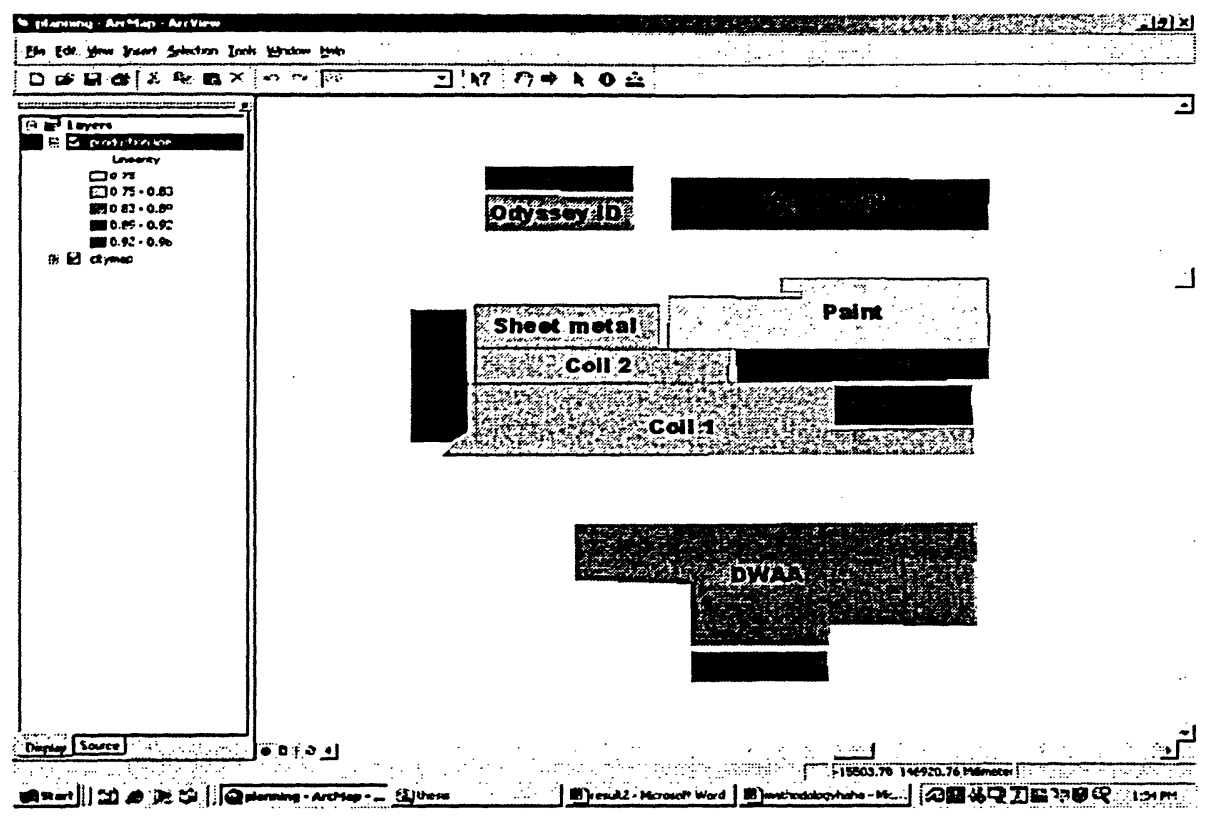

Figure 6.14 Linearity distribution

Figure 6.15 shows the classification of workforce utilization. The lighter the color, the smaller the ratio of actual used manpower against designed manpower, which means the more efficient the line is.

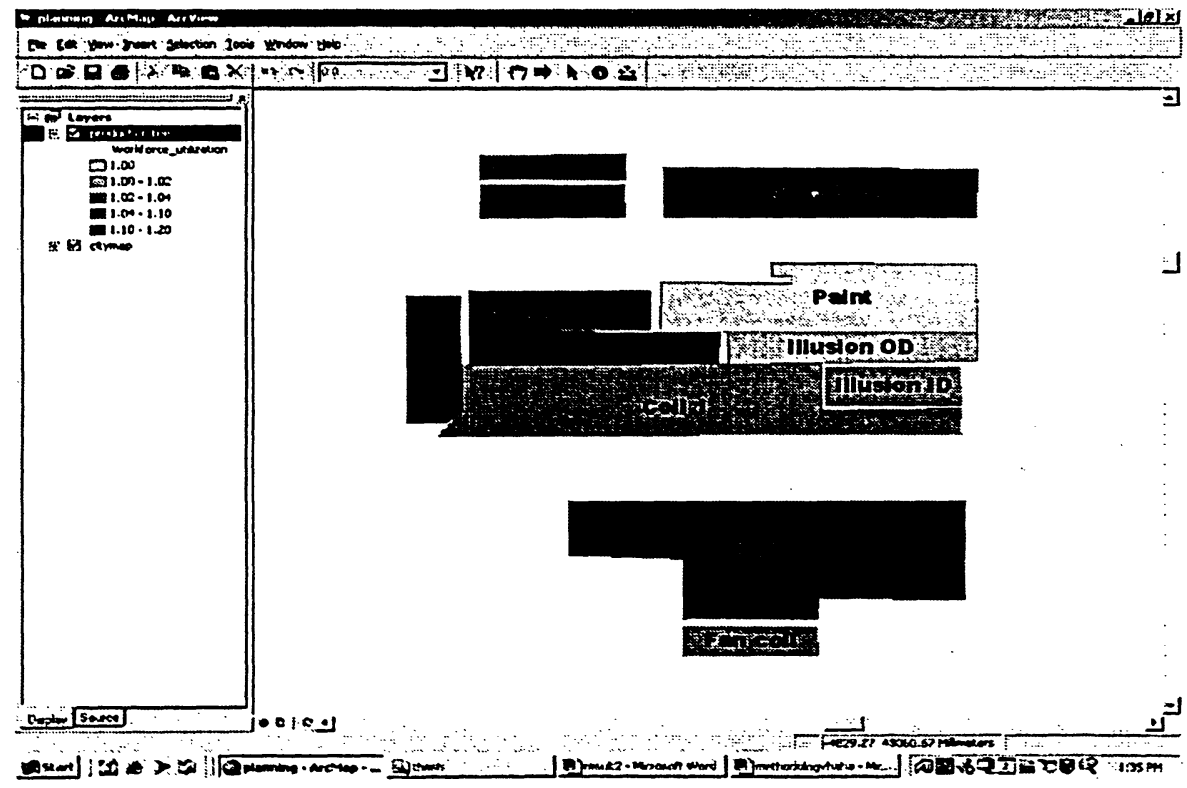

Figure 6.15 Workforce utility distribution 
Figure 6.16 show a query of "linearity $>0.83$ (average level) and workforce utility< 1.04 (average level)". The selected areas are highlighted, which are the production lines performs above average level. Different queries can be conducted for different criteria. Normally, if a line keeps low linearity and high workforce ratio. work design and line balancing should be reconsidered by the industrial engineers. This is another example of improved communication achieved by GIS.

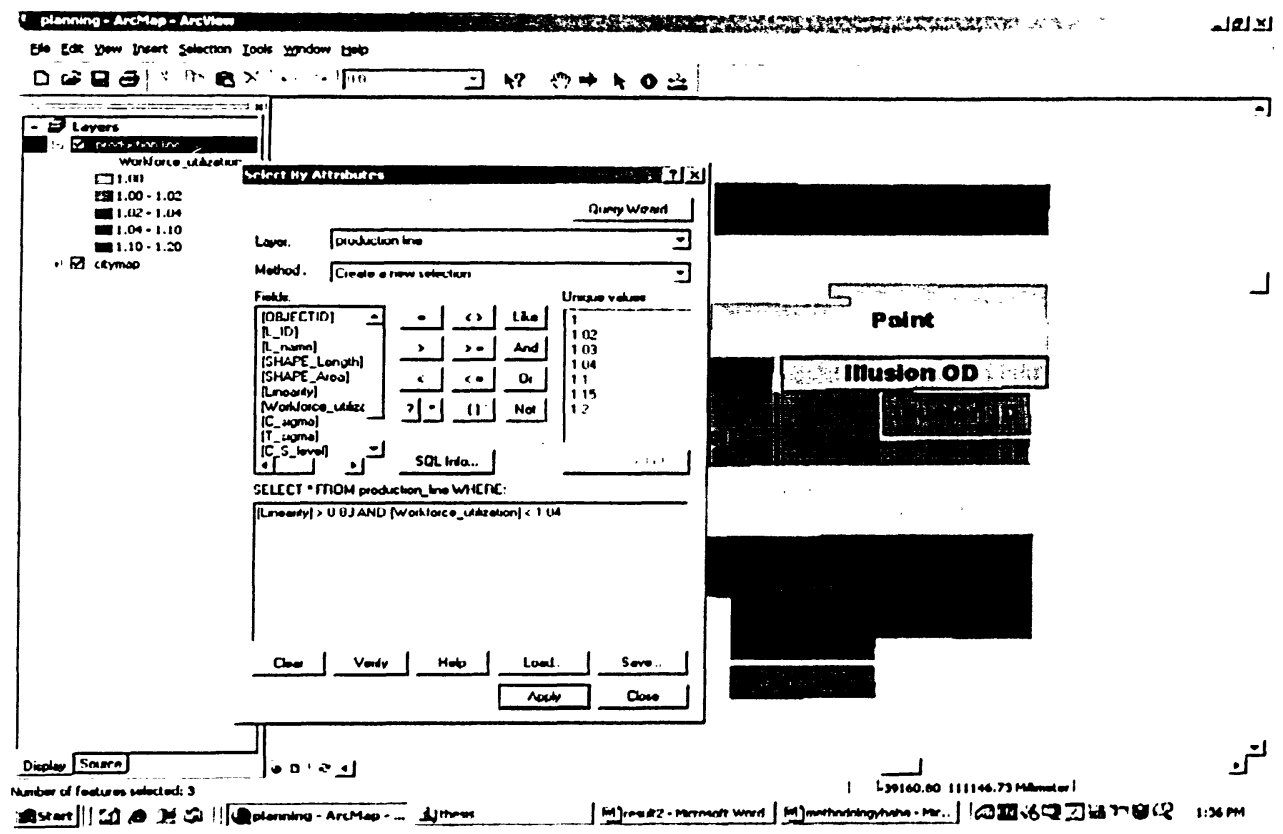

Figure 6.16 Query: Linearity $>0.83$, workforce utility $<1.04$

D. Maintenance

Using Illusion OD line as an example, Figure 6.17 shows the classification of $:$ equipment by the priority level. Blue color represents low priority, green color represents medium priority, and brown color represents high priority. 


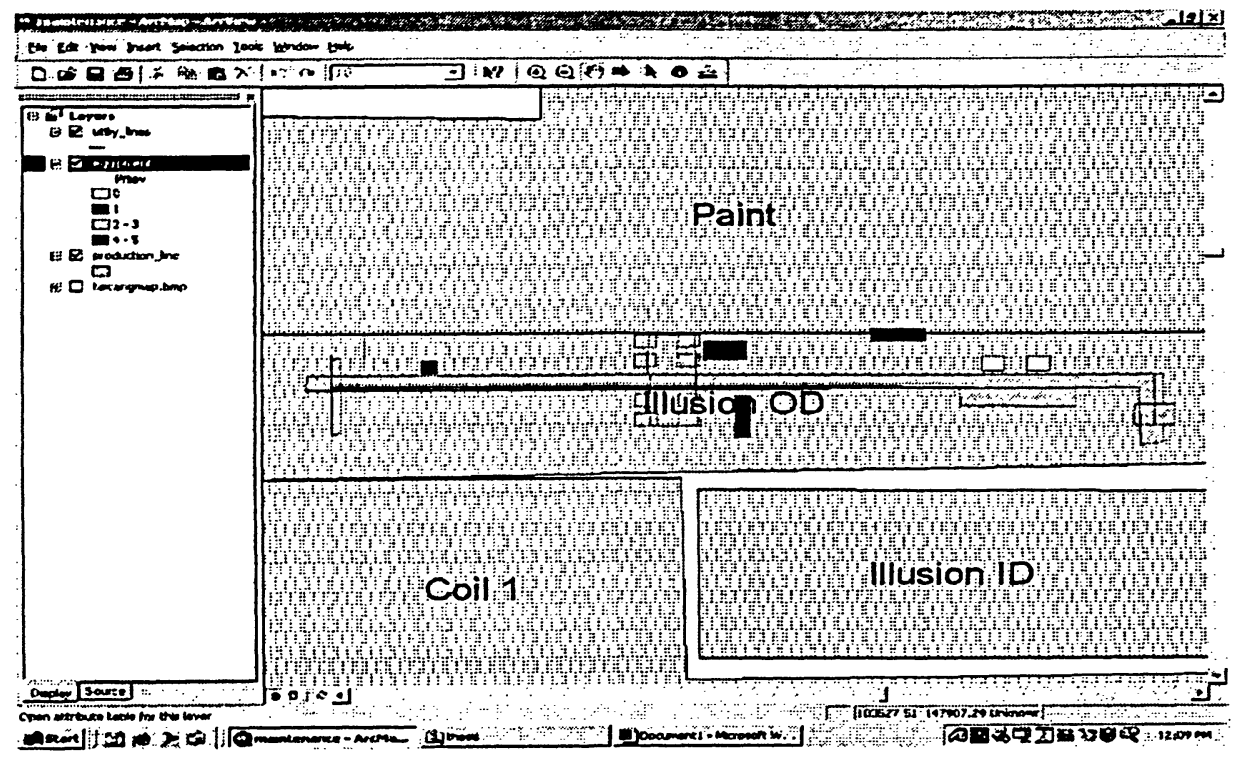

Figure 6.17 Maintenance classification by priority level

Figure 6.18 shows the classification by cost. The redder the color, the more expensive the maintenance project is. Actually, such kind of classification can be conducted for any interested attribute. By experiencing the classification function, a maintenance engineer can have an estimate on how the current equipment situation is distributed.

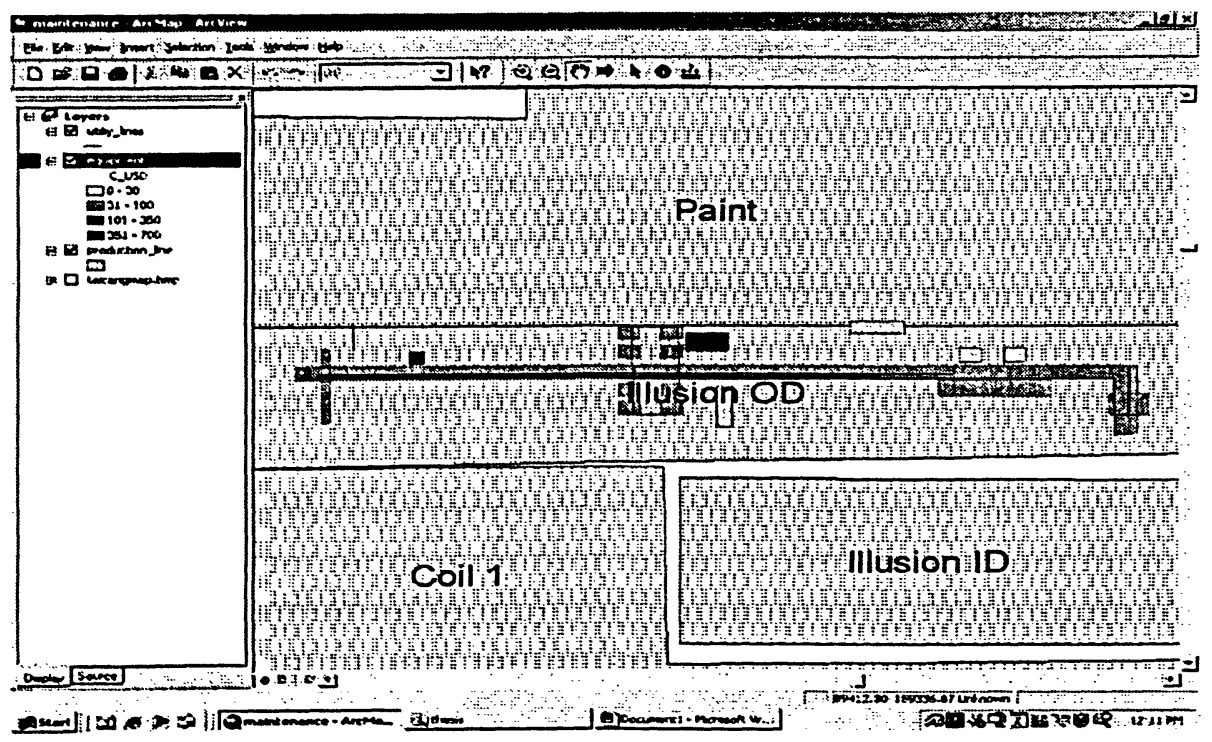

Figure 6.18 Maintenance classification by cost 
The maintenance engineer can select particular equipment to perform maintenance work according to some defined criteria. Figure 6.19 shows a query result under a certain (Deviation index=major. impact to production=minimum. cost<250USD) condition. In this case. the maintenance engineer wants to conduct maintenance work on the machines with the worst condition (deviation index = major), having minimum compact to production, and with low cost (less than 250 USD). The packing machine is selected in this case. Actually, the generation of the

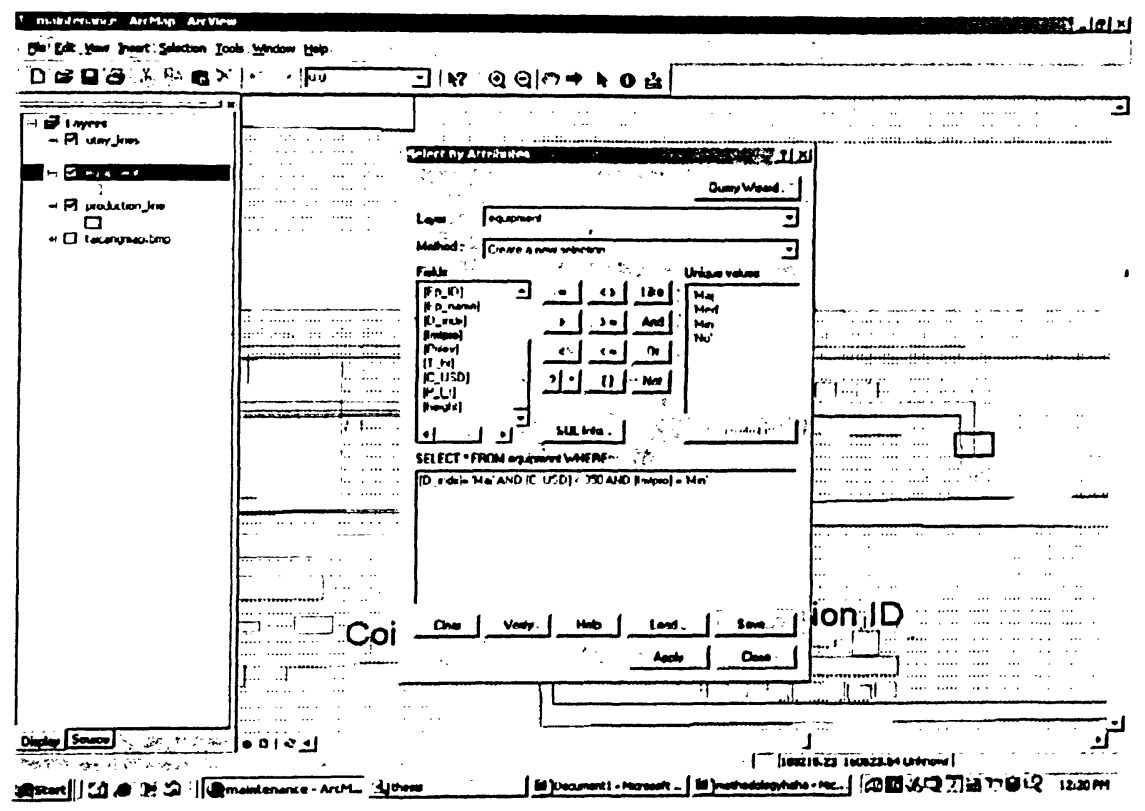

Figure 6.19 Query (Deviation index=major, impact to production=minimum, cost<250USD) maintenance is the process of prioritizing all the equipment: MCDM method is needed, which will not be considered in the prototyping stage.

$:$

E. Marketing

Geographical market segmentation is made much easier by GIS. Figure 6.20 shows the market size by region in the map. Figure 6.21 shows the same result in pie chart. The result shows that marketing efforts should be focused on the east and south 
areas. Using MS Power Point, it may take hours to generate this report, but with GIS, this is just a single minute work. Working efficiency is much improved.

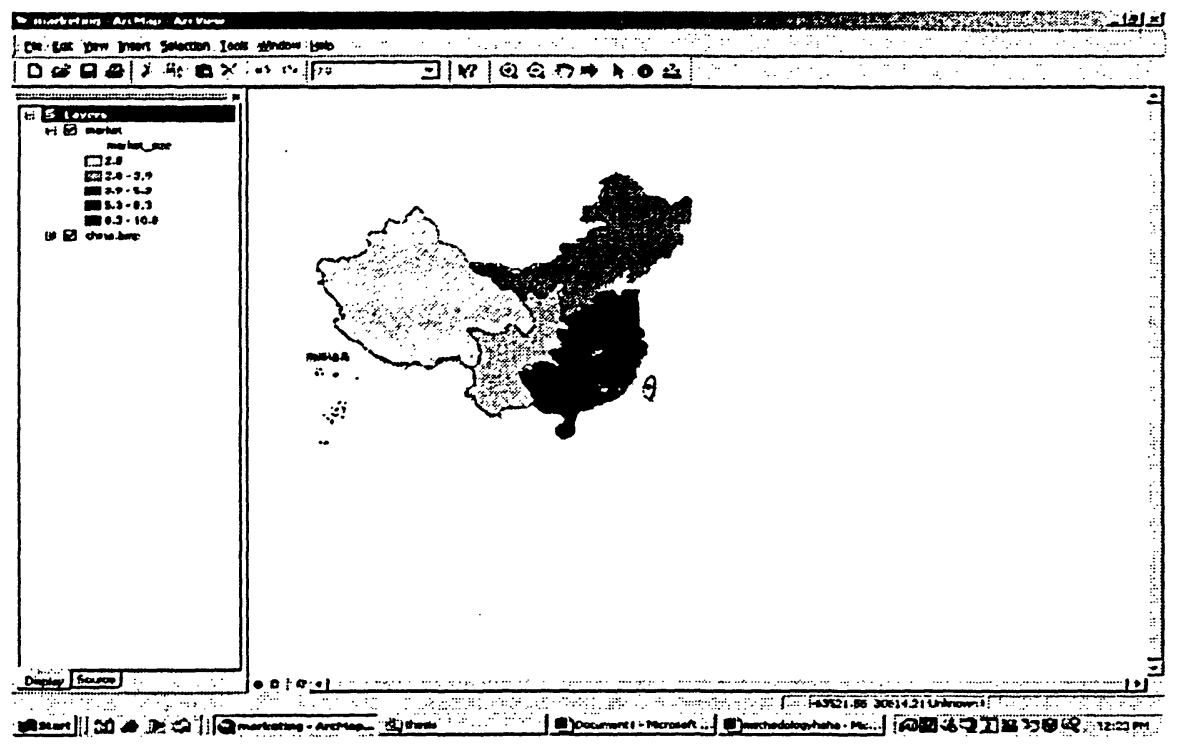

Figure 6.20 Market size by region

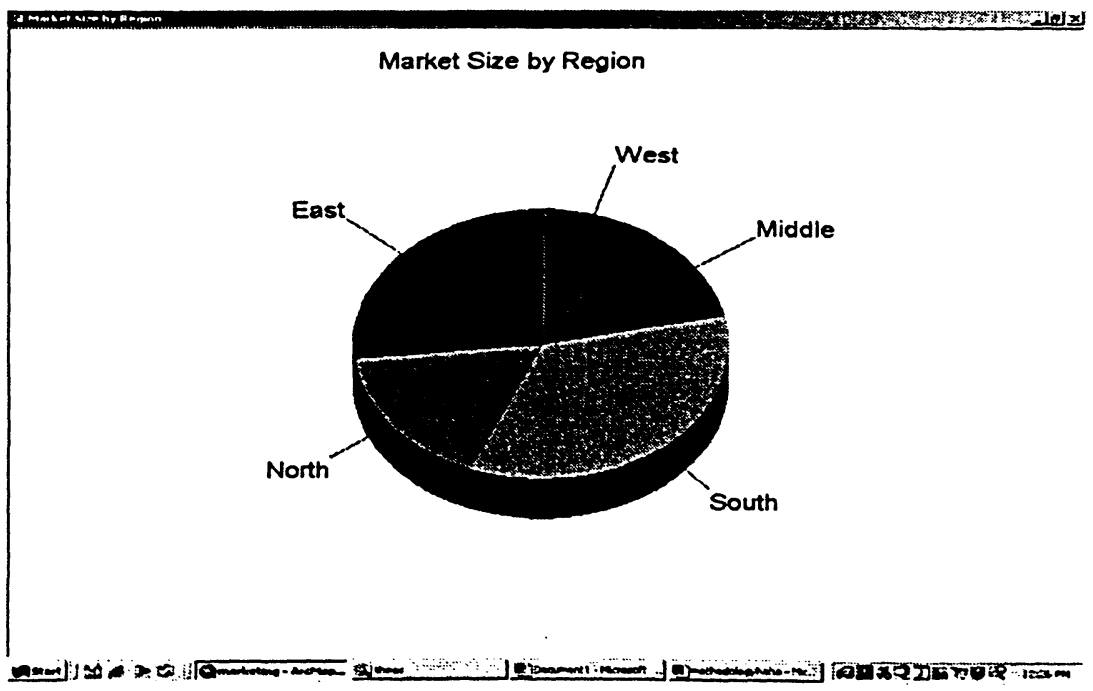

Figure 6.21 Market size by region - pie show 
F. Skill analysis

Figure 6.22 shows the classification of production lines regarding the current skill level. The deeper the color, the higher level of skill the line has. Figure 6.23 shows the classification of production lines based on the ratio of current skill level and required skill level. The lower the ratio, the lighter color in Figure 6.23, the more skill improvement is needed. The lines with the lowest ratios should get the highest priority for skill training. In this case, water-cooled and sheet metal lines are chosen.

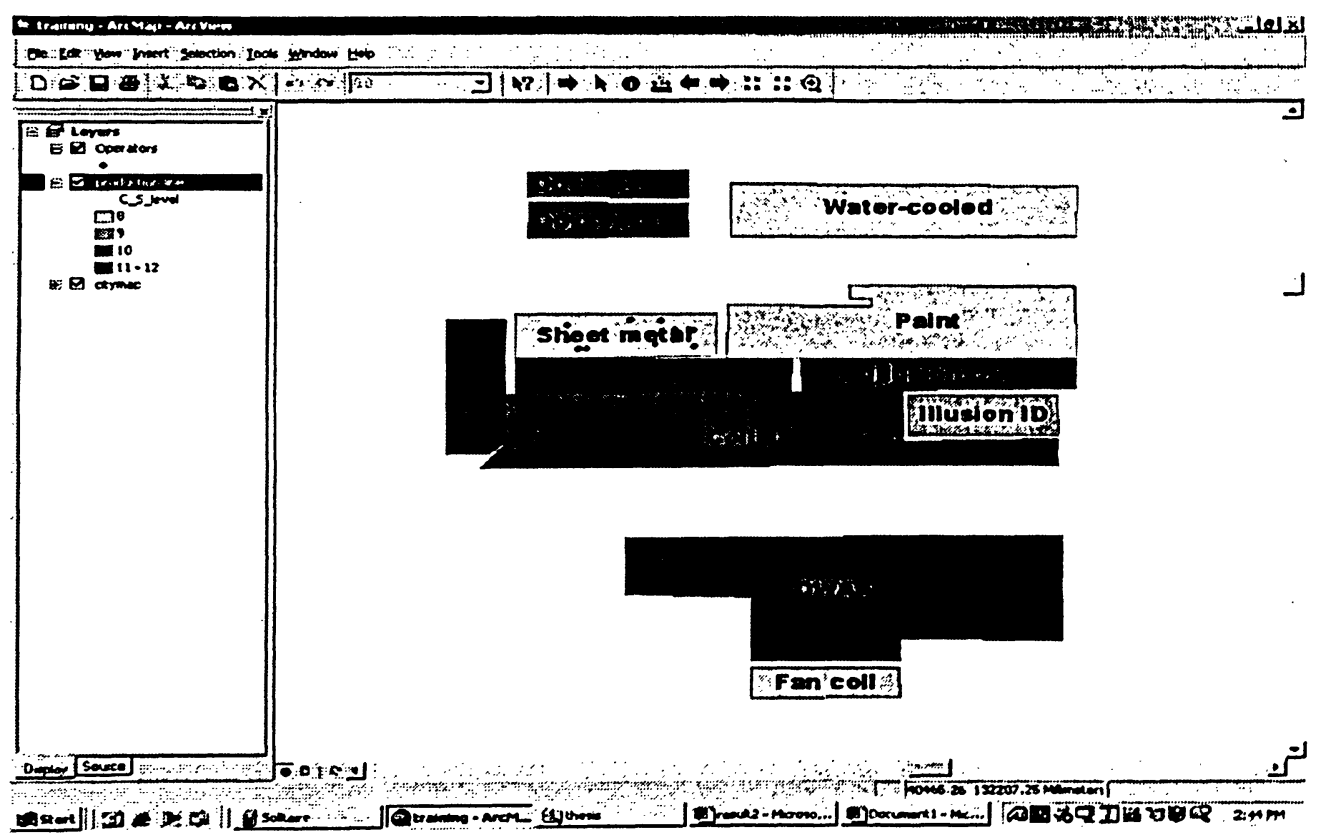

Figure 6.22 Current skill level classification 


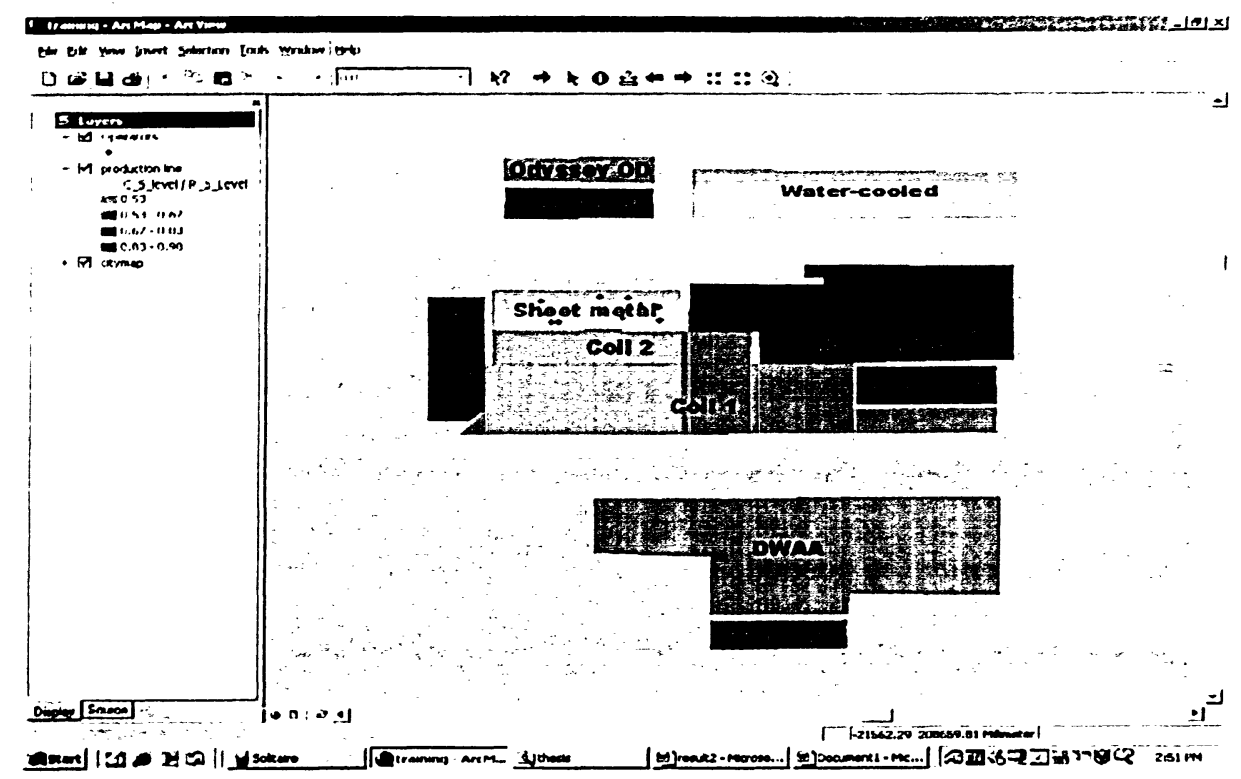

Figure 6.23 Current skill level/required skill level classification

By querying a pre-defined difference between the required skill level and the current skill level, the average number in this case, operators need to get skill training are finally selected as shown in Figure 6.24 the circled dots.

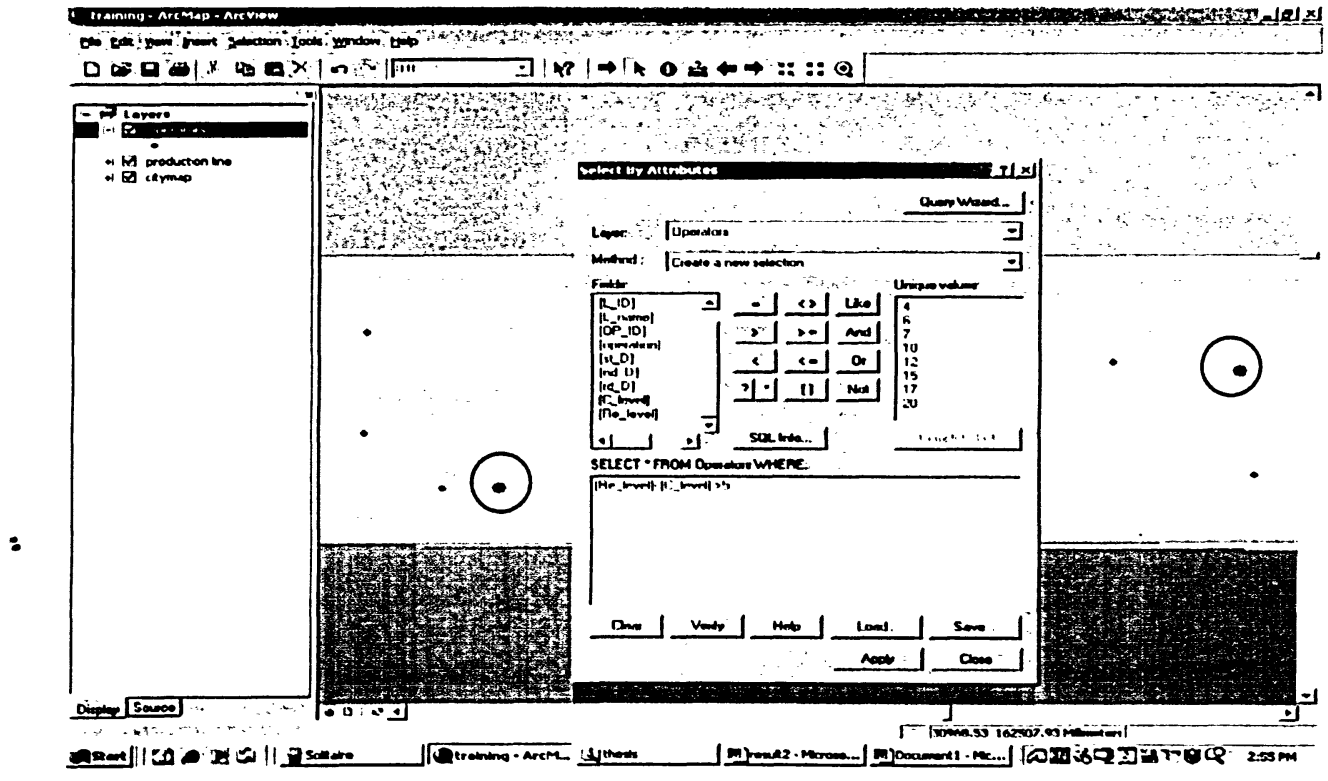

Figure 6.24 Skill trainee selection (required skill - current skill > 5) 
G. Layout

At the prototype stage, layout is focusing on checking the drawing functions ArcGIS provides and analyze the current layout including space use summary and visibility study. Figure 6.25 shows the classification of space usage. Red color represents inventory area; deep blue color represents office area, brown color represents open space, purple color represents training area, light blue color represents production area, and green color represents transportation area. Figures 6.26 and 6.27 show the summary of the space usage in tabular and pie form respectively. It is recommended that the inventory area needs to be further reduced. Open space provides opportunity for future development.

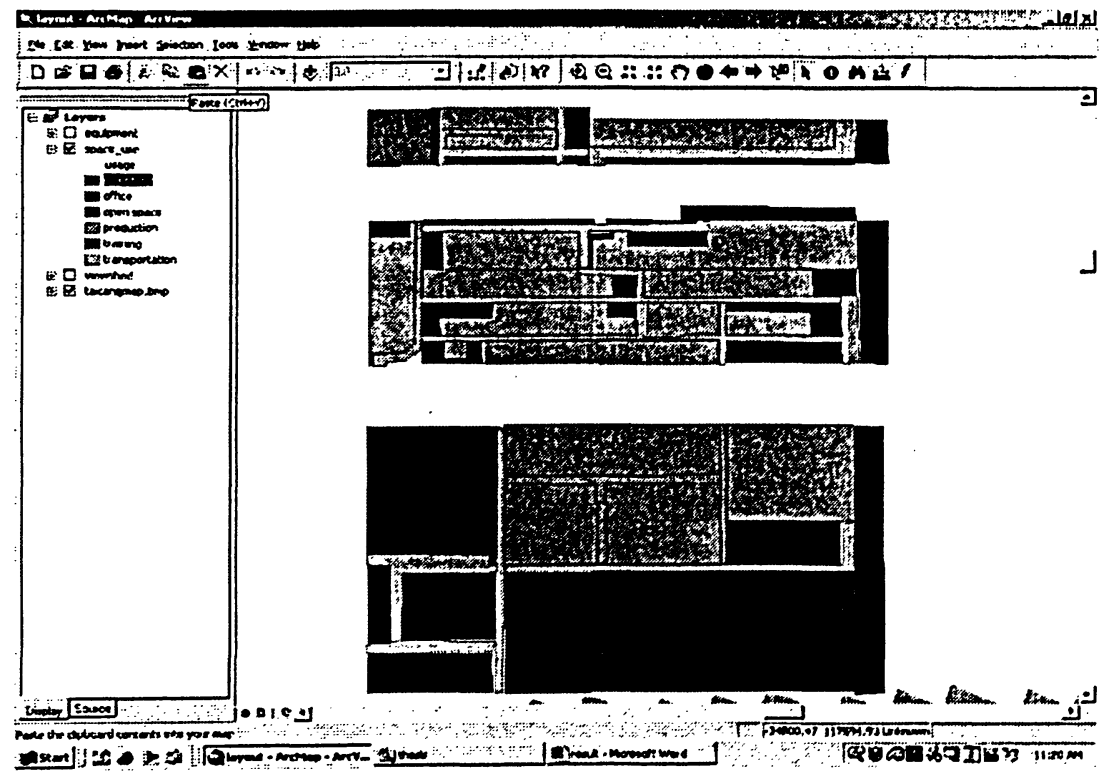

Figure 6.25 Space use classification 


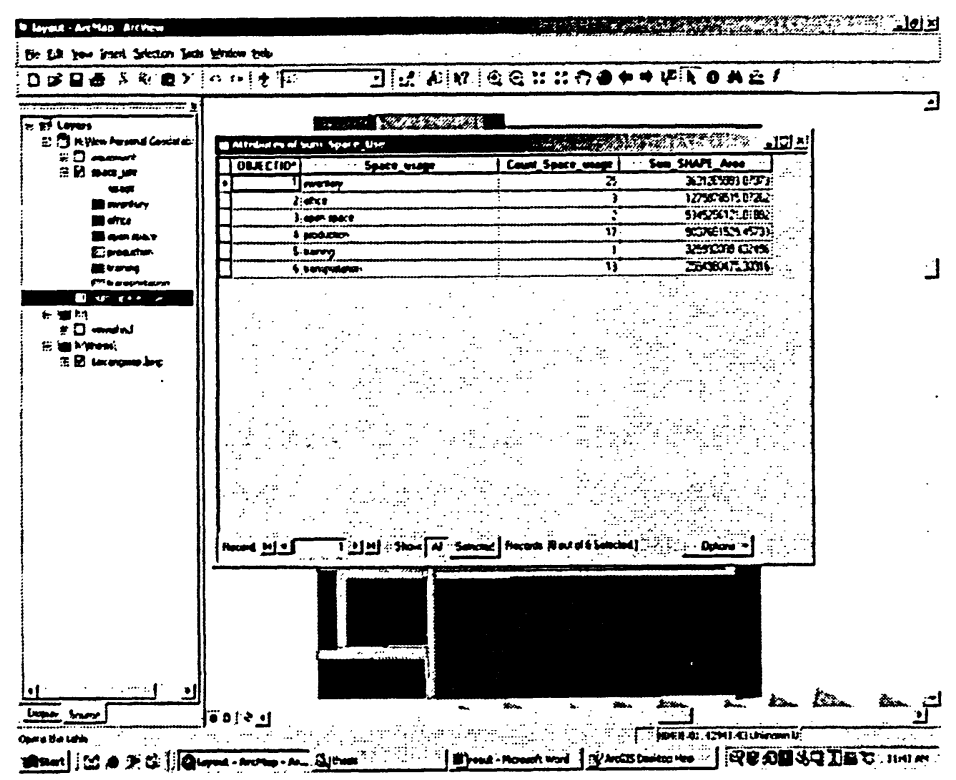

Figure 6.26 Space use summary - tabular form

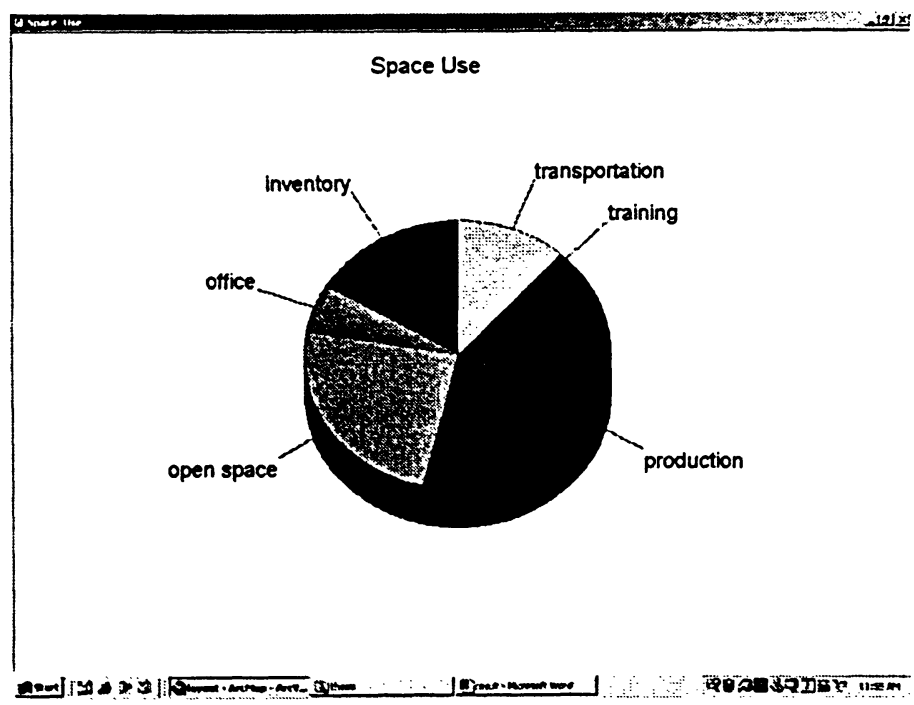

Figure 6.27 Space use summary - pie form

In ArcGIS 8.3, a visibility study is based on a 3D model. A $3 \mathrm{D}$ model is generated in the ArcScene interface of ArcGIS 8.3. To conduct a 3D visibility study, a point theme represents the observation points is needed. Figure 6.28 shows the $3 \mathrm{D}$ model 
of Building 2. Figures 6.29 and 6.30 report the results of visibility study from the shop floor office in the ArcSecene and ArcMap interfaces, respectively. In Figure 6.29 , red color represents invisible areas, while blue color represents visible areas. In Figure 6.30, the black color represents invisible areas, while the white color represents visible areas. The test reveals some interesting results. It is easy to figure out that the paint line is not visible because of the wall; some part of the coil 1 line is not visible because of the fin presses, expanders and degreasers; part of the Koolman line is not visible because of the brazing station and degreaser of the coil 2 line. It is also nature to think the sheet metal area is invisible because of the wall. However, the test results find that the sheet metal area, which was thought to be invisible because of the wall, is actually visible! This $3 \mathrm{D}$ visibility analysis function should be very useful during the facility layout design period.

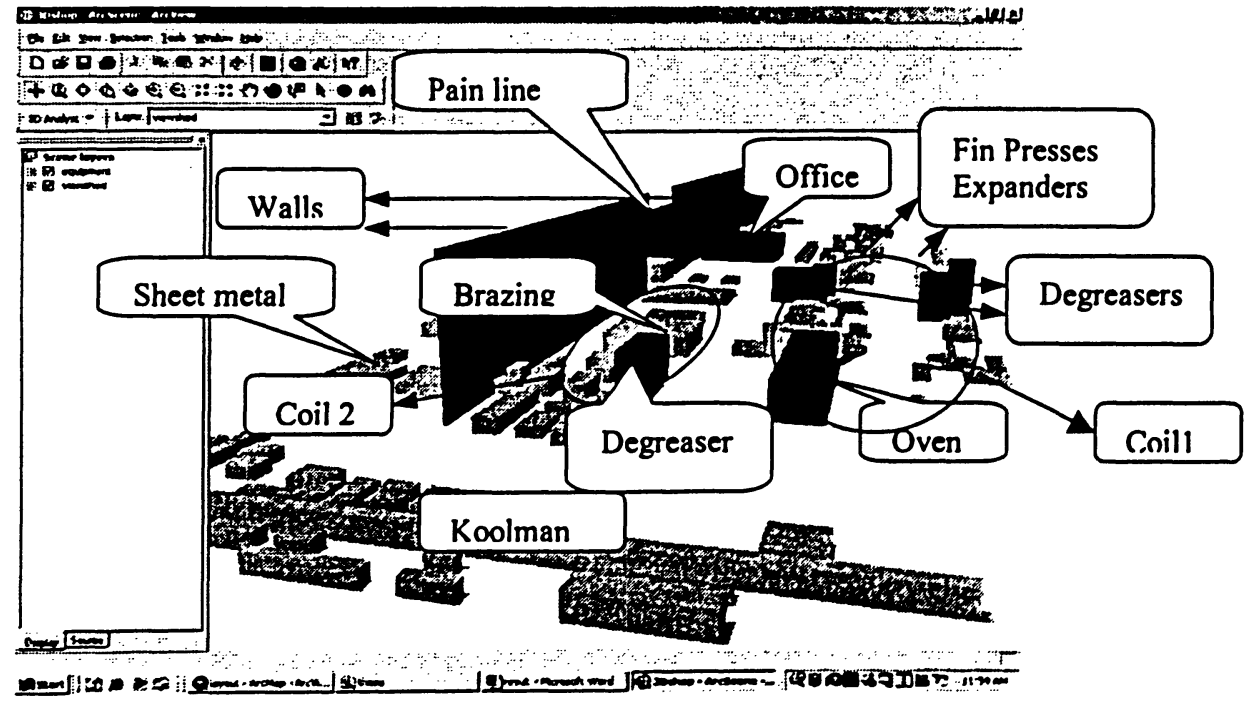

Figure 6.28 3D model of Building 2 


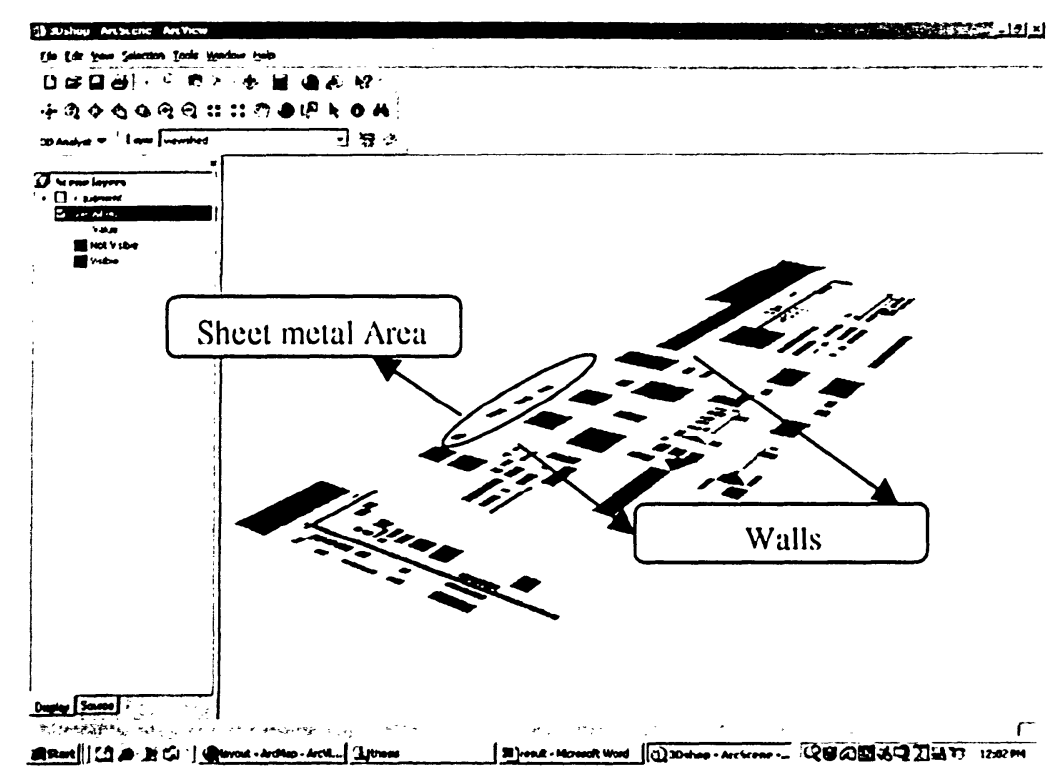

Figure 6.29 Visibility study result - ArcSecene interface

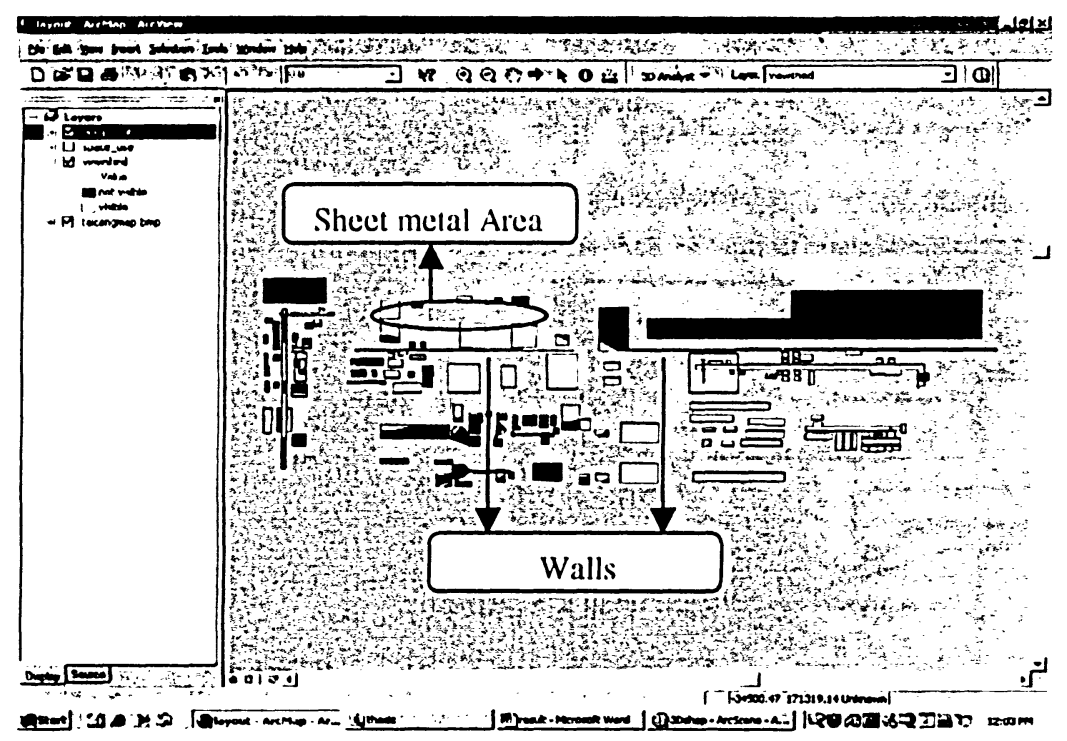

Figure 6.30 Visibility study result - ArcMap interface

$\because$

\subsection{Chapter Summary}

In this chapter, the prototype is tested. User interface is designed. Data are input into the system. Functions of each object module are tested. Discussions about the benefits of GIS-based SDSS are also conducted. The major findings are as follows: 
a) The advantages of GIS-based SDSS over CAD-based SDSS in a manufacturing environment can be obvious found in its Spatial Analyst, Network Analyst, and 3D Analyst models. Spatial Analyst can help an ES\&H engineer make reasonable recommendations on working environment improvement, thus reduce the working environment related medical cost. Network Analyst helps an ES\&H engineer find out if the emergency response system is well established by checking if the emergency response resources are sufficiently provided and well distributed, thus reduce the risk of running the manufacturing facility. 3D Analyst helps manufacturing engineers make right judge on the facility layout in regarding to the visibility of the facilities.

b) Although MS Excel and Power Point can achieve the classification, query, and reporting functions provided by ArcGIS 8.3, it is found that ArcGIS 8.3 improves communication and efficiency quite a lot. If the GIS system is already installed, it is a good idea to take full advantage of this system.

c) With the newly developed snapping, coordinate input, distance setting, and angle setting function, ArcGIS 8.3 can provide enough precision requirements of the facility layout drawings. However, the arc/circle drawing function still needs to be improved.

d) As a desktop version, ArcGIS 8.3 does not provide system security function; it is necessary to build a user interface to manage the authorized users.

e) It can be predicted that, by integrating more specially designed models such as MCDM, the advantages of GIS-based SDSS over CAD-based SDSS should be greatly enhanced. 


\section{CONCLUSIONS AND RECOMMENDATIONS}

In this thesis study, it is found that the GIS-based SDSS has many advantages over the current CAD-based SDSS in a manufacturing environment; however, research on the GIS-based SDSS in a manufacturing environment is partial, not systematic. Thus, the full advantages of GIS-based SDSS cannot be obtained. Efforts of this thesis are thus focused on the systematic approach to the development of GIS-based SDSS in a manufacturing environment. By using Trane China as an example, the prototype of TCSDSS is developed by adopting the unified software development process - one of the recent technology advances in information technology industry. Major findings of this study are found after the testing of the prototype, which is presented in Chapter 6. Conclusions and future studies are presented now in this chapter.

\subsection{Conclusions}

In this study, the possibility of developing a GIS-based SDSS in a manufacturing environment is investigated by the development of TCSDSS prototype. With the test results and major findings reported in Chapter 6, the following conclusions are drawn:

A. In regard to the functions, level of precision, and flexibility required in a manufacturing environment, a GIS-based SDSS is more suitable than a CAD-based SDSS. The former has direct link to a database that describes the attributes of the spatial features. Its spatial analysis functions, including 3D Analyst, Spatial Analyst, and Network Analyst, can achieve what a CAD-based SDSS can hardly achieve. The reporting function of a GIS-based SDSS is also much more advanced than that of a CAD-based SDSS. The open architecture of a GIS-based SDSS makes it easy 
to be integrated with other software packages. Newly developed commercial GIS software packages such as ArcGIS 8.3 have improved its drawing functions, which contain sophisticated, CAD-based editing tools such as coordinate input, angle and length defining, and snapping. This effort makes it possible for a GIS-based SDSS to draw facility layout graphics with higher precision level required in the manufacturing environment.

B. The adopting of recent technology advances in information technology industry unified software development process in this study helps to obtain the systematic approach to the development of the GIS-based SDSS in a manufacturing environment by its well defined step-by-step procedures, which are business modeling, requirement capturing, analysis model generation, design model generation, implementation model generation, and system test.

C. However, there are still some drawbacks in this prototype. First, ArcGIS cannot draw $100 \%$ precise arcs and circles. Drawing an arc or a circle just by defining a threshold is far away from perfect although zooming in to get more detailed and human judgment can still achieve desired precision for facility layout purpose. At least, it takes longer time. Second, the 3D analysis function is just for surface analysis. Strictly defined, ArcGIS extension 3D Analyst provides only 2.5D analysis function. It is not real 3D. That's why the sub-micro space planning of facility design, which requires real 3D topographic analysis, is not discussed in this study. Real 3D analysis is now an active topic of GIS pioneer research, such as Losa and Cervelle (1999), Tempfli (1998 a, b). 


\subsection{Main Issues on Future Studies}

Based on the investigations during this study, several main issues have been discussed as follows:

\section{A. Realization of the rest use cases}

The rest of the use cases need to be realized. These are the site selection related use cases - "Warehouse Selection", "Supplier Selection", "Facility Site Selection", and "Service Center Selection", for which the integration of MCDM model is considered. The "Harmful Agents Analysis" and the "Machinery and Plant Risk Analysis" use cases are considered to be integrated into the "ESH Analysis" use case. The former one will use the spatial analysis function same as "Working Environment Analysis". The other one is similar to "Maintenance Requirement Analysis" and "Quality Improvement Analysis" use cases, in which planning works need to be done by prioritizing the features. Integration of MCDM model should also be considered. The "Supra-space Design and Analysis" use case is considered to be combined into the "Layout" use case. For this use case, the algorithm for area layout needs to be researched.

B. Multiple Criteria Decision Making (MCDM) model

For site selection related use cases and planning efforts related use cases, integration of MCDM model is to be considered.

The MCDM approach involves the definition of a value function and a weight for each criteria and the calculation of the total value (amalgamation) for a specific selection, all of which involves different kinds of methods. A value function may be linear or non-linear and it is dependant on different assessors. Popular weighting 
methods include equal weights, observer derived weights, direct weighting, the analytic hierarchy process (AHP), swing weights, indifference tradeoff weights, and gamble method. All the methods need a lot of survey that involves people with different background. Mostly used amalgamation methods include addictive value function, goal programming, power law, multiplicative and addictive utility functions, outranking methods, and successive elimination (Hobbs and Meier, 2000). There are opportunities for different use cases to apply different methods, such as for "Facility Site Selection", a risk function oriented method may be more realistic.

C. Computerized Facility Layout software

The main objective of layout is to reduce the material handling costs. Activity relationship charts and space relationship diagrams are the two most important tools used in layout. Some popular commercial layout software includes CRAFT, COFAD, PLANET, CORELAP, and ALDEP. Efforts should be given to the integration of the layout software.

D. Networking and Collaborative Working

For a manufacturing company sized as Trane China, the single desktop development of the prototype is unworkable. In fact, people from the same department (same place) and different departments (different places) will use the system synchronously or asynchronously. For example, a manufacturing engineer in Building 1 and another manufacturing engineer in Building 2 may be editing the facility layout at the same time. Also, as an international group, Trane China has its headquarter located in U. S. A. In order to share the same database and communicate between different divisions, computer-supported cooperative work 
(CSCW) technologies should be considered ( $\mathrm{Li}, 2002)$. The roadmap of the whole system is shown in Figure 7.1. 


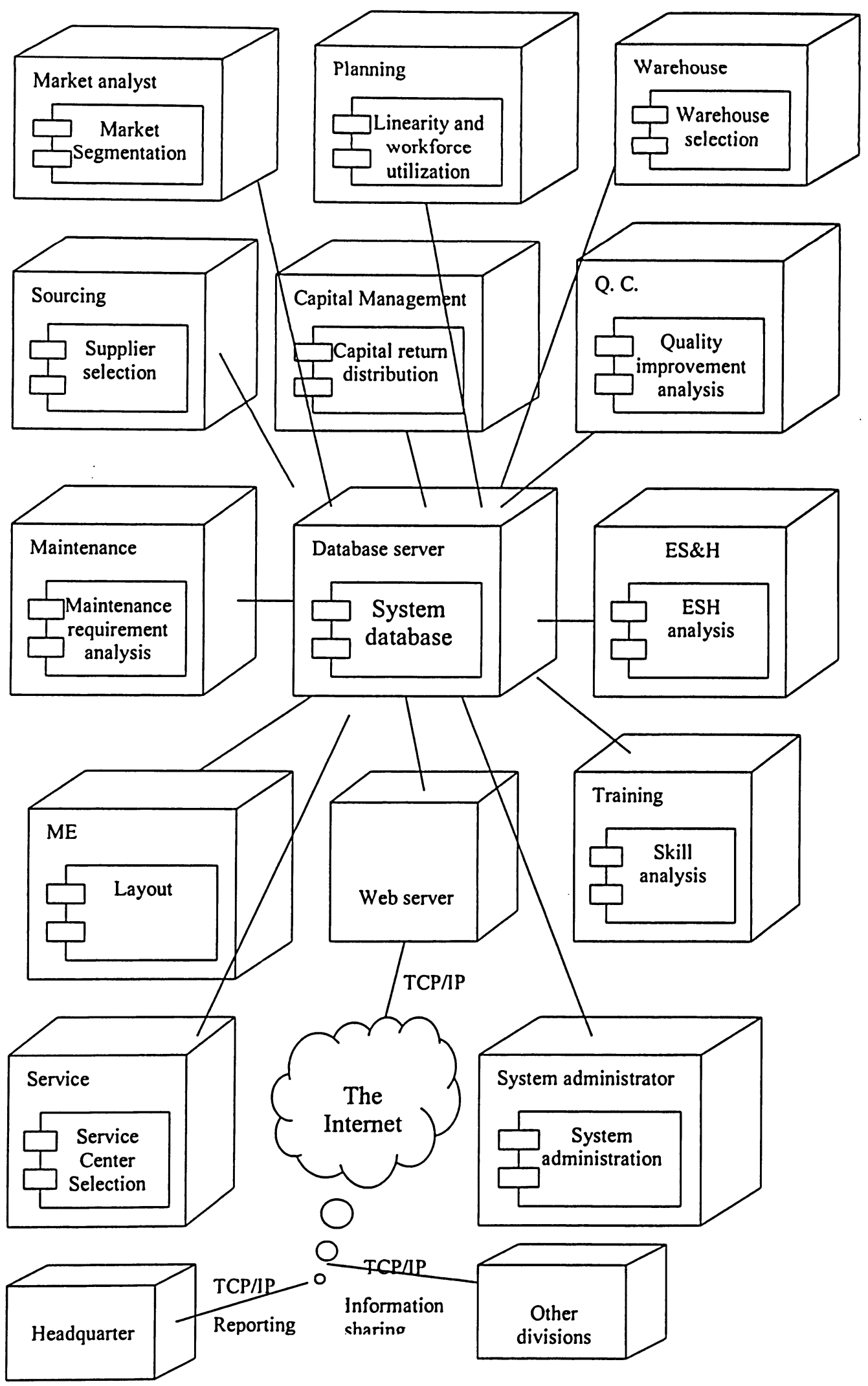

Figure 7.1 Overall system archutecture 


\section{BIBLIOGRAPHY}

Aggarwal, V., 2002. The application of the unified modeling language in objectoriented analysis of healthcare information system, Journal of Medical Systems, 26(5): $383-397$.

Aldosary, A. S. and S. A. Zaheer, 1996. An application mechanism for a GIS-based maintenance system: the case of Kfum, Computer, Environment and Urban Systems, 20(6): $399-412$.

Barlow, J. and J. White, 2001. Technology at the architect of the capitol: a case study, Facility Design and Management Handbook Edited by Teicholz, E., McGraw-Hill, New York.

Bennett, S. and J. Skelton, L. Ken, 2001. Schaum's Outlines of UML. McGraw-Hill, New York.

Berner, L. and N. Bogoyavlenskaya, S. A. Lliushin, E. Kiltaitseva, A. Kovalev, A. Rochtchin, 1995. Integrated approach to urban facilities maintenance and alarm management. Computer Environment and Urban Systems, 19(3): 201 - 206.

Booch, G. and J. Rumbaugh, I. Jacobson, 1999. The Unified Modeling Language User Guide. Addison Wesley.

Booth, B. and M. Andy, 2001. Getting Started with ArcGIS: GIS by ESRI. Environmental Systems Research Institute, Redlands, CA.

Cannon, S. J. and T. Kontuly, H. Miller, 1998. GIS-based emergency response planning in a Mexico-U.S. border community. Applied Geographic Studies, 2(2): 111-130.

Chang, M. et al., 2002. A symbiotic evolutionary algorithm for dynamic facility layout problem. Proceedings of the 2002 Congress ON, 2, pp. $1745-1750$.

Church, R. L., 2002. Geographical information systems and location science. Computers \& Operations Research, 29, pp. 541 - 562.

Clerc, J.M., 1985. Introduction to Working Conditions and Environment. International Labor Office, Geneva.

Corbett, J. D. et al., 2002. Spatial decision support systems and environmental modeling: an application approach. Geographic Information System and Environmental Modeling, edited by Clarke, K. C., Prentice Hall, New Jersey.

Daniel, L. 1992. SDSS for location planning, or the seat of the pants is out. Geoinfo System, 2(9): 16-24. 
Dechant, T. and M. Spear, J. Messervy, 2001. Managing the new healthcare real estate portfolio: a case study. Facility Design and Management Handbook, Edited by Teicholz, E., McGraw-Hill, U.S.

Densham, P. and M. Goodchild, 1990. Research initiative six, spatial decision support systems. Scientific Report for the Specialist Meeting, Technical Report 90-5, NCGIA National Center for Geographic Information and Analysis.

Dong, A. and A. M. Agogino, 1998. Managing design information in enterprise-wide CAD using 'smart drawings'. Computer-Aided Design, 30(6): 425-435.

Dougherty, T. M. 1999. Risk assessment techniques. Handbook of Occupational Safety and Health, edited by DiBerardinis, L. J., John Wiley \& Sons, U.S.

Douglas, W. J., 1995. Environmental GIS Applications to Industrial Facilities. Lewis Publisher, U. S.

Duckham, M., 200. Object calculus and the object-oriented analysis a nd design of an error-sensitive GIS. GeoInformatica, 5(3): $261-289$.

Eck, J.R. and V. Ritsema, T.D. Jong, 1999. Accessibility analysis and spatial competition effects in the context of GIS-supported service location planning. Computers, Environment and Urban Systems, 23, pp. 75 - 89.

Eneyo, E. S. and G. P. Pannirselvam, 1998. The use of simulation in facility layout design: a practical consulting experience. Proceedings of the 1998 Winter Simulation Conference.

ESRI, 2003. Utility GIS-more than just AM/FM. http://www.esri.com/library/ whitepapers/pdfs/utility-gis.pdf (accessed April 26, 2003).

Gorr, W. and M. Johnson, S. Roehrig, 2001. Spatial decision support system for home-delivered service. Journal of Geographical Systems, 3, pp. 181 - 197.

Grabot, B. and A. Letouzey, 2000. Short-term manpower management in manufacturing systems: new requirements and DSS prototyping. Computers in Industry, 43, pp. 11-29

Graham, I., 1994. Object-Oriented Methods, 2nd edn. Addison-Wesley, Reading, MA.

Gualtieri, G. and M. Tartaglia, 1998. Predicting urban traffic air pollution: a GIS framework. $\quad$ Transportation Research part D: Transport and Environment, 3(5): $329-336$.

Hanna, K. C. and R. B. Culpepper, 1998. GIS in Site Design. John Wiley and Sons.

Hobbs, B. F. and P. Meier, 2000. Energy Decisions and the Environment: $A$ Guide to the Use of Multicriteria Methods. Kluwer Academic Publishers, Boston.

Hoffer, J. A. and J. F. George, J. S. Valacich, 1999. Modern Systems Analysis and 
Design. Addison Wesley Longman, Inc.

Holl, A., 2001. Manufacturing location and impacts of road transport infrastructure: The case of Spain. NECTAR Conference no 6 European Strategies in the Globalising Markets; Transport Innovations, Competitiveness and Sustainability in the Information Age, Espoo, Finland.

Hsieh, M.D. et al., 2002. A decision support system of real time dispatching in semiconductor wafer fabrication with shortest process time in wet bench. Semiconductor Manufacturing Technology Workshop, 2002 , Dec. 10-11, 2002, pp. $286-288$.

Hunkeler, D. et al, 1999. A decision support system for life cycle management. Environmentally Conscious Design and Inverse Manufacturing, 1999. Proceedings. EcoDesign '99: First International Symposium On, 1-3 Feb. 1999, pp. 728 - 732.

Iqbal, M. and M. S. J. Hashmi, 2001. Design and analysis of a virtual factory layout. Journal of Materials Processing Technology, 118, pp. $403-410$.

Ittner, C. D. and D. F. Larcker, V. Nager, M. V. Rajan, 1999. Supplier selection, monitoring practices, and firm performance. Journal of Accounting and Public Policy, 18, pp. $253-281$.

Jacobson, I. and G. Booch, J. Rumbaugh, 1999, The Unified Software Development Process. Addison Wesley.

Jensen, S. S. and R. Berkowicz, H. S. Hansen, O. Hertel, 2001. Danish decisionsupport GIS tool for management of urban air quality and human exposures. Transportation Research, Part D, 6, pp. $229-241$.

Jordani, D. A. and D. Gondeck-Becker, 2001. GIS case study: space management at the University of Minnesota. Facility Design and Management Handbook, Edited by Teicholz, E., McGraw-Hill, U. S.

Kaiser, H. H. and T. Davies, 2001. Facilities condition assessment. Facility Design and Management Handbook, Edited by Teicholz, E., McGraw-Hill, U. S.

Karray, F. et al., 2000. Computational intelligence tools for solving the facilities layout planning problem. Proceedings of the American Control Conference, Chicago, U. S.

Klammt, F., 2001. Financial management for facility management. Facility Design and Management Handbook, Edited by Teicholz, E., McGraw-Hill, U. S.

Kliskey, A. D., 1995. The role and functionality of GIS as a planning tool in naturalresource management. Computer Environment and Urban Systems, 19(1): 15-22.

Kluijver, H. and J. Stoter, 2003. Noise mapping and GIS: optimizing quality and efficiency of noise effect studies. Computers, Environment and Urban Systems, 27 pp. 85-102. 
Kotler, P. and G. Armstrong, $\quad$ P. H. Cunningham, 1999. Principles of Marketing. Prentice Hall, Canada.

Lamb, C. W. Jr. and J. F. Jr. Hair, F. A. J. McDaniel, 2002. The Subject is Marketing. Nelson, Canada.

Lee, Q. and A. E. Amundsen, H. Tuttle, 1997. Facilities and Workplace Design. Engineering \& Management Press, Georgia, U. S.

Lehrer, D., 2001. Sustainable design. Facility Design and Management Handbook, Edited by Teicholz, E., McGraw-Hill.

$\mathrm{Li}$, Songnian, 2002. Design and Development of an Internet Collaboration System to Support GIS Data Production Management. Ph. D. Dissertation, Department of Geodesy \& Geomatics, University of New Brunswick, Frederiction, NB, Canada

Lin, W. M. and M. T. Tsay, S. W. Wu, 1996. Application of geographic information system for substation and feeder planning. Electric Power \& Energy Systems, 18(3): pp. $175-183$.

Liu, M., 2003. DrawCAD: using deductive object-relational databases in CAD. Software-Practice and Experience, 33, pp. 143-172.

Lo, C.P. and K.W. Yeung, 2002. Concepts and Techniques of Geographic Information Systems. Prentice Hall, Upper Saddle River, New Jersey.

Losa,A. and B. Cervelle, 1999. 3D Topological modeling and visualization for 3D GIS. Computers \& Graphics, 23, pp. $469-478$.

Lu, C. J. J. et al., 1996. Optimal layout design of automated systems using topology connectivity method. Proceedings of the 1996 IEEE International Conference on Robotics and Automation, U. S.

Malczeqski, J. 1997. Spatial Decision Support Systems, NCGIA Core Curriculum in GIScience, http://www.ncgia.ucsb.edu/giscc/units/127/, (Accessed August 14, 2003)

Marinho, J. et al., 1999. Decision support system for dynamic production scheduling. Assembly and Task Planning, 1999. Proceedings of the 1999 IEEE International Symposium on, 21-24 July 1999, pp. 424- 429.

McKinney, D. C. and X. Cai, 2002. Linking GIS and water resources management models: an object-oriented method. Environmental Modeling \& Software, 17, pp. 413-425.

McMahon, C. and B. Jimmie 1998. CADCAM Principles, practice and Manufacturing Management. Addison-Wesley, Edinburgh Gate, England.

Moorthy, S., 1999. Integrating the CAD model with dynamic simulation: simulation data exchange. Proceedings of the 1999 Winter Simulation Conference. 
Murphy, L. D., 1994. Manufacturing and GIS: a proposal for integrating manufacturing and environmental modeling. http://wwwsgi.ursus.maine.edu/gisweb/spatdb/gislis/gi94076.html (Accessed August 18, 2003).

Nasirin, S. and D. F. Birks, 2003. DSS implementation in the UK retail organizations: a GIS perspective. Information \& Management, 40, pp. 325 - 336.

Poulton, E.C., 1979. The Environment at Work. Charles C Thomas • Publisher, U. S.

Power, D. J., 1997. What is a DSS?. The On-Line Executive Journal for Data-Intensive Decision Support, October 21, no. 3, http://dssresources.com/papers/ whatisadss/. (Accessed August 13, 2003).

Puri, S.C., 1996. Stepping up to ISO 14000. Productivity Press, Portland, Oregon.

Rhind, D., 1989. “Why GIS?” Arc News, 11(3), Redland, CA: Environmental Systems Research Institute, Inc.

Rush, R., 1986. The Building Systems Integration Handbook. John Wiley \& Sons, NY.

Saleh, K., 2002. Documenting electric commerce systems and software using the unified modeling language. Information and Software Technology, 44, pp. 303 311.

Shelly, G. B. and T. J. Cashman, H. J. Rosenblatt, 2001. Systems Analysis and Design. Course Technology, 25 Thomas Place Boston, MA. U. S.

Springer, T.J. et al., 2001. Facility management - an introduction. Facility Design and Management Handbook, Edited by Teicholz, E., McGraw-Hill, U.S.

Swift, C. O., 1995. Preferences for single sourcing and supplier selection criteria. Journal of Business Research, 32, pp. 105-111.

Tavares, J. A. and C. Ramos, J. Neves, 1999. Constraint programming approach to solve facility layout design problems. Proceedings of the 1999 IEEE International symposium on Assembly and Task Planning, Portugal.

Tempfli, K., 1998a. 3D topographic mapping for urban. ITC Journal, 3(4): 181 - 190

Tempfli, K., 1998b. Urban 3D topographic data and texture by digital photogrammetry. Proceeding of ISPRS, March - Aprial, Tempa, Florida, USA, CD-ROM.

Tompkins, J. A. and J. A. White, 1984. Facilities Planning. John Wiley \& Sons, U. S.

Traub, H. S. and M. Koster, H. Holtkotter, N. Nipper, 1998. Conceptual plant layout. Computers Chemical Engineering, 22, Suppl., pp. 499 - 504.

Trotter, C.M. and J. R. Leathwick, . D. Pairman, 2001. Spatial Information for Ecosystem Classification, Analysis, and Forecasting. Spatial Information and the 
Environment, edited by Halls, P. J., Taylor \& Francis, London, England.

Vlachopoulou, M. and G. Silleos, V. Manthou, 2001. Geographic information systems in warehouse site selection decisions. International Journal of Production Economics, 71, pp. $205-212$.

Yamada, Y. and Y. Teraoka, 1998. An optimal design of piping route in a CAD system for power plant. Computers Mathematics Application, 35(6): 137 - 149.

Yeh, G. A. and M. H. Chow, 1996. An integrated GIS and location-allocation approach to public facilities planning - an example of open space planning. Computer Environment and Urban Systems, 20(4/5): 339 - 350.

Yu, K. and T. Froese, F. Grobler, 2000. A development framework for data models for computer-integrated facilities management. Automation in Construction, 9, pp. 145-167.

Zetu, D. and P. Banerjee, P. Schneider, 1998. Data input model for virtual realityaided facility layout. IIE Transactions, 30, pp. 597-620. 
$22-22-10$ 